SANDIA REPORT

SAND88-1700 • UC-721

Unlimited Release

Printed June 1997

RECENED

JIII $1^{4} 1997$

OSTI

\title{
Interim Radiological Safety Standards and Evaluation Procedures for Subseabed High-Level Waste Disposal
}

Robert D. Klett

Prepared by

Sandia National Laboratoties

Albuquerque, New Mexico $87185 \%$, w W Wora California 94550

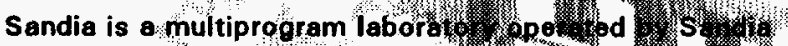

Corporation, a Lockheed Martin Conpany, for the thited States

Department of Energy under Conthat DE-ACO4-94AL85000.

Whix

Approved for public release; distribution is unlimit.

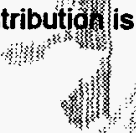

Fi. Sandia National Labetatories

3.

3:

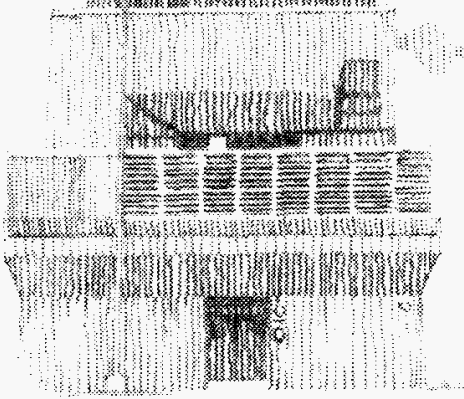

$S F 29000(8-81)$
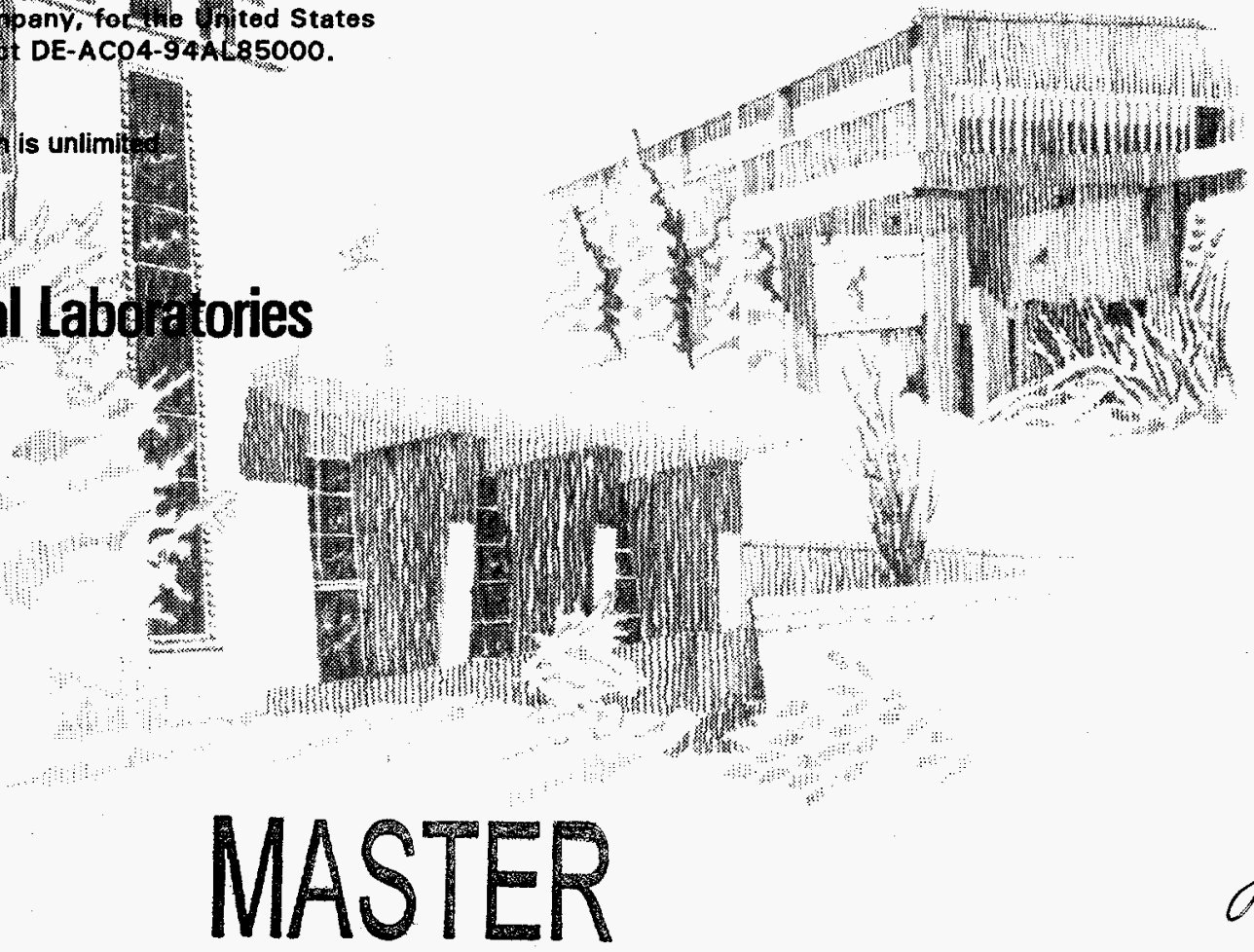
Issued by Sandia National Laboratories, operated for the United States Department of Energy by Sandia Corporation.

NOTICE: This report was prepared as an account of work sponsored by an agency of the United States Government. Neither the United States Government nor any agency thereof, nor any of their employees, nor any of their contractors, subcontractors, or their employees, makes any warranty, express or implied, or assumes any legal liability or responsibility for the accuracy, completeness, or usefulness of any information, apparatus, product, or process disclosed, or represents that its use would not infringe privately owned rights. Reference herein to any specific commercial product, process, or service by trade name, trademark, manufacturer, or otherwise, does not necessarily constitute or imply its endorsement, recommendation, or favoring by the United States Government, any agency thereof, or any of their contractors or subcontractors. The views and opinions expressed herein do not necessarily state or reflect those of the United States Government, any agency thereof, or any of their contractors.

Printed in the United States of America. This report has been reproduced directly from the best available copy.

Available to DOE and DOE contractors from

Office of Scientific and Technical Information

P.O. Box 62

Oak Ridge, TN 37831

Prices available from (615) 576-8401, FTS 626-8401

Available to the public from

National Technical Information Service

U.S. Department of Commerce

5285 Port Royal Rd

Springfield, VA 22161

NTIS price codes

Printed copy: A06

Microfiche copy: A01 


\title{
Interim Radiological Safety Standards and Evaluation Procedures for Subseabed High-Level Waste Disposal
}

\author{
Robert D. Klett \\ WIPP Performance Assessment Code Development Department \\ Sandia National Laboratories \\ P.O. Box 5800 \\ Albuquerque, NM 87185-1328
}

\begin{abstract}
The Seabed Disposal Project (SDP) was evaluating the technical feasibility of high-level nuclear waste disposal in deep ocean sediments. Working standards were needed for risk assessments, evaluation of alternative designs, sensitivity studies, and conceptual design guidelines. This report completes a three part program to develop radiological standards for the feasibility phase of the SDP. The characteristics of subseabed disposal and how they affect the selection of standards are discussed. General radiological protection standards are reviewed, along with some new methods, and a systematic approach to developing standards is presented. The selected interim radiological standards for the SDP and the reasons for their selection are given. These standards have no legal or regulatory status and will be replaced or modified by regulatory agencies if subseabed disposal is implemented.
\end{abstract}




\section{ACKNOWLEDGMENTS}

The author gratefully acknowledges the valuable contributions of Maureen Kaplan, Eastern Research Group (formerly of TASC), Charles Koplik, TASC, and Daniel Ensminger, TASC to the previous two stages in the development of interim radiological standards for subseabed high-level waste disposal that were foundations for this report. 


\section{DISCLAMIER}

Portions of this doenment may be illegible in electronic image products. Images are produced from the best available original document. 
1. INTRODUCTION.

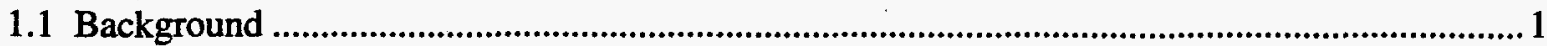

1.2 Purpose and Organization of the Subseabed Disposal Project Radiological Standards

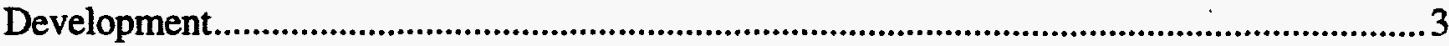

1.3 Summary of Parts 1 and 2 of the Subseabed Disposal Project Standards Development .............5

1.3.1 Options for Radiological Protection..............................................................................5

1.3.2 Workshop to Evaluate Radiological Protection Options.................................................. 8

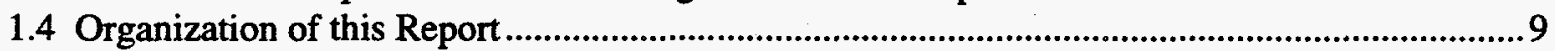

2. CHARACTERISTICS OF SUBSEABED HIGH-LEVEL WASTE DISPOSAL.................................12

2.1 Radiological Risks from Subseabed HLW Disposal....................................................................13

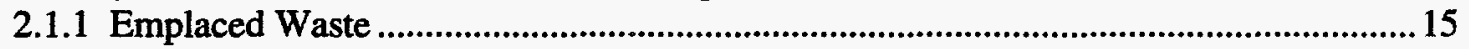

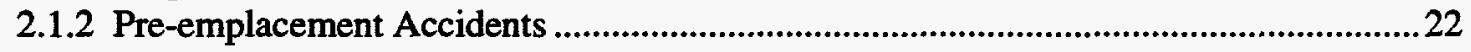

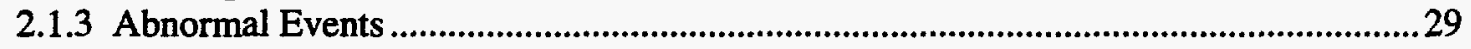

2.1.4 Robustness, Reliability, and Confidence Potentials of Subseabed Disposal ................31

2.2 Characteristics of Subseabed Disposal as They Apply to Radiological Standards ...................32

2.3 Similarities and Differences in Terrestrial and Subseabed Disposal Characteristics .................35

3. GENERAL RADIOLOGICAL PROTECTION STANDARDS FOR HIGH-LEVEL WASTE ...........37

3.1 Relationships Between Doses and Biological Response ....................................................37

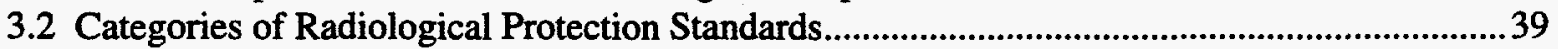

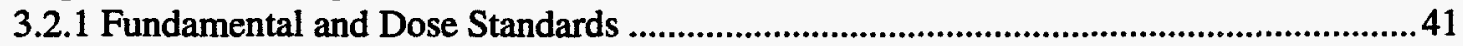

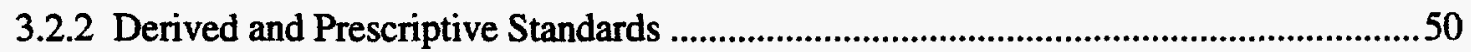

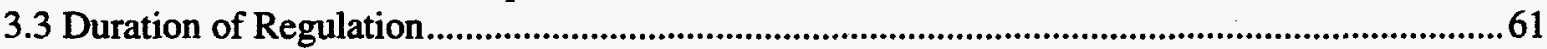

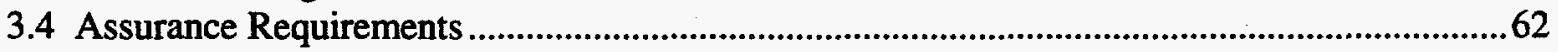

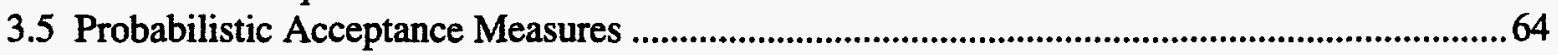

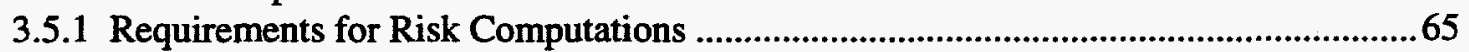

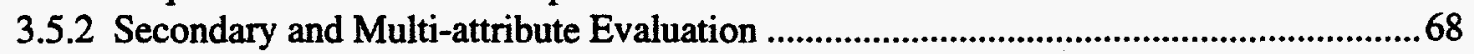

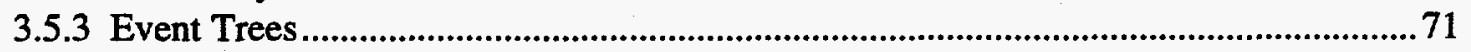

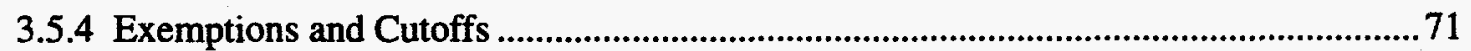

3.5.5 Implementation and Limitations of Probabilistic Risk Assessments ...........................74

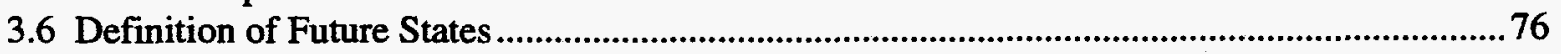

3.7 Summary of General Radiological Protection Standards....................................................... 77

4. STANDARDS USED IN THE 1983 AND 1987 FEASIBILITY ASSESSMENTS ................................80

4.1 Standards for Peak Dose Rates to Maximally Exposed Individuals ..........................................8 81

4.2 Standards for Collective Doses to the World Population ........................................................81

4.3 Comparison of 1987 Preliminary SDP Risk Assessment with the 1987 Interim Standards ......82

\section{RECOMMENDED STANDARDS FOR THE REMAINDER OF THE FEASIBILITY PHASE OF}

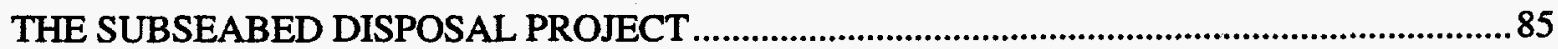

5.1 Dose Standards for Subseabed Disposal of High-Level Waste ...............................................86

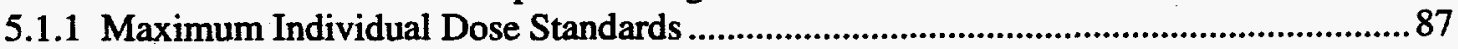

5.1.2 Maximum Single Generation Dose Standards .........................................................8 


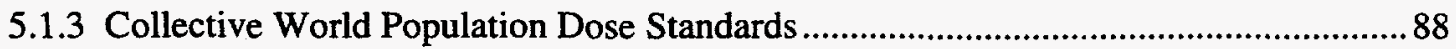

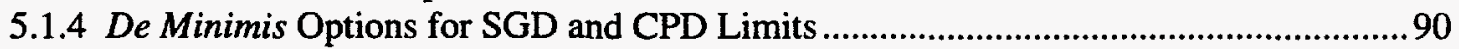

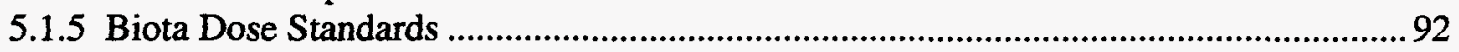

5.1.6 Comparison of Preliminary SDP Risk Assessments with the Recommended

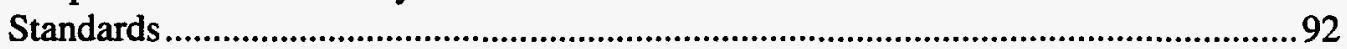

5.2 Derived and Prescriptive Standards for Subseabed Disposal ..............................................96

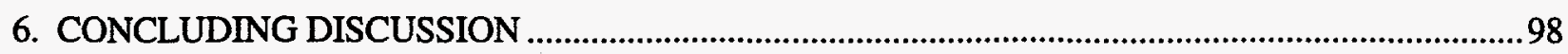

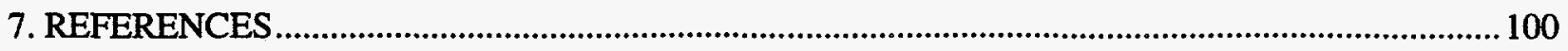

\section{Figures}

Figure 1. Conceptual design of the Subseabed Nuclear Waste Disposal system. .................................2

Figure 2. Major Subseabed Disposal Pathways and Nuclide Transport Processes................................. 14

Figure 3. Atlantic Ocean Site with Model Compartments..............................................................16

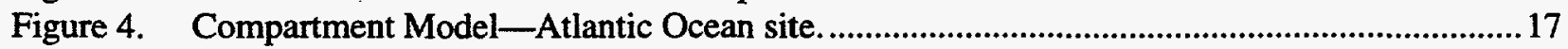

Figure 5. Post-emplacement individual dose vs. time, by compartment-mean-risk parameter

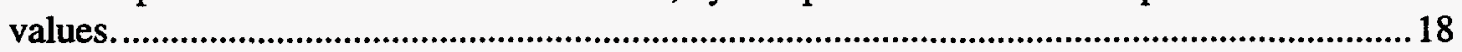

Figure 6. Post-emplacement population dose vs. time in the world ocean compartment, by

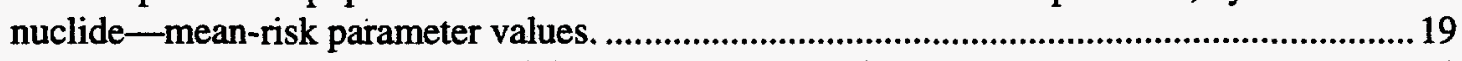

Figure 7. Coastal-waters compartment model (Middle Atlantic Bight)...........................................23

Figure 8. Deep-ocean accident individual dose vs. time, by compartment-mean-risk parameter

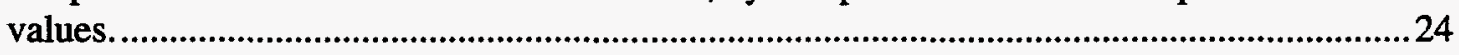

Figure 9. Deep-ocean accident population dose vs. time from the world ocean compartment, by

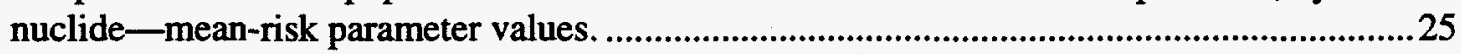

Figure 10. Coastal-waters accident individual dose vs. time, by compartment-mean-risk parameter values.

Figure 11. Coastal-waters accident population dose vs. time in the bottom plume 2 sediment compartment, by nuclide-mean-risk parameter values.

Figure 12. Generic biological response to radiation.

Figure 13. Average allowable individual dose rate and allowable population dose rate as a function of population at risk.

Figure 14. Control surface for combined standards.

Figure 15. Combined standards modified by natural constraints and specific regulations and to expedite evaluation

Figure 16. Comparison of risk assessment procedures with dose or risk standards (top path) and with derived standards (bottom path).

Figure 17. Comparison of integrated release and ocean burden for a typical radionuclide released to the oceans (half life $=10^{4} \mathrm{yrs}, \mathrm{K}_{\mathrm{D}}=10^{-2} \mathrm{~m}^{3} / \mathrm{kg}$, emplacement depth $=30 \mathrm{~m}$ ) ......................56

Figure 18. Dose rates from three release scenarios. ................................................................................58

Figure 19. Normalized apparent margins of safety for duration of regulation for the reference subseabed repository using collective population dose criteria.

Figure 20. Probability curve for an annual risk of less than $10^{-5}$ from all sources except natural and medical (Reference 4).

Figure 21. Graphical representation of risk. ..........................................................................................

Figure 22 Effects of individual dose cutoff on predicted population doses for two radionuclides and three atmospheric release modes.

Figure 23. Doses to the Maximally Exposed Individual from a $10^{5}$ MTHM Subseabed Repository........ 79

Figure 24. Collective Population Doses per MTHM from a Subseabed Repository................................8 80 
Figure 25. Comparison of a proposed MID limit when large populations are exposed, with regulating agencies traditional de minimis and de manifestis risk levels for chemical and radiological carcinogens....

Figure 26. Time-averaged world population dose rate from the time of emplacement to the time on the abscissa

Figure 27. Dose rates to the maximally exposed individuals from HLW emplaced in deep ocean sediments

Figure 28. Dose ratio to the world population from HLW emplaced in deep ocean sediments.

Figure 29. Collective dose to the world population from HLW emplaced in deep ocean sediments.......90

\section{Tables}

Table 1. Options for Development of SDP Working Radiological Protection Standards*...................5

Table 2. Maximally-Exposed Individual Dose Parameters (Emplaced Waste) ...................................20

Table 3. Collective Population Dose Parameters (Emplaced Waste) ....................................................20

Table 4. Peak Biota Dose-Rate Parameters (Water Ingestion in the Benthic Mixed Layer)

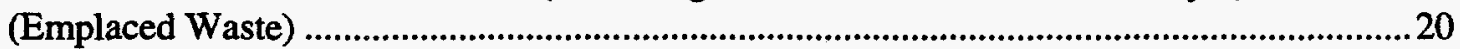

Table 5. Dose Attenuation Factors in a Subseabed Disposal System (Emplaced Waste)....................21

Table 6. Dose Attenuation Factors with Waste Canister Lying on Deep Ocean Sediments (Deep

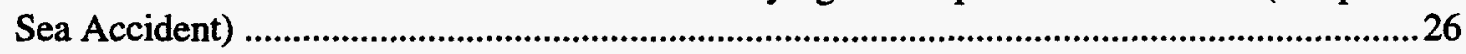

Table 7. Dose Attenuation Factors with Waste Canisters Lying on the Continental Shelf (Near

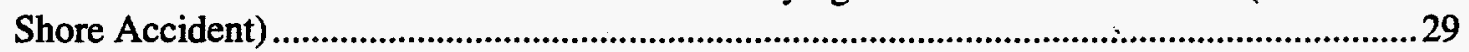

Table 8. Probabilistic Doses for Sea Transportation and Emplaced Waste per MTHM .....................30

Table 9. Dose Parameters for Emplaced Waste and Sea Transportation Accidents .............................34

Table 10. Underprediction Factors of Collective Doses vs. Individual Dose Cutoff..............................74

Table 11. Criteria Tractability Using the Yucca Mountain Project Thermal Design Requirements

Branch as an Example

Table 12. Margins of Safety for a $10^{5}$ MTHM Repository using 1987 Limits

Table 13. Comparison of SGD and CPD Limits using the Reference Parameters.

Table 14. Comparison of Subseabed Disposal Dose Predictions with Recommended Multiple Radiological Standards.

Table 15. Comparison of Subseabed Disposal Dose Predictions with Multiple Radiological Standards with SGD and CPD constrained by a $10^{-7}$ Per Year Individual De Minimis Risk.. 96 


\section{ACRONYMS}

$\begin{array}{ll}\text { AF } & \text { attenuation factor } \\ \text { ALARA } & \text { as low as reasonably achievable } \\ \text { CCDF } & \text { complementary cumulative distribution function } \\ \text { CDF } & \text { cumulative distribution function } \\ \text { CEC } & \text { Commission of the European Communities } \\ \text { CPD } & \text { collective time integrated population dose } \\ \text { DOE } & \text { US Department of Energy } \\ \text { DP } & \text { derived and prescriptive (standards) } \\ \text { DPTRA } & \text { Defense Programs Transportation Risk Assessment } \\ \text { EPA } & \text { US Environmental Protection Agency } \\ \text { HE } & \text { health effects } \\ \text { HLW } & \text { high-level waste } \\ \text { IAEA } & \text { International Atomic Energy Agency } \\ \text { ICRP } & \text { International Commission on Radiological Protection } \\ \text { LCF } & \text { latent cancer fatalities } \\ \text { LDC } & \text { London Dumping Convention } \\ \text { LLW } & \text { low-level waste } \\ \text { MID } & \text { maximally-exposed individual dose rate } \\ \text { MS } & \text { margin of safety } \\ \text { MTHM } & \text { metric ton of heavy-metal fuel } \\ \text { NAP } & \text { Nares Abyssal Plain } \\ \text { NAS } & \text { National Academy of Sciences } \\ \text { NCRP } & \text { National Council on Radiation Protection and Measurements } \\ \text { NEA } & \text { Nuclear Energy Agency } \\ \text { NID } & \text { negligible individual dose } \\ \text { NIRL } & \text { negligible individual risk level } \\ \text { NRC } & \text { US Nuclear Regulatory Commission } \\ \text { OECD } & \text { Organization for Economic Cooperation and Development } \\ \text { PA } & \text { performance assessment } \\ \text { PAGIS } & \text { Performance Assessment of Geological Isolation Systems } \\ \text { PRA } & \text { probabilistic risk assessment } \\ \text { QA } & \text { quality assurance } \\ \text { RATG } & \text { Radiological Assessment Task Group } \\ \text { SD } & \text { Subseabed Disposal } \\ \text { SDP } & \text { Subseabed Disposal Project } \\ \text { SF } & \text { spent fuel } \\ \text { SGD } & \text { single-generation dose } \\ \text { SWG } & \text { Seabed Working Group } \\ \text { TRU } & \text { transuranic } \\ \text { US } & \text { United States } \\ \text { WISP } & \text { Waste Isolation Systems Panel } \\ & \end{array}$




\section{GLOSSARY}

abnormal natural events - Low probability natural events occurring in the vicinity of a repository that could result in release of radioactive material. Includes volcanism, earthquakes, climate changes, glaciation, meteor impacts, etc.

accessible - Capable of inflicting risk because of location, form, quantity, or concentration.

activity - A measure of the amount of a radioactive material expressed in terms of its rate of radioactive decay. The unit is becquerel $(\mathrm{Bq})$, where $1 \mathrm{~Bq}=1$ disintegration per second. $1 \mathrm{~Bq}=2.7 \times 10^{-11}$ curies (Ci).

advection - The transport of dissolved material by the motion of a fluid.

ALARA - The philosophy that radiation exposures be kept "as low as is reasonably achievable." As defined by the ICRP, it includes the concepts that the exposures be justified and that cost/benefit analyses be performed to determine the optimum level of protection.

attenuation - Reduction of a detrimental potential.

attenuation factor - The factor by which a component or entire disposal system reduces a dose or risk potential.

barrier - A material object that inhibits or restricts free movement of either the waste or the populace being protected.

biosphere - Generally includes the earth's surface, the oceans, and the atmosphere; those zones that contain or support life.

collective dose - The sum of doses to all the individuals in a specific group over a given period of time. Also called population dose. The unit is person-Sv.

component - Any part of the disposal system that can be treated separately because of function or location and can be analyzed as a unit.

conservative - Use of the assumptions, data, analyses, and interpretations that would lead to over predictions of risk and overly restrictive regulations.

CPD - Collective time-integrated world population dose. Integration time is usually $10^{4}$ to $10^{5}$ years following emplacement. The unit is person-Sv or person-Sv/MTHM.

de manifestis risk - a risk of obvious regulatory concern. Analogous to obvious risk; one so plain that it would be instantly recognized by a person of ordinary intelligence.

de minimis risk - Used by regulators to define an acceptable level of risk that is below regulatory concern. From de minimis non curat lex; the law does not take notice of very small or trifling matters.

derived standards - Requirements placed on the performance of components or processes in the disposal system, or on the flux or concentration of radionuclides at locations along pathways from the waste site to humans to facilitate regulation, control, and monitoring. 
dilution - Diminishing the strength or concentration of a contaminant by mixing it with large quantities of another substance.

disposal system - All engineered and natural components that act as pathways and alter the risk potential between the initial waste location and possible recipients of detrimental effects.

dose equivalent - The product of the absorbed dose and a modifying of weighting factor. Values are assigned to this factor according to the relative ability of the several types of radiation (alpha, beta, gamma, neutron, etc.) to induce deleterious effects. The unit is sievert (Sv). $1 \mathrm{~Sv}=100 \mathrm{rem}$.

dose factor - A numerical conversion factor that gives the dose equivalent from an initial intake of radioactive material by an individual. The unit is $\mathrm{Sv} / \mathrm{Bq}$.

dose standards - Limits on allowable dose rates to individuals or populations, lifetime doses to individuals, or time-integrated doses to populations.

fundamental standard - The standard that specifies the allowable detriment to humans, biota, and the environment from a process or substance. It is usually stated as a limit on risk or premature deaths and genetic effects.

genetic effects - Generally used in radiation protection to designate harmful effects to progeny that could result from radiation-induced mutations in the germ cells of one or both parents. Can include a spectrum of effects from stillbirth to various diseases of genetic origin.

health effects - Fatal cancers and first-generation genetic effects (leading to early death in individuals) predicted to occur in population groups exposed to ionizing radiation.

high-level waste - The highly radioactive materials resulting from the fission process in nuclear reactors. Can include the separated radioactive residues from chemical reprocessing of spent fuel or the unreprocessed spent fuel, when the latter is intended for disposal.

human intrusion - Actions of humans in the future that would result in contact with radioactive materials placed in a repository.

leaching - The dissolution of soluble constituents of a solid material (e.g., waste in repository) by the natural action of percolating water or other fluids.

linear hypothesis - The assumption that health effects are linearly related to exposure of individuals to low- and mid-dose levels of ionizing radiation.

lithosphere - The outer zone of the solid earth including the crust and upper part of the mantle.

maximally exposed group of individuals - A hypothetical group of persons who, because of the combination of assumptions used to estimate the dose, is predicted to receive the largest dose among all groups that could receive exposure from a postulated release of radioactive material.

MID - Peak individual dose rates to the maximally exposed group regardless of time. The unit is Sv/yr or Sv/yr-MTHM.

MTHM - The amount of HLW generated by the burnup of one metric ton of uranium. 
natural background radiation - Radiation in the human environment from naturally occurring radioactive isotopes and from cosmic radiation.

near field - Referring to a zone within the repository that is in the proximity of the emplaced waste packages.

nuclide - A species of atom characterized by its mass number, atomic number, and nuclear energy state.

ocean burden - The total quantity of radioactive waste in the oceans at any given time.

pathway - A route taken by radionuclides in the lithosphere, hydrosphere, atmosphere, and biosphere between the initial waste location and the recipient of the detriment.

performance assessment - An analysis that predicts the behavior of a system or component under a given set of conditions.

population dose - see collective dose.

pore water velocity - The linear bulk velocity of water moving through a porous medium.

potential - A measure of the capacity of a risk related characteristic to develop into actuality at any time or location in the disposal system.

prescriptive standards - Requirements placed on a repository that are intended to reduce risk but are not traceable through models to the fundamental or dose standards.

quality assurance - As applied to radiologic standards, it is all the systematic actions necessary to provide confidence that the requirements will provide adequate protection to the populace in a costeffective manner.

recover - Removal of a waste container that has not been properly emplaced because of an accident or malfunction.

repository - A facility, and the associated engineered structures and equipment, where radioactive wastes are placed for disposal. For SD it is the sediment volume containing the emplaced waste canisters.

resilience - The ability of a disposal system to function satisfactorily with a component or components operating at less than full efficiency. This is a system characteristic for a given set of components.

retardation - A process that causes an increase in the time required for waste to move between two locations allowing more time for the waste to decay or degrade.

retardation factor - A measure of the delay of nuclide transport through geologic media due to sorption on particle surfaces.

retrieve - Removal of a properly emplaced waste canister.

risk - Probabilistic exposure to hazards and their severity or consequence; the expected detriment per unit time. 
risk assessment - The modeling and analyses of conceptual or operating disposal systems to predict the probabilistic detriment to humans or biota.

robustness - The ability to function satisfactorily under adverse conditions. See "resilience" and "stability."

SGD - Peak dose to a single generation of the world's population regardless of time. The unit is personSv or person-Sv/MTHM.

solubility - A measure of the amount of a soluble material that can be contained dissolved, in solution, in a liquid; the equilibrium concentration of a solute in a solution saturated with respect to that solute at a given temperature and pressure. The unit is $\mathrm{kg} / \mathrm{m}^{3}$ or equivalent.

sorption - The binding on a microscopic scale of one substance to another, such as by adsorption or ion exchange, (e.g., the sorption of soluble radionuclides from the liquid phase onto the solid phase of a geologic formation or the particulates in a body of water).

spatial dispersion - The expansion of a moving plume or band of contaminant carried by a moving fluid. Also, scattering of a concentrated source by a multi-directional circulating fluid.

spent fuel - Fuel assemblies removed from a nuclear power reactor after their useful life, usually 2 to 3 years of operation at power.

stability - The ability of a component to function satisfactorily over a wide range of environments or with an environmental change. This is a component characteristic for a given environmental variation and a given function in the system.

stable environment - An environment with negligible changes or fluctuations of important characteristics during the period of interest.

temporal dispersion - Causing a potentially high intensity, short duration release of waste from a component, to be released at a lower rate over a longer period of time; pulse spreading.

validation - The documented confirmation that the software under review is suitable for its intended purpose. It includes assurance that the model used in the software is a correct representation of the actual system, component, or process.

verification - The documented confirmation that software performs exactly the mathematical and logical operations specified in the numerical model. It can include benchmarking the software against the results of other verified software that solve a similar class of problems.

waste form - The solid material that is comprised of the radioactive wastes together with the incorporating matrix or filler material. 


\section{INTRODUCTION}

\subsection{Background}

High-level radioactive waste is produced in many countries as a result of generating electricity by nuclear reactors. The long period of time this type of waste remains potentially hazardous require a reliable, long-term disposal system. One of the proposed disposal methods would bury high-level waste (HLW) or spent fuel (SF) in remote deep ocean sediments.

The US Subseabed Disposal Project (SDP) was investigating the scientific, engineering, economic, and environmental feasibilities of Subseabed Disposal (SD) of nuclear wastes. This project was sponsored by the US Department of Energy (DOE), Office of Civilian Waste Management under the technical direction of Sandia National Laboratories (SNL). In 1976, the Seabed Working Group (SWG) was formed under the auspices of the Nuclear Energy Agency (NEA) to provide scientific and technical information to international and national authorities to enable them to assess long-term safety and engineering feasibility of subseabed disposal. Members used the SWG to promote information exchange, coordinate individual research efforts, and facilitate cooperative research. The membership of the SWG grew to 10 countries plus the Commission of European Communities (CEC) in 1987.

Potential disposal sites for SD are abyssal hills or plains at ocean depths greater than $5000 \mathrm{~m}$. These vast sedimentary areas are some of the most seismically stable formations on earth. Existing clay sediments in these areas are stable and uniform, and new sediments are being formed by slow but continuous deposition of fine particles. The plasticity of the sediments makes them self-healing after emplacement of waste or following any motion of the sediments. Because these sediments have low permeability, the primary radionuclide transport mechanism is diffusion, which is slowed for most nuclides by the sorptive properties of the fine clays. At the depths being considered, low temperatures (about $2^{\circ} \mathrm{C}$ ) reduce chemical reaction rates and high pressures prevent boiling. These formations are remote from human activities and have few useful resources. Biota are very sparse at the depths under consideration. The oceans above the prospective repository have the capacity to disperse and dilute any radionuclides that leave the repository before they decay. Locations with potential mineral or biological resources, with active pore water movement or surface erosion, or those that are near the edges of tectonic plates or continental margins would be avoided.

The SD process that was proposed by the SDP would begin with transportation of the nuclear waste from a reprocessing plant or storage facility using conventional land shipping casks and carriers (truck, rail, or barge) as illustrated in Figure 1. At an assembly plant or the port facility, the waste canisters may be placed in a secondary container for some methods of emplacement. The waste would then be loaded onto specially designed ships and transported to the disposal site. There are several methods being considered for emplacing the waste in the sediments. Free-fall penetrators holding one US waste canister each would achieve burial depths between 30 and $70 \mathrm{~m}$. Reduced pressure would cause the holes to close behind the penetrators during emplacement. With penetrators placed about 180 meters apart, a $500 \mathrm{~km}^{2}$ repository could accept 10 years worth of the world's HLW. Another method 


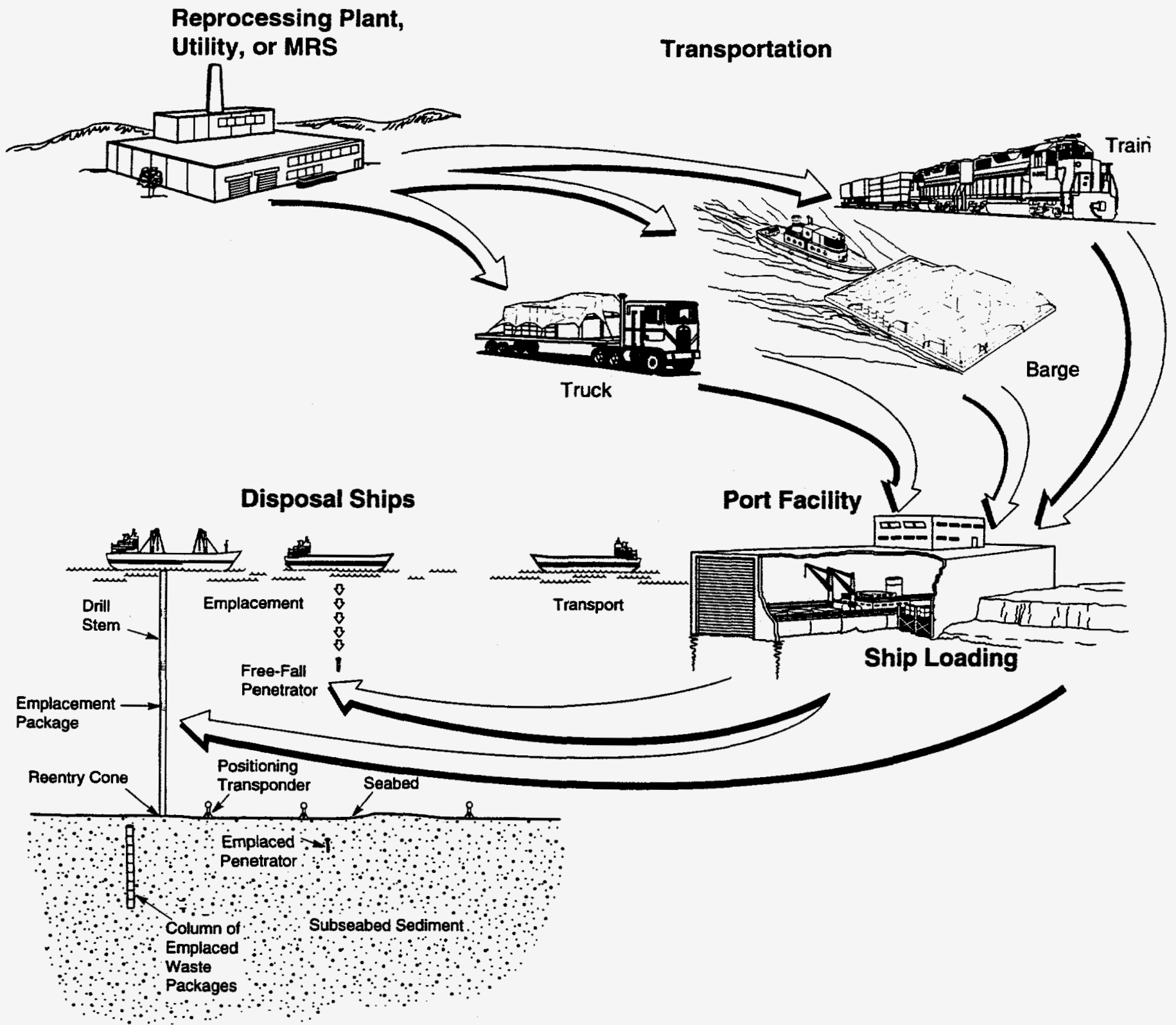

Figure 1. Conceptual design of the Subseabed Nuclear Waste Disposal system. 
for sites with thick sediments would use predrilled holes approximately 800 meters into the sediments. A 500 meter column of waste packages would be placed in the holes, and the remainder of each hole would be filled with sediment.

With both options, the waste package would protect and contain the wastes for the first several thousand years after transportation and emplacement. For the next several thousand years the waste would slowly be released to the sediments, which would be one of the principle barriers in the disposal system. The small amount of waste that would eventually escape from the sediments would be dispersed and diluted by the oceans. A more detailed description of the SDP concept can be found in the 1983 status report [1], and the 1988 preliminary feasibility risk assessment [2].

\subsection{Purpose and Organization of the Subseabed Disposal Project Radiological Standards Development}

The SDP began the feasibility phase of development in 1976. Radiological standards were needed to assure proper measurements and computations were made for concept evaluation, and to evaluate the absolute safety of the concept and the safety relative to other disposal concepts. Standards were also needed during the feasibility phase to develop functional requirements for transportation and emplacement engineering, for interim performance assessments to detect any problems early in the design, to help direct the research and development program, and for sensitivity studies to show where the largest gains could be made in design and which parts of the database should be expanded. However, no national or international radiological criteria apply to the disposal of $\mathrm{HLW}$ or SF in ocean sediments. Existing US dose and prescriptive radiological criteria [3] and performance assessment procedures were developed by regulatory agencies specifically for mined geologic repositories, and exclude disposal processes such as subseabed disposal. Although there are international radiological protection guidelines for the disposal of solid radioactive waste $[4,5]$ and criteria for dumping low-level waste (LLW) in the oceans $[6,7,8]$, subseabed $\mathrm{HLW}$ disposal is not covered. Therefore, it was necessary to develop interim radiologic standards and evaluation procedures for the feasibility phase of the SDP.

A general evaluation procedure was developed for assessing the efficiency and safety of hazardous waste disposal processes using attenuation factors [9]. A program to define which interim radiological standards to use with these performance assessment procedures during the feasibility phase of the SDP consisted of the following three parts.

1. Definition of options. This step consisted of an examination of the history of radiological protection, a review of existing laws and regulations, an investigation of problems particular to the SDP, and a compilation of the options available for regulation of SD. The findings are given in Reference 10.

2. Evaluation of the options. This step considered the legal, institutional, and social issues, and made recommendations on each of the options defined in the first stage. A workshop organized by M. Kaplan and held in Washington, D.C., April 12-13, 1984 was a major part of this stage. The results of the workshop are summarized in Reference 11. 
3. Development of interim radiological standards and procedures. Parts 1 and 2 were major contributions to the development of SDP standards. However, since 1984, advances in radiation biology, improved guidelines from regulatory agencies, and a better understanding of nuclide transport from a subseabed repository have made it possible to modify and expand the inputs from the first two stages. In part 3, the predicted detriments to individuals and populations that could be caused by subseabed disposal of HLW were used to develop dose and derived standards for an operational subseabed repository and for abnormal events. Recommendations were made for implementing these standards during the early phases of the SDP. The results of part 3 are the subject of this report.

Since the SDP was not bound by existing criteria, standards development could be innovative while taking advantage of what was learned from the successes and problems of other programs. There were some general guidelines that applied to all three parts of the standards development. The primary requirement for SDP standards is that they cannot allow higher risks than those allowed by existing regulations or guidelines. International regulations take precedence because of the international aspects of subseabed disposal. National regulation may be broader or more stringent than international regulation, and there may be some areas within national boundaries where only national regulations apply. Self-imposed requirements for the SDP standard were:

- standards should apply to all subseabed disposal and transportation methods.

- standards should not be limited by predicted SD capabilities but should include all potential sources of risk predicted by performance assessments.

- standards for the SDP feasibility phase must assure adequate protection and be defensible; but should not unnecessarily restrict the system design.

- standards and procedures must be implementable for subseabed disposal.

- multiple standards could be carried through the SDP feasibility phase. There are several advantages to multiple standards: (1) they make it possible to evaluate the feasibility more thoroughly from several perspectives, (2) they facilitate comparisons with other disposal processes, and (3) they form a broader and more complete basis for future legislation and regulations. Subseabed performance assessment procedures can handle multiple standards with very little additional effort and expense.

The discussions in this report concentrate on limiting hazards to humans from all potential seabed disposal sources, but make no recommendation for implementation of SDP standards by regulating agencies. The standards used during the feasibility phase of the SDP are not intended for final acceptability evaluation, and have no legal or regulatory status.

\subsection{Summary of Parts 1 and 2 of the Subseabed Disposal Project Standards Development}

The definition of options for subseabed disposal radiological standards and the evaluation of the options by an international workshop are summarized briefly in this section. These topics are discussed in more detail in References 10 and 11, respectively. The results and conclusions of each of the first stages were used as information for the next stages, and were not meant to be constraints. 


\subsubsection{Options for Radiological Protection}

Applicable radiological standards already exist for land transportation and port facilities. Table 1 lists options that must be considered in developing standards for sea transportation, waste emplacement, and repository operation. This list is not all inclusive, nor are all combinations of options possible.

Table 1. Options for Development of SDP Working Radiological Protection Standards*

\begin{tabular}{|c|c|}
\hline Regulatory Strategies & $\begin{array}{l}\text { - Risk-level standards } \\
\text { - Derived and Prescriptive standards }\end{array}$ \\
\hline Object to be Protected & $\begin{array}{l}\text { - Individuals } \\
\text { - Population } \\
\text { - Biota }\end{array}$ \\
\hline Hazard Measure & $\begin{array}{l}\text { - Dose (peak, accumulated) } \\
\text { - Health effects (per year, integrated) } \\
\text { - Release rate or integrated release } \\
\text { - Concentration in the environment }\end{array}$ \\
\hline Time Frame for Evaluation & $\begin{array}{l}\text { - All time } \\
\text { - Time of peak hazard measure } \\
\text { - Predetermined time limit }\end{array}$ \\
\hline Where Standard is Applied & $\begin{array}{l}\text { - Recipient } \\
\text { - Some location in the nuclide pathway }\end{array}$ \\
\hline Value of Standard & $\begin{array}{l}\text { - ICRP dose limit } \\
\text { - Natural background, fraction thereof } \\
\text { - De minimis } \\
\text { - Time-integrated dose limit }\end{array}$ \\
\hline Probabilistic Measures & $\begin{array}{l}\text { - Expected value of risk } \\
\text { - Limits on probability of occurrence } \\
\text { - Confidence limits (a means of } \\
\text { demonstrating reasonable assurance) }\end{array}$ \\
\hline Optimization Approach & $\begin{array}{l}\text { - Risk/benefit } \\
\text { - Limit on incremental risk or activity }\end{array}$ \\
\hline
\end{tabular}

\subsubsection{REGULATORY STRATEGIES}

One approach to minimizing disposal risks is to specify detailed, derived and prescriptive criteria for system design and operation. Alternatively, the design and operation could be controlled by risk- 
based radiological protection standards. Derived criteria can be a regulatory method of assuring compliance with risk-based criteria.

\subsubsection{OBJECT TO BE PROTECTED}

Individuals, populations, and aquatic biota need to be protected from undue harm. This goal may be achieved by setting radiological protection objectives for one or more of these categories. Releases of radioactive material that would be mixed in the world oceans could affect many individuals. Therefore, an individual-protection standard would either need to be stringent enough to protect populations, or combined with a population-protection standard.

\subsubsection{HAZARD MEASURE}

Humans and biota are the natural endpoints for assessing radiological hazard. However, standards can also be set for intermediate measures, such as nuclide flux across a boundary or nuclide concentrations. Health effects, i.e., premature deaths and genetic effects, doses, and release rates (or fluxes) can be measured at a specific time or at their peak value. Integrated values may be calculated over a specified period of time. Regulating the peak value provides protection at any point in time, while limiting the integrated value addresses the effects of multi-generational exposures.

\subsubsection{TIME FRAME FOR EVALUATION OF THE STANDARD}

For a subseabed repository, releases to the ocean are not expected to begin earlier than $10^{4}$ years after emplacement and can occur over millions of years. It is necessary to describe whether radiological protection objectives should require model predictions over the entire time period of release or over some limited time frame.

\subsubsection{WHERE STANDARD IS APPLIED}

Risks incurred at the endpoint of the system, i.e., by the recipient of the dose, are usually the basis for evaluation. However, it can be more convenient to regulate nuclide flux or concentrations at some other location in the nuclide pathway, such as the sediment/water interface. Standards applied closer to the source exercise more control over the repository design, and increasingly constrain system optimization.

\subsubsection{VALUE OF STANDARD}

One option for the value of the standard is the International Commission on Radiological Protection (ICRP) guidelines, which limit the annual dose to an individual $\left(10^{-3} \mathrm{~Sv} / \mathrm{yr}\right)[4,5]$ but limit 
population exposures to doses only as low as reasonably achievable (ALARA), taking into account economic and social factors. The ICRP guidelines are used primarily for regulating exposures to the present population. A second option involves the use of natural background radiation levels (or some fraction thereof) for the standard. The basis for this option is that people are already exposed to background radiation from natural sources and have been for numerous generations. A third option is to set the value of the standard to a de minimis level (on the order of $10^{-5} \mathrm{~Sv} / \mathrm{yr}$ or less). This approach does not assume there is no risk at this level, but rather that the risk is sufficiently small compared to that from natural background. A fourth option is to set a limit on integrated dose (or, equivalently, on integrated health effects).

\subsubsection{PROBABILISTIC MEASURES}

Evaluating the safety of subseabed disposal of HLW requires considering the probability of future events and the uncertainty in the estimated consequences of these events. The probability of events and the estimated consequences can provide a measure of disposal risk. Standards can be formulated either to account explicitly for the probabilistic aspects of risk or to address them indirectly.

\subsubsection{OPTIMIZATION APPROACH}

The purposes of optimization in nuclear waste management include:

- Reducing risk to the lowest possible level commensurate with disposal costs and the benefits from the power generated

- Assuring that disposal of radioactive wastes from all sources, present and future, will not cause an excessive hazard.

An upper limit can be placed on allowable harm to individuals or populations. This overall limit is based on the total radiation accumulated in the sea from all sources (e.g., from subseabed disposal, dumping operations, and releases from land-based installations). Under this approach, each disposer is allocated a limited amount of waste.

Traditionally, criteria have been based on a single set of options. However, multiple combinations are possible, with the repository designed to meet an envelope of requirements, e.g., limits on integrated world population dose and peak individual dose.

\subsubsection{Workshop to Evaluate Radiological Protection Options}

The primary purposes of the workshop were to review the options for radiological criteria for subseabed disposal of $\mathrm{HLW}$ and to make recommendations for working standards to be used during the feasibility phase of the SDP. Secondary topics included optimization, protection of biota, acceptable 
dose levels, probabilistic treatments of risk, retrieval, recovery, monitoring, confidence levels, reliability, definition of feasibility, prescriptive standards, and methods of working with regulators and the public.

Workshop participants were selected to provide national and international expertise in regulatory, institutional, and scientific areas relevant to evaluation of subseabed disposal standards. The recommendations of the workshop are the consensus of the group. The participants did not agree on all topics and did not resolve several items on the agenda. Most participants agreed that standards for radioactive waste disposal should be based on risk (the probability of harm to an individual from radioactive exposure) rather than on some fraction of background or some multiple of the upper level of de minimis. Except where noted, the following recommendations are intended to be applied to all exposures without restrictions on the time of occurrence or on the location of exposure. The major recommendations of the workshop were:

1. In general, the interim radiological protection working standards for SD should use one set of requirements to eliminate disposal processes that are unacceptable. Another set of requirements should be coupled with economic, engineering, political, and social factors to determine the acceptability of subseabed disposal, select the process, and optimize the system.

2. Feasibility (i.e., not unacceptable) should be based on peak dose to a maximally exposed individual. The participants supported an upper limit on the probability of premature death of approximately $10^{-5}$ per year from all nonmedical anthropocentric sources of radioactivity, or the dose limit of $10^{-3}$ Sv/yr recommended in ICRP-46 [4]. This is the same as the current dose limited recommended in ICRP-60 [5]. An undefined fraction of this limit would be allocated to HLW disposal. Design objectives should be lower than any of these limits.

3. The radiological standards used to determine acceptability, select the process, and optimize a subseabed disposal system should be time-integrated dose to the world population. Participants did not agree upon the time interval of integration, but most agreed that a good cutoff would be when doses from all disposal processes were equivalent. Other suggestions were based on specified times or dose levels.

4. Protection of biota should be achieved by limiting doses to populations, with no limits on individual biota doses. The SDP will need to prove HLW disposal will not cause any species to become extinct or disrupt any significant food chain. Not enough is known at this time to set levels on allowable doses, but a small fraction of local background would be a conservative limit.

5. Derived and prescriptive standards may eventually be required for subseabed disposal, but their development should be delayed to allow for design flexibility. Input from sensitivity studies and risk assessments would help regulatory agencies set functional and realistic prescriptive criteria.

6. The workshop did not reach a consensus on the methods or the stringency for regulating events of low probability, such as accidents, improper emplacement, etc. The system should be designed to limit the consequences of these events, and contingency plans should be developed for recovery. The probabilistic approach was suggested, in which the risk equals the probability of occurrence 
times the consequence. However, the consequences of these abnormal events must also be presented.

7. Communication among the SDP, national and international regulatory agencies, legislative bodies, and the public is very important. The public is particularly interested in the control of waste disposal, including retrievability, recovery, monitoring, and prescriptive regulation.

8. A basic assumption of the workshop participants was that there would be both national and international control of subseabed disposal and that the workshop recommendations would only be used for the development of interim standards. Some participants cautioned against selecting a single set of standards during the feasibility phase before the regulatory agencies set their standards for the process. The SDP should use quantitative standards cautiously, because numbers intended to be only guidelines have a tendency to become fixed.

\subsection{Organization of this Report}

This report concludes the three part program to develop and recommend interim radiological standards for use during the feasibility phase of the SDP. After describing the characteristics of SD, general radiological protection methods are reviewed, and their advantages and disadvantages are discussed. Several types of dose standards are recommended for emplaced waste and for low-probability abnormal events. Derived and prescriptive standards appropriate to SD are suggested.

Chapter 2 discusses the characteristics of SD, how they differ from those of mined geologic repositories, and how they affect doses to individuals, populations, and biota. Emplaced waste, accidents, and abnormal events are covered. This information must be known before appropriate regulations can be promulgated to control the disposal process, and before performance assessment procedures can be defined to evaluate compliance with the regulations. Chapter 3 is a general discussion of protection methods. Included are relationships between doses and health effects, risks and methods of regulating doses from low probability events, equity of risks and benefits, categories of standards, duration of regulation, assurance requirements, assessment, requirements, existing related standards, and modifications that can be made to facilitate implementation. Chapter 4 defines the interim standards that were used in the 1983 and 1987 feasibility assessments. The recommended standards for the remainder of the feasibility phase of the SDP appear in Chapter 5. Peak individual dose, peak single generation dose, and collective population dose standards can all be used with SD which provides a complete assessment of risk. Some examples of the use of the standards are given. Explanations are given for why some existing derived and prescriptive standards cannot be adapted to SD, and alternate approaches are suggested. 


\section{CHARACTERISTICS OF SUBSEABED HIGH-LEVEL WASTE DISPOSAL}

Safety standards must be set in accordance with the types of risks that may be encountered. This chapter describes the nature of radiological hazards from subseabed disposal of $\mathrm{HLW}$ and the requirements these potential hazards place on dose, derived, and prescriptive standards. Differences between the attenuation processes of terrestrial and subseabed disposal and the resulting doses to individuals and populations are discussed.

The land transportation segment of SD would be similar to that for terrestrial repositories. However, for the port facility, sea transportation, emplacement, and routine post-emplacement operation, subseabed disposal has some unique attenuation processes and pathways to humans.

There would be equipment and procedures to recover any waste lost in an accident. However, there would still be a possibility that some of the canisters could not be recovered or that some leaching could occur prior to recovery of damaged canisters. If a canister is lost on the floor of the ocean, the canister and waste form would delay release resulting in some radioactive decay. The slow release from the waste form would help ocean currents and diffusion dilute and disperse any released waste. Scavenging would remove some waste from the oceans and deposit it on the sediments.

For the much more likely case of properly emplaced waste, all forms of the accident scenario attenuation would exist. In addition, the canister would also isolate the waste during the potential periods of waste-induced thermal convection, thermally-driven diffusion, and detrimental radiation chemistry. The sediment surrounding the canister would greatly delay release to the ocean and spread the release period over millions of years.

Potential pathways to humans would be from the waste form, through the sediments and the oceans, and finally through one of the following:

1. Ingestion of various aquatic biota (fish, seaweed, crustaceans, mollusks, and plankton) that were directly contaminated by the water or sediment.

2. Ingestion of fish from a contaminated food chain.

3. Ingestion of contaminated sea salt and desalinized seawater.

4. Immersion in contaminated water.

5. Exposure to shore sediments.

6. Inhalation of sea spray and shore sediments.

7. Evaporation of -129 and C-14 from the oceans followed by atmospheric precipitation and ingestion of contaminated terrestrial food and water. 
Preliminary safety assessments [1,2] have shown that pathways 1 and 2 above are the dominant pathways for emplaced waste and for all accidents and abnormal events that have been investigated. The major pathways and nuclide transport processes are illustrated in Figure 2.

Barriers, risk attenuation processes, pathways, and the populations at risk from subseabed nuclear waste repositories are greatly different than those of terrestrial mined geologic repositories. Individual risks would be much lower for SD, but a larger population would be affected. Therefore, SD would have a larger safety margin using peak individual dose standards than with time-integrated population dose standards. The inverse is true for mined geologic repositories. To some extent terrestrial repositories can be treated independently because of limited mixing outside the repository and the smaller population at risk. However, all sources entering the ocean will eventually mix, and all similar sources must be combined in risk assessments. Fundamental and dose standards [12] and methods of PA could apply to both repository types, but derived or prescriptive standards and specific detailed PA procedures are not interchangeable.

The next section covers predicted SD risks from emplaced waste, pre-emplacement accidents and abnormal events, and describes how the potential doses are reduced by each component in the system. The following sections interpret the predicted risks from the standpoint of radiological standards and show the similarities and differences between subseabed and terrestrial disposal. More specific characteristics of SD will be given in the chapters on dose, derived, and prescriptive SD standards.

\subsection{Radiological Risks from Subseabed HLW Disposal}

The dose and risk predictions presented in this section are taken from the 1987 international subseabed disposal radiological assessment (Volume 2 of Reference 2). The reference contains bracketing studies that use best estimate, least favorable, and most favorable input data, along with statistical uncertainty analyses, but only the results based on best estimate data and a $50 \mathrm{~m}$ burial depth are presented in this chapter. Because the total amount of nuclear waste that would be disposed of is not defined, the calculations were normalized to the HLW from one metric ton of heavy-metal fuel (MTHM). Each repository would contain approximately $10^{5}$ MTHM, the waste produced from generating $3 \times 10^{9}$ kilowatt-years of electricity. Doses and risks for one repository can be obtained by multiplying the values in this section by $10^{5}$.

The principle measures of doses to humans used throughout this report are:

1. MID - Peak individual dose rates to the maximally-exposed group, regardless of time (Sv/yr.MTHM).

2. SGD - Peak dose rates to a single generation of the world population, regardless of time (Person.Sv/yr.MTHM). When lifetime doses are computed, 70 years of exposure is assumed and the units are Person.Sv/MTHM. 


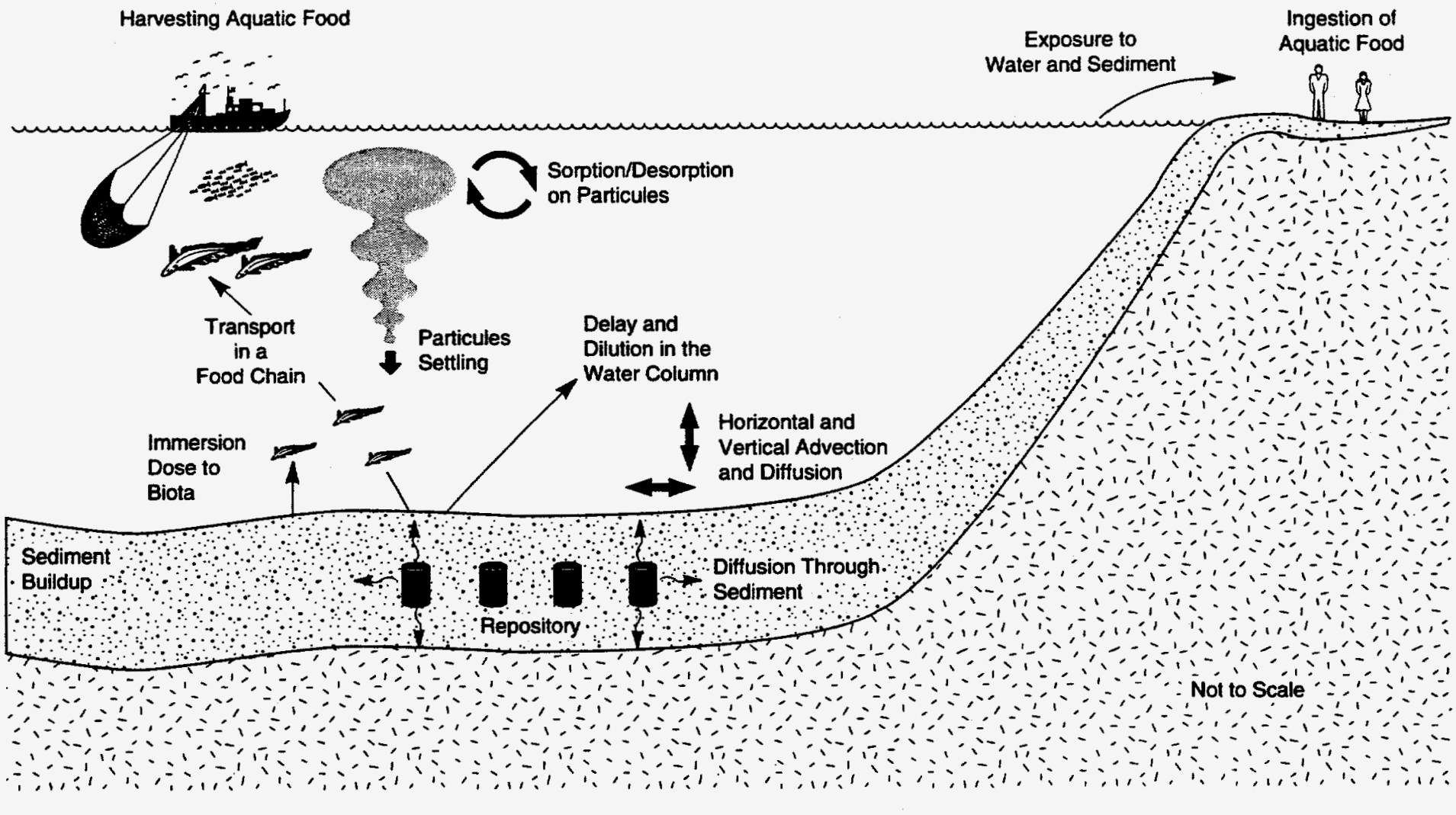

TA1.6342.3430-0

Figure 2. Major Subseabed Disposal Pathways and Nuclide Transport Processes. 
3. CPD - Collective time-integrated world population dose (Person.Sv/MTHM). Integration time is 105 years unless noted.

For aquatic food consumption, which is the dominant pathway to humans, the maximally exposed individual is that of a Japanese fisherman, and the consumption rates for the world population are the potential maximum harvest rates from the oceans without depleting the species. This approach to individual and population dose predictions for SD does not depend on predictions of human populations or population distributions. Doses are related to risk in the mid-dose range using 0.05 latent cancer fatalities per Sv [5]. Absorbed dose rates (Gy/yr. MTHM) are computed for biota because weighting factors to compute dose equivalents are not available.

\subsubsection{Emplaced Waste}

The physical oceanographic model used for analyses of emplaced waste and deep ocean transportation accidents is shown in Figures 3 and 4. The waste is emplaced in the sediment under the Eddy compartment. The locations referred to in the dose predictions are the compartments in this model. Dose rates to the maximally-exposed individual, the world population, and biota were computed from the time of emplacement to $10^{7}$ years. Also, the world population dose is time integrated from the time of emplacement in decade increments. Figure 5 shows individual dose rates by compartment with principal pathways indicated in parentheses. Figure 6 shows world population dose rates by nuclide and the total dose rates from all nuclides. Since the mixing time in the ocean is only several thousand years, the shape of the dose curves for individual nuclides is primarily controlled by that nuclide's diffusion rate through the sediments and its half life. Nuclides that are not sorbed by the sediments reach the oceans long before the sorbed nuclides. Doses from short-lived nuclides peak earlier than those from long-lived nuclides. Many short-lived and highly-sorbed nuclides decay before they reach the ocean. Tables 2 through 4 summarize the most significant results relative to peak maximally-exposed individual dose rate (MID), collective time-integrated world population doses (CPD), and population dose rates to biota.

Another study that illustrated the characteristic of SD was an attenuation factor (AF) analysis [9]. This analysis computed the reduction in dose potential by each component in the waste disposal system. Table 5 shows the attenuation factors of MID and CPD by each major component and total attenuation of a SD system. Integration time for CPD is $10^{5}$ years. A significant amount of attenuation of both MID and CPD occurs in the sediments above the emplaced canisters and in the oceans. The retardation by the canister, waste form, and sediments, which provides time for most of the nuclides to decay, has approximately the same effect on MID and CPD. However, the spreading of nuclide releases to the oceans by sediment over time and dilution by the oceans are more effective in reducing MID than CPD. Time integration negates the effects of temporal dispersion, and population integration negates the effects of dilution for CPD. The total system attenuation for MID is a factor of $4 \times 10^{10}$ greater than for CPD. With the standards used in the 1987 interim risk assessment (Chapter 4 of this report) and assuming 10 subseabed repositories each containing $10^{5} \mathrm{MTHM}$, the required MID attenuation factor would be $8.5 \times 10^{15}$ and the required CPD attenuation factor would be $8.5 \times 10^{6}$. The required system attenuation factors were computed by dividing the initial dose potential of exposed waste (no disposal system) by the allowable dose or dose rate. Comparing these values to the AFs in Table 5 shows that SD has a large 


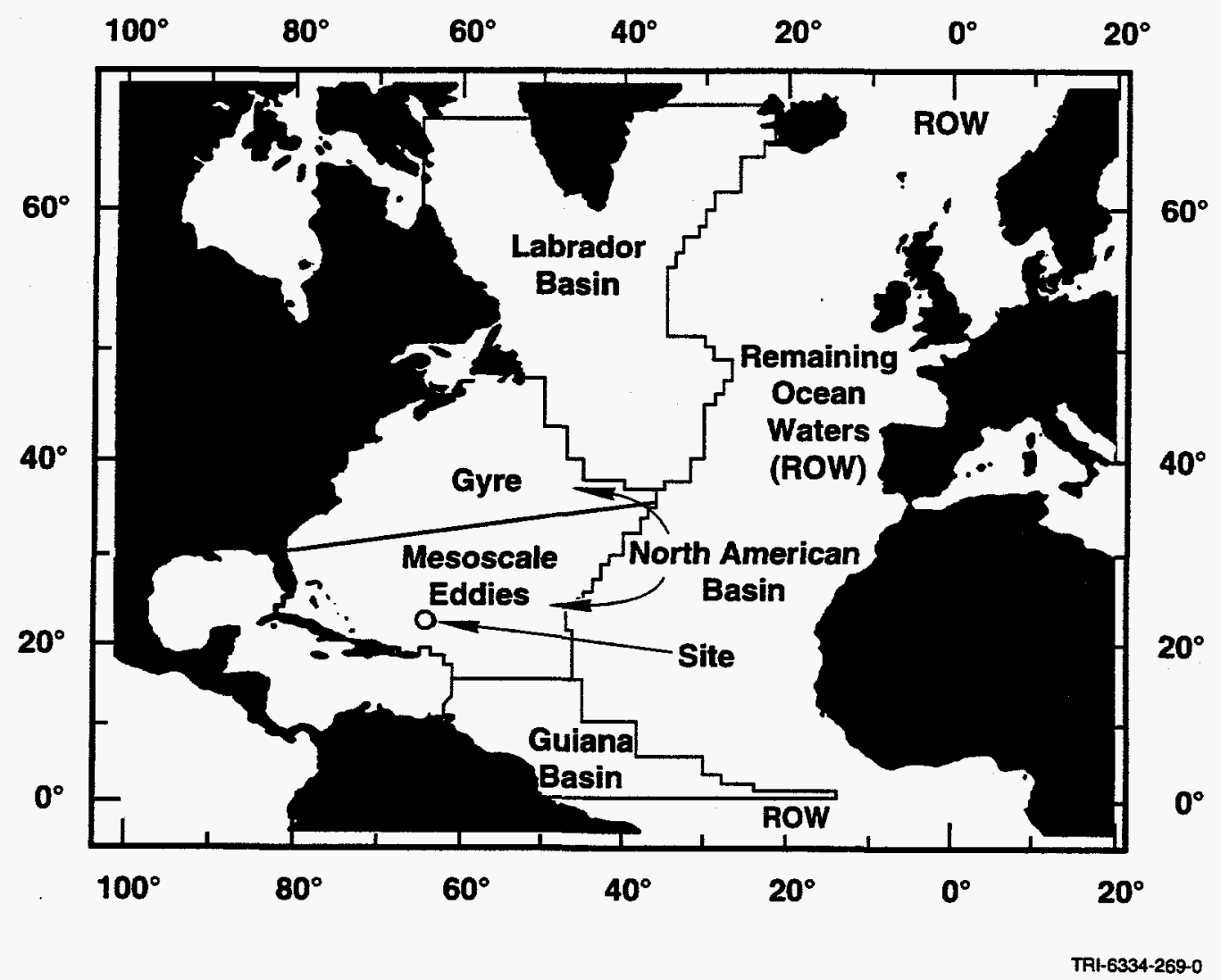

Figure 3. Atlantic Ocean Site with Model Compartments. 


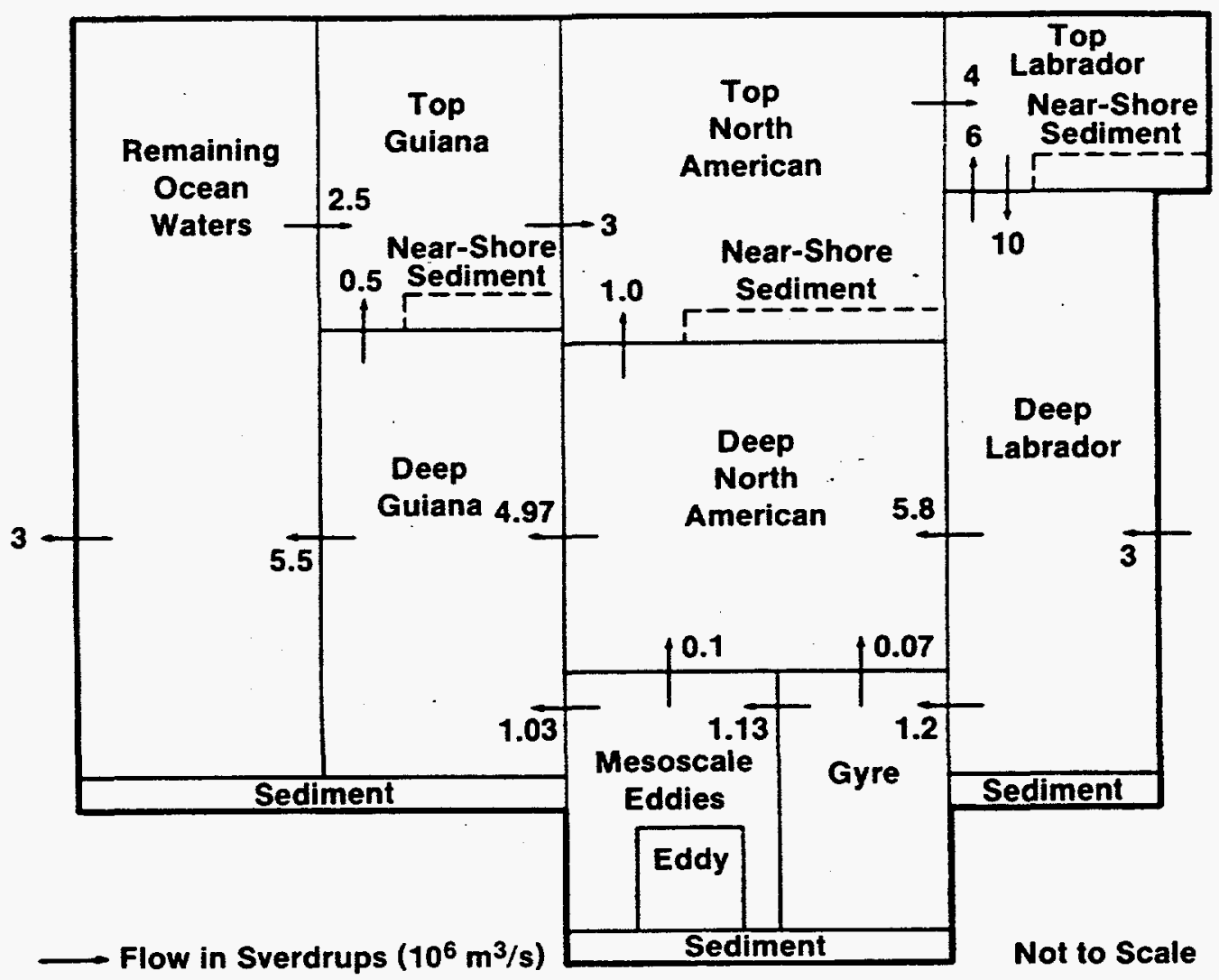

TRI-6334-136-0

Figure 4. Compartment Model-Atlantic Ocean site. 


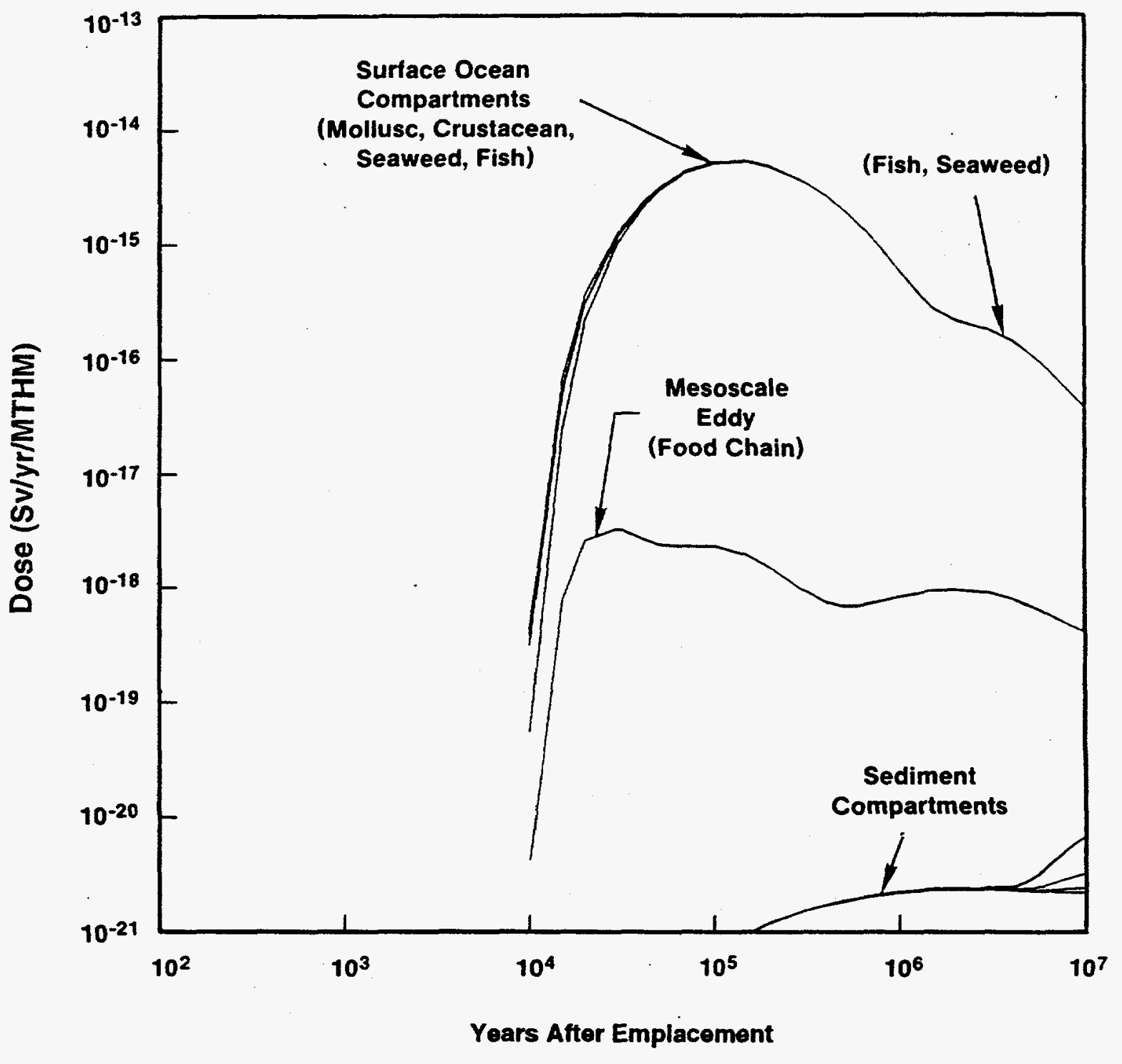

TRI-6334-137-1

Figure 5. Post-emplacement individual dose vs. time, by compartment-mean-risk parameter values. 


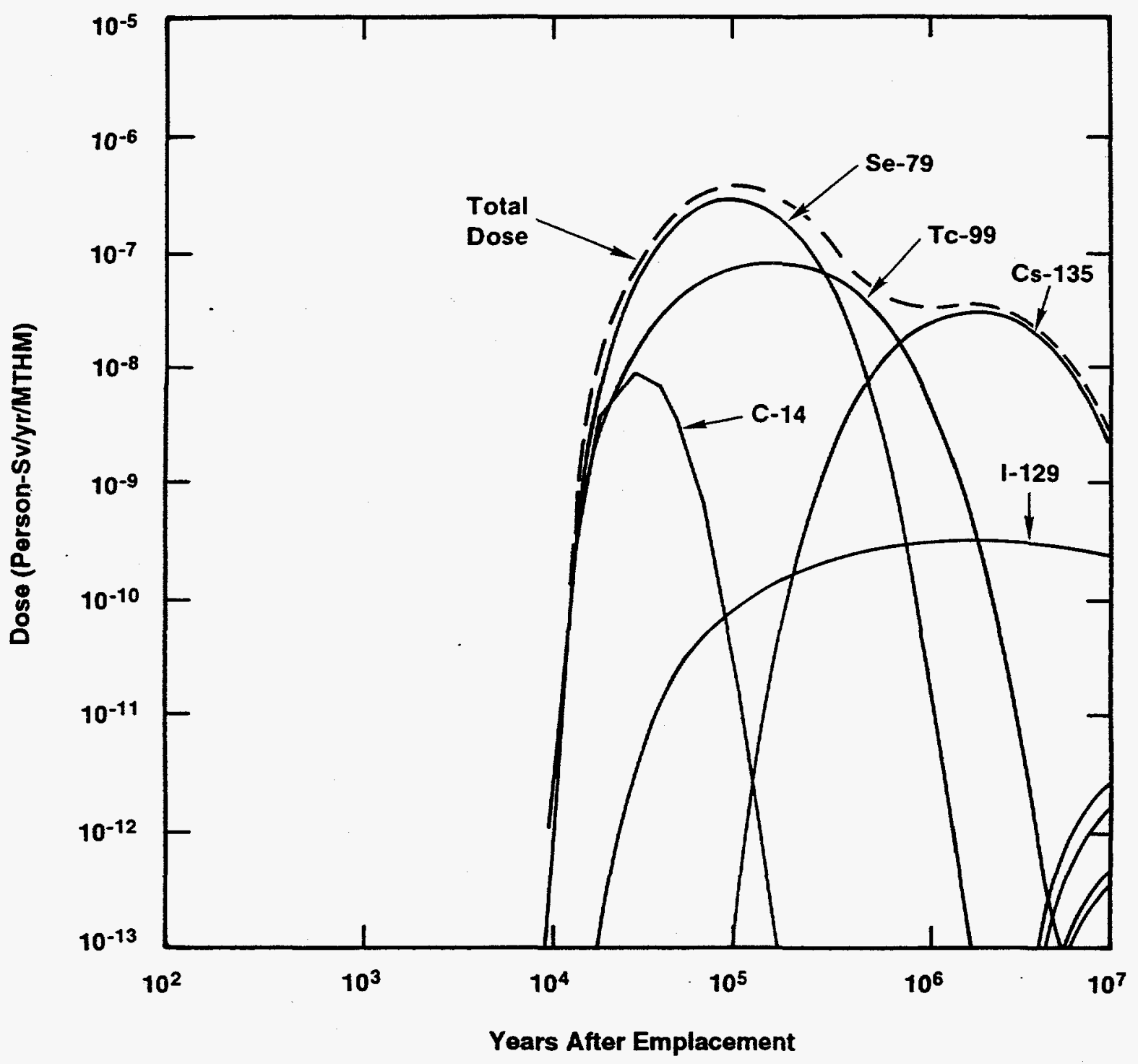

TRI-6334-138-0

Figure 6. Post-emplacement population dose vs. time in the world ocean compartment, by nuclidemean-risk parameter values. 
Table 2. Maximally-Exposed Individual Dose Parameters

(Emplaced Waste)

\begin{tabular}{|c|c|c|c|c|}
\hline $\begin{array}{c}\text { Peak Individual } \\
\text { Dose Rate } \\
\text { (Sv/yr-MTHM) }\end{array}$ & $\begin{array}{c}\text { Time of Peak } \\
\text { Dose } \\
\text { (Yr) }\end{array}$ & Compartment & $\begin{array}{c}\text { Principal } \\
\text { Nuclides and \% } \\
\text { Contribution }\end{array}$ & $\begin{array}{c}\text { Principal } \\
\text { Pathways and \% } \\
\text { Contribution }\end{array}$ \\
\hline $5.2 \times 10^{-15}$ & $1.5 \times 10^{5}$ & Top N. Amer. & $\begin{array}{l}\text { Tc-99 }(71 \%) \\
\text { Se-79 }(29 \%)\end{array}$ & $\begin{array}{l}\text { Mollusc (29\%) } \\
\text { Crustacean } \\
(28 \%) \\
\text { Seaweed }(24 \%) \\
\text { Fish }(19 \%)\end{array}$ \\
\hline
\end{tabular}

Table 3. Collective Population Dose Parameters (Emplaced Waste)

\begin{tabular}{|c|c|c|c|}
\hline $\begin{array}{c}\text { Endpoint of Dose } \\
\text { Integration } \\
(\mathrm{Yr}) \\
\end{array}$ & $\begin{array}{c}\text { Integrated Population } \\
\text { Dose } \\
\text { (Person Sv/MTHM) }\end{array}$ & $\begin{array}{l}\text { Principal Nuclides } \\
\text { and \% Contribution }\end{array}$ & $\begin{array}{l}\text { Principal Pathways } \\
\text { and } \% \text { Contribution }\end{array}$ \\
\hline $10^{4}$ & $6.0 \times 10^{-9}$ & $\begin{array}{l}\text { Tc-99 (71\%) } \\
\text { C-14 (19\%) } \\
\text { Se-79 (10\%) }\end{array}$ & $\begin{array}{l}\text { Fish }(48 \%) \\
\text { Crustacean }(27 \%) \\
\text { Mollusc }(20 \%)\end{array}$ \\
\hline $10^{5}$ & $2.2 \times 10^{-2}$ & $\begin{array}{l}\text { Se-79 }(80 \%) \\
\text { Tc-99 (19\%) }\end{array}$ & $\begin{array}{l}\text { Fish }(83 \%) \\
\text { Crustacean }(9 \%) \\
\text { Mollusc }(5 \%)\end{array}$ \\
\hline $10^{6}$ & $1.2 \times 10^{-1}$ & $\begin{array}{l}\text { Se-79 }(55 \%) \\
\text { Tc-99 (38\%) } \\
\text { Cs-135 (7\%) }\end{array}$ & $\begin{array}{l}\text { Fish }(72 \%) \\
\text { Crustacean }(15 \%) \\
\text { Mollusc }(8 \%)\end{array}$ \\
\hline $10^{7}$ & $2.8 \times 10^{-1}$ & $\begin{array}{l}\text { Cs-135 (56\%) } \\
\text { Se-79 }(24 \%) \\
\text { Tc-99 }(18 \%)\end{array}$ & $\begin{array}{l}\text { Fish }(84 \%) \\
\text { Crustacean }(8 \%) \\
\text { Mollusc }(4 \%)\end{array}$ \\
\hline
\end{tabular}

Table 4. Peak Biota Dose-Rate Parameters

(Water Ingestion in the Benthic Mixed Layer) (Emplaced Waste)

\begin{tabular}{|c|c|c|}
\hline Biota & $\begin{array}{l}\text { Peak Dose Rate } \\
\text { (Gy/Yr-MTHM) }\end{array}$ & $\begin{array}{c}\text { Time of Peak Dose } \\
(\mathrm{Yr})\end{array}$ \\
\hline Fish & $5.2 \times 10^{-14}$ & $3.0 \times 10^{4}$ \\
\hline Crustaceans \& Molluscs & $6.3 \times 10^{-13}$ & $4.0 \times 10^{4}$ \\
\hline
\end{tabular}


Table 5. Dose Attenuation Factors in a Subseabed Disposal System

(Emplaced Waste)

\begin{tabular}{lccc}
\hline \multicolumn{1}{c}{ Component } & $\begin{array}{c}\text { Maximum Individual } \\
\text { Dose Rate }\end{array}$ & & $\begin{array}{c}\text { Collective World } \\
\text { Population Dose }\end{array}$ \\
\cline { 1 - 1 } Canister & $2.9 \times 10^{2}$ & & $1.3 \times 10^{3}$ \\
Waste Form & & & $1.6 \times 10^{1}$ \\
Sediments & $1.6 \times 10^{5}$ & & $1.1 \times 10^{3}$ \\
Oceans & $1.3 \times 10^{11}$ & & $2.3 \times 10^{3}$ \\
Total System & $1.6 \times 10^{20}$ & & $3.9 \times 10^{9}$ \\
\hline
\end{tabular}

margin of safety with either standard but the margin of safety for MID is a factor of 41 higher than for CPD. Peak biota doses would be $5 \times 10^{-14} \mathrm{~Gy} / \mathrm{yr} \cdot \mathrm{MTHM}$ for fish and $6 \times 10^{-13}$ for crustaceans and mollusks in the benthic mixed layer.

Based on the information in Figures 5 and 6, Tables 2 through 5, and Reference 2, the following conclusions can be drawn regarding doses from HLW emplaced in deep ocean sediments.

1. There are almost no doses to individuals or populations for first $10^{4}$ years after emplacement. This is approximately the time required for the first of the most mobile nuclides to diffuse through the sediments after canister failure.

2. Nuclide release from the sediments continues at a very slow rate for $10^{5}$ to $>10^{7}$ years depending on the sorptive properties of the nuclides in the sediments. The sediment acts as a passive, slow release valve. Most of the nuclides decay in the $10^{4}$ to $>10^{7}$ years it takes them to reach the ocean.

3. Aquatic food is the dominant pathway to humans so MID is controlled by maximum aquatic food consumption rate while CPD and peak single-generation dose (SGD) are controlled by maximum allowable harvest rates from the oceans.

4. Most food consumption comes from surface layers of the oceans.

5. Aquatic food is contaminated primarily by external exposure. Therefore, it is proportional to the nuclide concentration in the oceans.

6. Mixing times in the oceans are very short compared to the release time from the sediments so concentrations in the oceans are fairly uniform at any given time.

7. Peak doses for MID and SGD occur at approximately the same time.

8. The maximum dose to individuals comes primarily from Tc-99 (71\%) and Se-79 (29\%). Pathways are the consumption of mollusks, crustaceans, seaweed, and fish in nearly equal percentages.

9. The principal nuclides and pathways for collective population doses vary with the integration interval. Principal nuclides for integration times from $10^{4}$ to $10^{7}$ years include Tc-99, C-14, Se-79, 
and Cs-135. Fish consumption is the dominant pathway ( $48 \%$ to $84 \%$ ) followed by crustacean and mollusk consumption.

10. Peak dose rates are very low, but nearly the entire world population could be affected, some at extremely low dose rates.

11. The attenuation by the canister and waste form are approximately the same for MID and CPD because the primary function of these components is retardation. The retardation function of the sediments has approximately the same effect on both types of doses, but the temporal dispersion is much more effective in reducing peak dose rates. Dilution throughout the oceans reduces the concentration in the surface regions inhabited by most food sources, resulting in attenuation of all types of doses. Dilution and spatial dispersion also greatly reduce the availability to individuals but have little effect on time-integrated doses to the world population. Although subseabed disposal would reduce the collective world population dose potential by a factor of $4 \times 10^{9}$, it would be much more effective for reducing doses to maximally exposed individuals (factor of $2 \times 10^{20}$ ).

All the above characteristics are significant inputs for developing standards for SD. Of particular interest are items 1 and 2 that suggest time intervals for regulation; 3, 8, and 9 that show knowledge of world populations and population distributions are not necessary to compute CPD or MID and that there is a single dominant pathway to humans; 5 and 6 that show derived standards should be based on nuclide concentration in the oceans rather fluxes across a specified boundary; and 11 that defines the dose attenuations that can be expected from a subseabed disposal system.

\subsubsection{Pre-emplacement Accidents}

All land transportation and assembly activity would be similar to those activities for terrestrial disposal and are covered by existing criteria. Only sea transportation and emplacement will be covered in this report. Predicted accidents, probabilities, and consequences are based on the conceptual design of the US disposal ship $[2,13,14]$. This ship would have extensive collision and fire protection, positive buoyancy with all compartments flooded, and have a capacity of 450 penetrators (1693 MTHM). Sea transportation accident analyses treat shallow water (ports and continental shelf) and deep ocean accidents separately because of different accident and recovery probabilities, oceanographic dilution and dispersion, and pathways to humans. Deep ocean accident analyses used the model shown in Figures 3 and 4, while coastal accident analyses used the model shown in Figure 7. Doses from pathways within the coastal model are much higher than those from the rest of the world oceans.

Although the dose consequences of waste lost in an accident are higher than those from properly emplaced waste, the probability of the loss with no recovery is extremely low; consequently, preemplacement risks are much lower than for the emplaced waste. Risk is defined as the probability that an event will happen times the consequences if the event does happen.

Figures 8 and 9 show the dose consequences if waste is lost and not recovered in deep ocean waters. Doses would occur from the North American basin approximately 200 years after the waste enters the ocean. The peak dose rates are higher than for emplaced waste, but they drop off more rapidly 


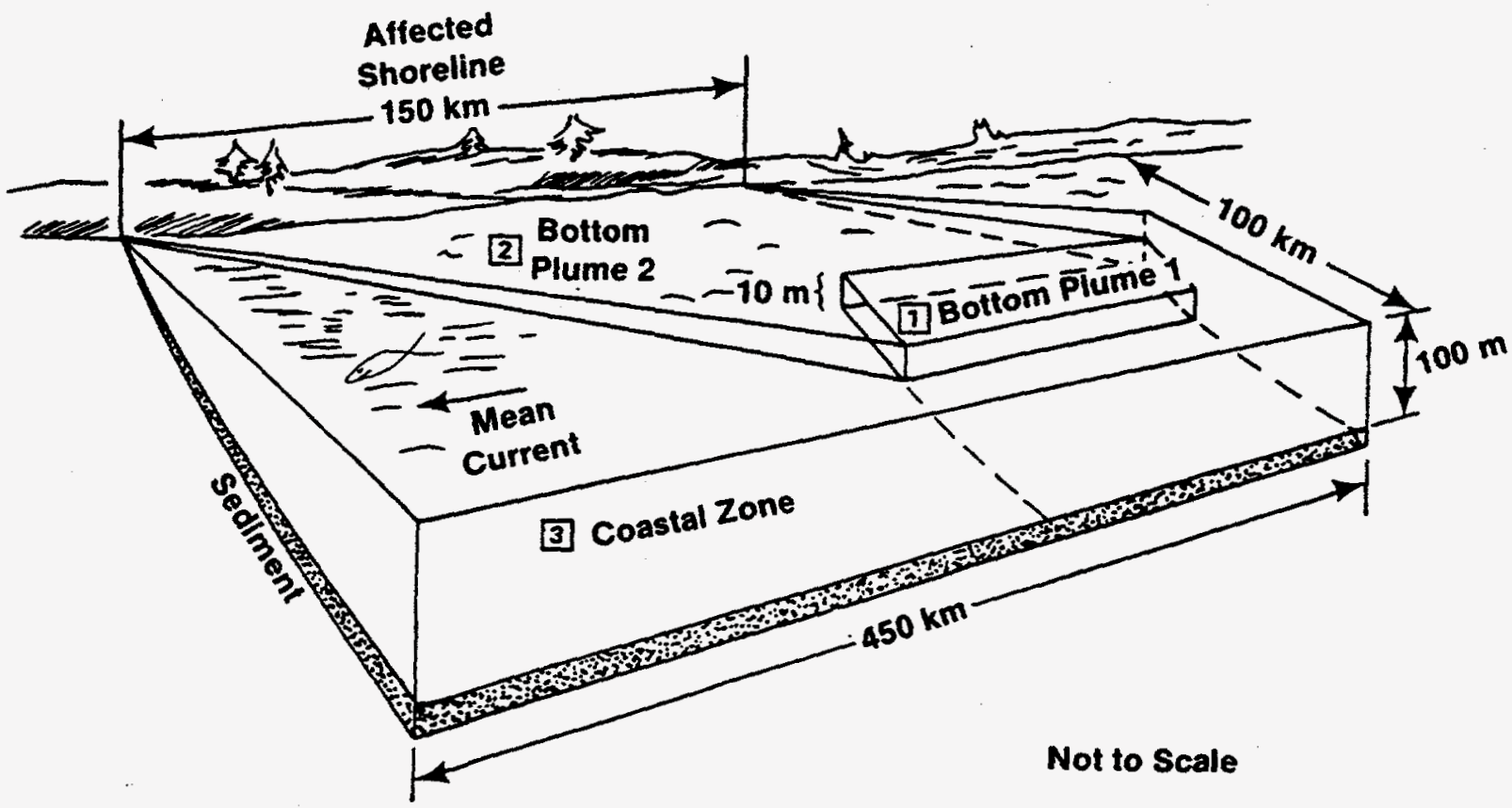

TR1-6334-139-0

Figure 7. Coastal-waters compartment model (Middle Atlantic Bight). 


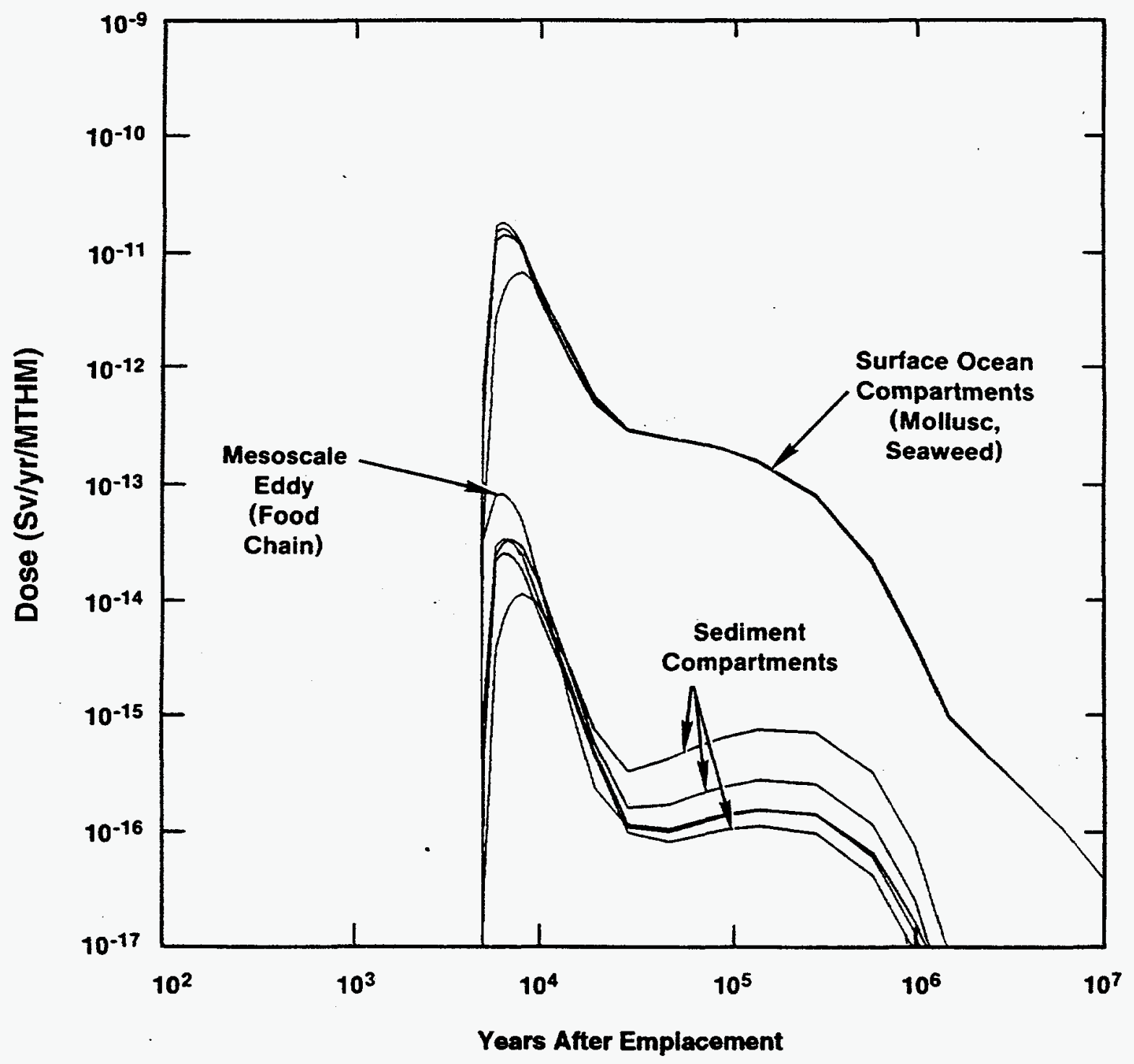

TRI-6334-140-1

Figure 8. Deep-ocean accident individual dose vs. time, by compartment-mean-risk parameter values. 


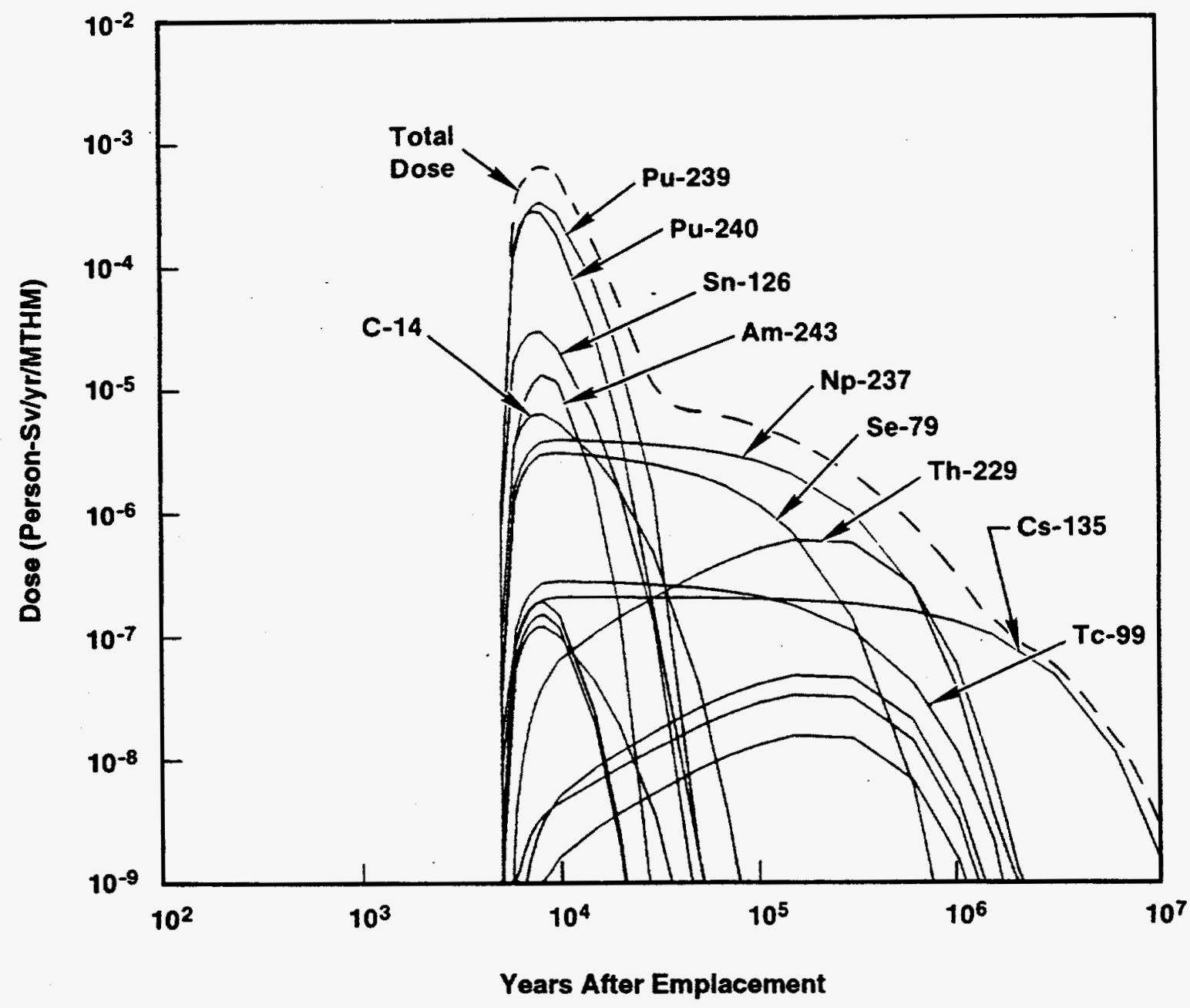

TRI-6334-141-0

Figure 9. Deep-ocean accident population dose vs. time from the world ocean compartment, by nuclide-mean-risk parameter values. 
following the decay rates of the short-lived nuclides. The MID would occur at $6.5 \times 10^{3}$ years and would be $1.8 \times 10^{-11} \mathrm{~Sv} / \mathrm{yr}$ for each MTHM that is lost. The dominant nuclides in order of importance for MIDwould be Pu-240, Pu-239, and Am-243. These shorter-lived nuclides would decay in the sediments if the waste is emplaced. Principal pathways to humans would be mollusk, seaweed, and crustacean consumption. The world-population dose-rate curve in Figure 9 is similar to the individual dose-rate curve. However, if the population dose-rate curve is integrated $10^{5}$ years, some additional nuclides and pathways become significant. The CPD would be 5.4 person-Sv/MTHM, principal nuclides would be $\mathrm{Pu}-240, \mathrm{Am}-241, \mathrm{Cs}-137$, and Pu-239, and principal pathways would be plankton, fish, and mollusks. Nearly all the doses come from the surface layers of the oceans. Peak biota doses would be $2 \times 10^{-4}$ Gy/yr-MTHM for fish and crustaceans and $9 \times 10^{-4}$ for mollusks in the benthic mixed layer. Table 6 shows the attenuation of the major components when the canisters are lying on the sediment surface in the deep oceans. The attenuation by the canister and waste form is the same as for emplaced waste, but the attenuation of the oceans is slightly higher when the sediments are not in the system, because the oceans then accomplish some of the attenuation that would have taken place in the sediments. Total MID attenuation is a factor of $3.7 \times 10^{3}$ lower than for emplaced waste and CPD attenuation is $2.6 \times 10^{2}$ lower.

Figures 10 and 11 show dose consequence of HLW lost and not recovered from the continental shelf. Peak doses occur shortly after the waste form leaches; and the dose level decays rapidly as the nuclides are transported off the shelf and dispersed and diluted in ocean waters of lower productivity. The MID of $9.0 \times 10^{-7} \mathrm{~Sv} / \mathrm{yr} \cdot \mathrm{MTHM}$ occurs $5.25 \times 10^{3}$ years after emplacement from bottom plume 1 . Am-243, Pu-240, and Pu-239 are the principal nuclides, and mollusks are the principal pathway to humans followed by seaweed. The CPD would be 27 Person-Sv/MTHM with principal nuclides the same as for MID. Most of the CPD would come from the continental shelf before the nuclides are transported to the deep oceans. Collective population doses following an unrecovered coastal accident is the only scenario where aquatic food ingestion is not the only significant pathway to humans. In this case, shore exposure (46\%), mollusks (29\%), and inhalation of sediment and salt spray (17\%) are the principal pathways. Peak doses to biota would be $3.7 \times 10^{-7} \mathrm{~Gy} / \mathrm{yr} \cdot \mathrm{MTHM}$ for fish and crustaceans and $1.0 \times 10^{-6}$ for mollusks. Table 7 shows the attenuation of the major components if canisters are lying on the continental shelf. The attenuation by the canister and waste form is the same as for emplaced waste and deep ocean accidents. However, the MID attenuation of the ocean is a factor of $5.0 \times 10^{4}$ less than for deep ocean accidents because the waste is released in a high productivity area and it contaminates a food supply before it is diluted by the world oceans. The CPD attenuation is only a factor of 5 less than for deep ocean accidents because only a relatively small number of people are exposed to the higher dose rates, and the higher dose rate levels last a relatively short period of time.

Table 6: Dose Attenuation Factors with Waste Canister Lying on Deep Ocean Sediments (Deep Sea Accident)

\begin{tabular}{|c|c|c|}
\hline Component & $\begin{array}{c}\text { Maximum Individual } \\
\text { Dose Rate } \\
\end{array}$ & $\begin{array}{l}\text { Collective World } \\
\text { Population Dose }\end{array}$ \\
\hline Canister & $2.9 \times 10^{2}$ & $1.3 \times 10^{3}$ \\
\hline Waste Form & $2.6 \times 10^{1}$ & 1.2 \\
\hline Oceans & $5.5 \times 10^{12}$ & $9.5 \times 10^{3}$ \\
\hline Total System & $4.3 \times 10^{16}$ & $1.5 \times 10^{7}$ \\
\hline
\end{tabular}




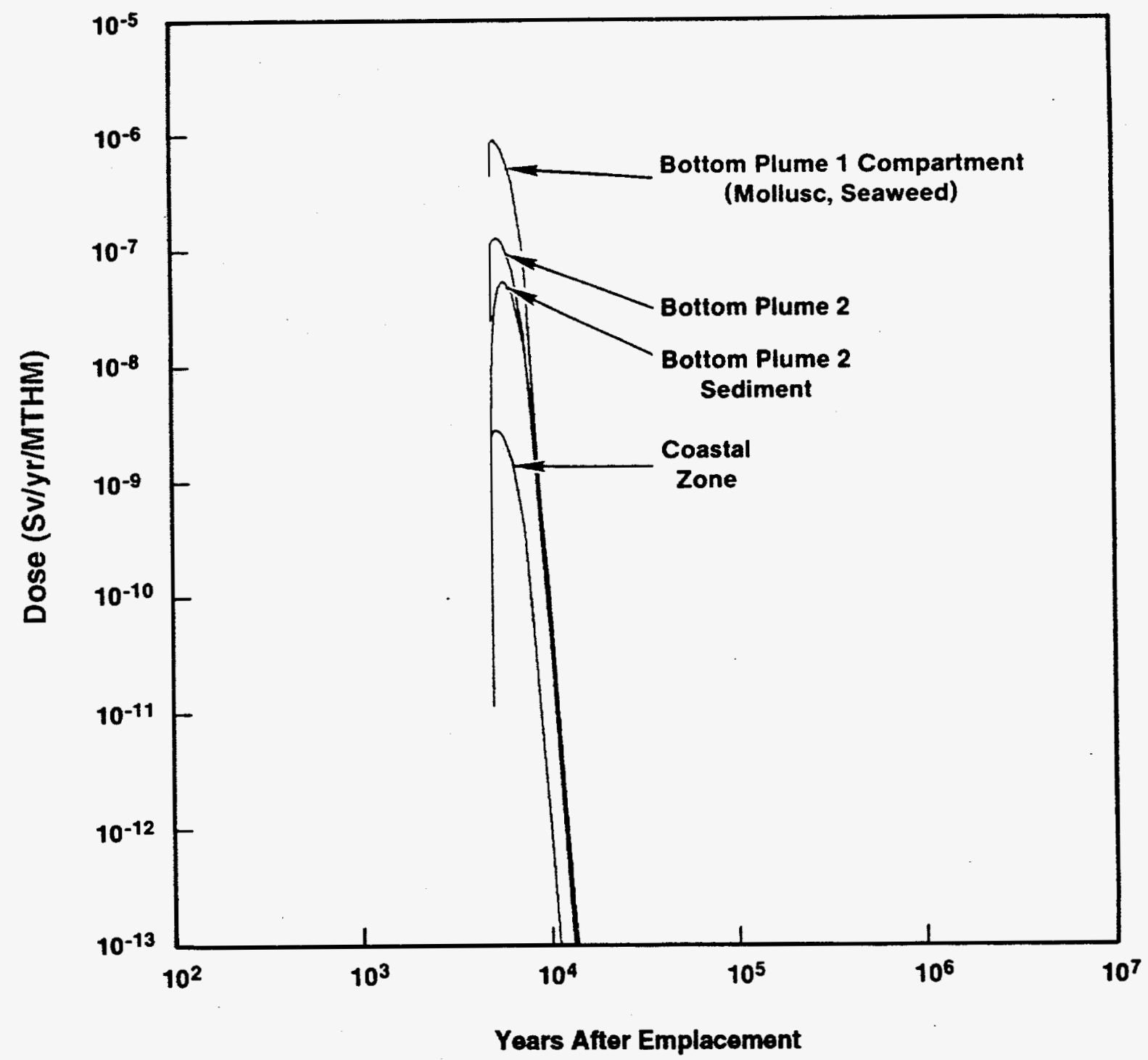

TRI-6334-142-1

Figure 10. Coastal-waters accident individual dose vs. time, by compartment-mean-risk parameter values. 


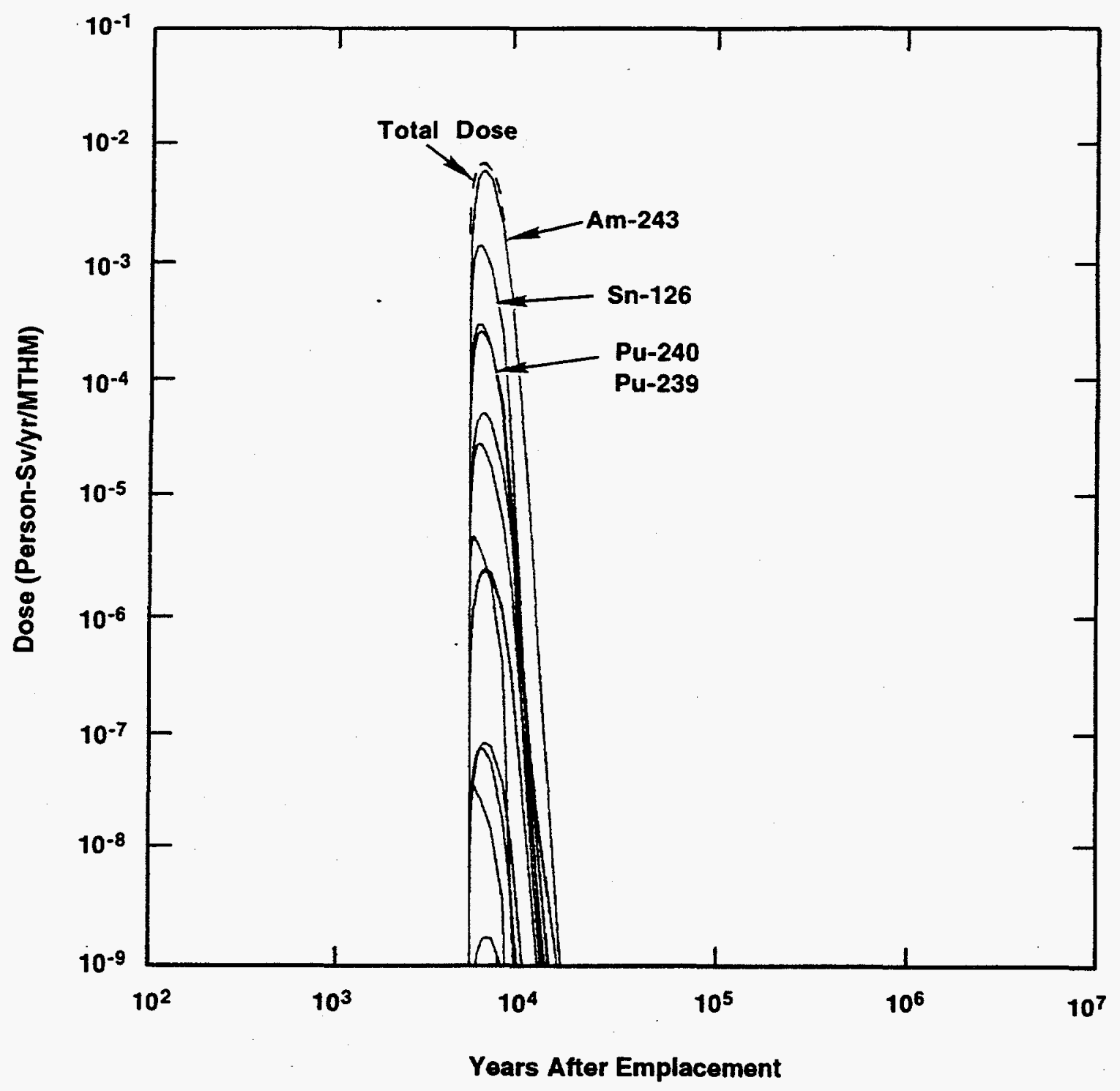

TRI-6334-143-0

Figure 11. Coastal-waters accident population dose vs. time in the bottom plume 2 sediment compartment, by nuclide-mean-risk parameter values. 
Table 7. Dose Attenuation Factors with Waste Canisters Lying on the Continental Shelf (Near Shore Accident)

\begin{tabular}{lccc}
\hline \multicolumn{1}{c}{ Component } & $\begin{array}{c}\text { Maximum Individual } \\
\text { Dose Rate }\end{array}$ & $\begin{array}{c}\text { Collective World } \\
\text { Population Dose }\end{array}$ \\
\cline { 1 - 1 } Canister & & $2.9 \times 10^{2}$ & \\
Waste Form & & & $1.3 \times 10^{1}$ \\
Oceans & $1.1 \times 10^{8}$ & & 1.2 \\
Total System & $8.6 \times 10^{11}$ & & $1.9 \times 10^{3}$ \\
\hline
\end{tabular}

Table 8 summarizes the probabilistic doses per MTHM (dose X probability) for the summation of all sea transportation accidents and for emplaced waste. Risks to humans and biota range from $4 \times 10^{2}$ to $5 \times 10^{9}$ greater for emplaced waste than for sea transportation.

The following conclusions apply to doses and risks from pre-emplacement sea transportation accidents:

1. Doses begin earlier, are higher, and drop off more rapidly than for emplaced waste, particularly for near-shore accidents.

2. Doses from deep-ocean accidents come from ingestion of aquatic food from the surface compartments of the oceans. Dose rates are approximately proportional to the radionuclide concentration in the ocean at any given time.

3. Doses from near-shore accidents come from aquatic food, external exposures, and inhalation. Highest doses come from the shelf area near the accident. Doses are approximately proportional to nuclide concentration, and also to the release rates, because of the short residence time in this region.

4. Aquatic food is contaminated primarily by external exposure.

5. The dominant nuclides are shorter-lived, and some have higher sorption potentials than the dominant nuclides for emplaced waste.

6. Total risk from sea transportation accidents is much less than from emplaced waste.

\subsubsection{Abnormal Events}

Under normal conditions, some release to the oceans is expected as canisters degrade, the waste form leaches, and waste materials diffuse through the overlying sediments. There are some abnormal, low-probability events that could increase this release. As part of the 1987 risk assessment, the Radiological Assessment Task Group (RATG) of the SWG investigated a series of abnormal scenarios that could possibly affect the efficiency of a subseabed repository [2]. These were as follows: 
Table 8. Probabilistic Doses for Sea Transportation and Emplaced Waste per MTHM

\begin{tabular}{|c|c|c|c|c|c|}
\hline Scenario & $\begin{array}{c}\text { Peak } \\
\text { Individual } \\
\text { Dose Rate } \\
\text { (Sv/yr) } \\
\end{array}$ & $\begin{array}{c}10^{5}-\mathrm{Yr} \\
\text { Collective World } \\
\begin{array}{c}\text { Population Dose } \\
\text { (person-Sv) }\end{array} \\
\end{array}$ & $\begin{array}{l}\text { Fish } \\
(\mathrm{Gy} / \mathrm{yr})\end{array}$ & $\begin{array}{c}\text { Crustaceans } \\
\text { (Gy/yr) }\end{array}$ & $\begin{array}{l}\text { Molluscs } \\
\text { (Gy/yr) }\end{array}$ \\
\hline $\begin{array}{l}\text { Total Sea } \\
\text { Transportation }\end{array}$ & $4.4 \times 10^{-20}$ & $4.4 \times 10^{-12}$ & $1.2 \times 10^{-16}$ & $1.3 \times 10^{-16}$ & $5.0 \times 10^{-16}$ \\
\hline Emplaced & $5.2 \times 10^{-15}$ & $2.2 \times 10^{-2}$ & $5.2 \times 10^{-14}$ & $6.3 \times 10^{-13}$ & $6.3 \times 10^{-13}$ \\
\hline
\end{tabular}

1. Shallow emplacement of penetrators.

2. Damaged canister.

3. Incomplete hole closure behind the penetrator.

4. Degraded canister or glass waste matrix or both.

5. Removal of top layers of sediment by climatic effects or manganese nodule mining.

6. Vertical pore-water velocity in the sediments after emplacement caused by compaction due to sedimentation and settling, natural convection cells caused by an increased thermal gradient, or other unidentified causes.

7. Changes in sediment properties and sorption.

8. Dislocations in the sediment caused by tectonics or differential compaction.

9. Changes in ocean currents and biological pathways to humans.

For all scenarios except high vertical pore-water velocities, the MID and CPD were acceptable even if every canister was damaged. If vertical-pore water velocities exceed $0.1 \mathrm{~m} / \mathrm{yr}$, only half the canisters in the repository could be damaged without exceeding $10^{-3} \mathrm{~Sv} / \mathrm{yr} \mathrm{MID}$. If vertical pore velocities exceed $10 \mathrm{~m} / \mathrm{yr}$, doses would be almost as high as they would be for unburied canisters. The results of the abnormal event analyses should not alter dose standards for seabed disposal, but suggest a prescriptive standard limiting vertical pore water movement in the repository area. There are some events such as disruptive human activities, the presence of undetected geologic features, tectonic activity, and construction-induced alterations that are of great concern for terrestrial repositories, but are far less significant for seabed disposal [10].

\subsubsection{Robustness, Reliability, and Confidence Potentials of Subseabed Disposal}

In addition to having acceptable risks, repositories should be robust and reliable, and there should be high confidence in risk predictions. Many characteristics of a repository that make it reliable also enhance confidence in risk predictions. Resilience and stability quantify reliability and confidence 
by evaluating how well a disposal system will function if there are component failures, changes in the environment, or hypothetical deviations in system performance. Resilience of the disposal system, stability of important pathway parameters, and large margins of safety all contribute to the robustness of a disposal process.

Resilience is a characteristic of the disposal system for a given set of components with a given source location and given risk recipients. It is the ability of the system to function satisfactorily when one or more of the components fail or operate at less than full efficiency. Resilience can be obtained by using redundant engineered barriers, multiple barriers, or by a site selection and system design that transfers the function of a failed component to the following components in the system. System effectiveness is not a linear function of component effectiveness, and may be nearly independent of single components or subsystems. Reference 9 shows that complete canister failure and instantaneous leaching of waste in a SD repository would cause almost no reduction in risk attenuation. Since the SD system utilizes all four risk attenuating processes, and the design includes multiple barriers and function transfer capabilities, the resilience is high for all scenarios.

Another multi-purpose characteristic is the stability of system components. This is the ability of components to function satisfactorily over a wide range of expected environments or with an environmental change. Stability is also a measure of how predicted risks are affected by imprecision in all parameters used in performance assessments. This is a component characteristic for a given environmental variation and a given function in the system. A conceptual disposal system design may be insensitive to variations of some parameters, and can usually be modified to reduce the sensitivity to others. The sensitivity studies in References 2,15 , and 16 show that the safety of the proposed SD repository has low sensitivity to changes in almost all parameter values over reasonable ranges. The exception is reduced sediment retardation efficiency by vertical pore water flow. The potential vertical pore water flow problem can be eliminated by proper site selection.

Confidence in risk prediction is enhanced by a stable environment in and around the repository; that is, one with relatively small changes or fluctuations in important parameters during the time of interest. Other advantageous site characteristics are a simple uniform geologic structure, seismic stability, and a lack of abundant mineral resources or other characteristics that invite human intrusion. The site should be relatively easy to characterize without jeopardizing its integrity. High resilience and stability make the system less sensitive to changes, and performance assessments less sensitive to the quality of input data. Since subseabed sediments are self-healing, sufficient core samples can be taken to thoroughly characterize the repository without changing its integrity. Therefore, there would be little chance of undetected geologic features that could increase nuclide transport in the sediments. The selected sites would be tectonically stable, and not subject to erosion. SD is not as dependent on predictions of future states as other disposal systems. Climatic changes and glaciation would have little or no effect on nuclide transport from a subseabed repository. Human intrusion is extremely unlikely because of the remoteness and lack of resources. Predictions of total populations and population distributions are not needed because SD population risks are based on maximum harvest rates. The dominant pathway for MID is aquatic food ingestion, so only maximum consumption rates are requires. All of these features enhance confidence in SD risk predictions. 
Using the dose predictions given earlier in this chapter and the interim standards in Chapter 4 for the protection of individuals and collective populations, the margins of safety for SD of HLW range from 500 to 200,000 . These margins of safety added to the high resilience and stability of the disposal system and the stability of important environmental parameters make SD a very robust system.

\subsection{Characteristics of Subseabed Disposal as They Apply to Radiological Standards}

This section summarizes the characteristics of SD that could affect the selection of dose, derived, and prescriptive radiological standards, the time periods to regulate, and how standards are implemented.

Individual dose rates from emplaced waste would be very low (peak doses from a $10^{5}$ MTHM repository would be approximately a factor of $2 \times 10^{6}$ below average background levels) but they would continue for a very long time, and could potentially affect a large part of the world population. Because of the dispersion in and mixing by the oceans, all added radioactivity is eventually mixed, so subseabed repositories can not be regulated independently of each other. Regulations must account for the attenuation of each site and the total amount of present and future radioactive waste from all sources. Subseabed disposal takes place in international waters, and people outside the country of origin that do not benefit from the nuclear power generation could incur radiological risks from the waste. This is similar to atmospheric pollution that crosses national borders or the dumping or leakage of wastes into the oceans. These characteristics indicate a need for both national and international regulation.

The characteristics of SD that could influence dose, derived, and prescriptive standards fall into three categories: emplaced waste, coastal accidents, and deep ocean accidents. Table 9 summarizes the most significant parameters for each category. Risks can be found by multiplying the probabilistic doses in Table 9 by $5 \times 10^{-2}$ Health Effects per Sievert [5].

The information in Table 9 and previous sections leads to several conclusions about SD characteristics which should be considered in the development of radiological standards.

1. All probabilistic doses from emplaced waste would be higher than from sea transportation. Assuming an accident occurs and canisters are lost and not recovered, the doses from those canisters would be much higher than if they were emplaced, but the combined probabilities of loss are so low for each canister that sea transportation risks are very low. Pre- and post-emplacement risks could be combined using stochastic methods and regulated with a single set of standards, or separate standards could be used for transportation and emplaced waste.

2. The only abnormal event found that would significantly increase the risk of SD was vertical porewater advection in the repository sediments. Areas with measured pore-water velocity or the potential for future pore-water movement should be avoided. 
Table 9. Dose Parameters for Emplaced Waste and Sea Transportation Accidents

\begin{tabular}{|c|c|c|c|}
\hline Parameter & Emplaced & $\begin{array}{l}\text { Deep Ocean } \\
\text { Accident }\end{array}$ & Coastal Accident \\
\hline Beginning of risk, $10^{-6}$ peak value (yr) & $1 \times 10^{4}$ & $5 \times 10^{3}$ & $5 \times 10^{3}$ \\
\hline Time of peak risk rate (yr) & $1.5 \times 10^{5}$ & $6.5 \times 10^{3}$ & $5.3 \times 10^{3}$ \\
\hline End of risk, $10^{-6}$ peak value (yr) & $>10^{7}$ & $1 \times 10^{7}$ & $1.3 \times 10^{4}$ \\
\hline Dose duration $>0.5$ peak rate $(\mathrm{yr})$ & $3.2 \times 10^{5}$ & $2.7 \times 10^{3}$ & $1.3 \times 10^{3}$ \\
\hline Dose duration $>0.1$ peak rate $(y r)$ & $9.8 \times 10^{5}$ & $9.5 \times 10^{3}$ & $2.7 \times 10^{3}$ \\
\hline $\begin{array}{l}\text { System peak individual dose rate } \\
\text { attenuation }(-)\end{array}$ & $1.6 \times 10^{20}$ & $4.3 \times 10^{16}$ & $8.6 \times 10^{11}$ \\
\hline $\begin{array}{l}\text { System collective population dose } \\
\text { attenuation }(-)\end{array}$ & $3.9 \times 10^{9}$ & $1.5 \times 10^{7}$ & $3.0 \times 10^{6}$ \\
\hline Peak individual dose rate (Sv/yr-MTHM) & $5.2 \times 10^{-15}$ & $1.8 \times 10^{-11}$ & $9.0 \times 10^{-7}$ \\
\hline $\begin{array}{l}\text { Peak population dose rate (Person-Sv/yr- } \\
\text { MTHM) }\end{array}$ & $3.6 \times 10^{-7}$ & $6.2 \times 10^{-4}$ & $7.8 \times 10^{-3}$ \\
\hline $\begin{array}{l}10^{5} \text { yr collective population dose (Person- } \\
\text { Sv/MTHM) }\end{array}$ & $2.2 \times 10^{-2}$ & $5.4 \times 10^{0}$ & $2.7 \times 10^{1}$ \\
\hline $\begin{array}{l}\text { Probability of loss without recovery per } \\
\text { MTHM (-) }\end{array}$ & NA & $5.8 \times 10^{-13}$ & $4.9 \times 10^{-14}$ \\
\hline Probabilistic MID (Sv/yr-MTHM) & $5.2 \times 10^{-15}$ & $1.0 \times 10^{-23}$ & $4.4 \times 10^{-20}$ \\
\hline Probabilistic SGD (Person-Sv/yr-MTHM) & $3.6 \times 10^{-7}$ & $3.6 \times 10^{-16}$ & $3.8 \times 10^{-16}$ \\
\hline Probabilistic CPD (Person-Sv/MTHM) & $2.2 \times 10^{-2}$ & $3.1 \times 10^{-12}$ & $1.3 \times 10^{-12}$ \\
\hline Principal nuclides & Tc-99, Se-79 & $\begin{array}{l}\mathrm{Pu}-239, \mathrm{Pu}-240 \\
\mathrm{Am}-243, \mathrm{~Np}-237\end{array}$ & $\begin{array}{l}\text { Am-243, Pu-240, } \\
\text { Pu-239 }\end{array}$ \\
\hline Principal pathways & Aquatic Food & Aquatic Food & $\begin{array}{l}\text { Aquatic Food, } \\
\text { External Exposure, } \\
\text { Inhalation }\end{array}$ \\
\hline Principal ocean regions & $\begin{array}{l}\text { World Ocean } \\
\text { Near Surface }\end{array}$ & $\begin{array}{l}\text { World Ocean } \\
\text { Near Surface }\end{array}$ & $\begin{array}{l}\text { Bottom Plume } \\
\text { Near Accident }\end{array}$ \\
\hline
\end{tabular}

3. For emplaced waste, there is almost no risk the first $10^{4}$ years. Individual and world population dose rates peak at about $1.5 \times 10^{5}$ years, and the dose rates remain greater than $10 \%$ of peak values for almost one million years. These time frames indicate a long period of regulation would be appropriate. The high stability of subseabed repositories and the high confidence in risk predictions make a long regulation time feasible.

4. Since ingestion of aquatic food is the dominant pathway to humans, maximum individual dose rates are proportional to the individual's aquatic food consumption, and the maximum world population dose rates are proportional to the maximum rates food can be harvested from the oceans.

5. Over $99 \%$ of the doses come from only three to five nuclides for all scenarios. For emplaced wastes these nuclides have long half lives, and are not sorbed by the sediments.

6. Release rates from the sediments are very slow compared to the mixing times in the ocean for the non-sorbed nuclides. Therefore, these nuclides are fairly well mixed in the ocean during the times of highest dose rates. The aquatic foods are contaminated primarily by external exposure, which is proportional to the concentration of radionuclides in the water. These relationships make dose rates 
proportional to the quantity of waste in the oceans at any given time (ocean burden), and not to the release rate from the sediments. This information is important if derived standards are developed.

7. The high resilience of SD reduces the need for derived and prescriptive standards to enhance reliability. Derived standards could be used to facilitate regulation [12].

8. All four attenuating processes: retardation, temporal dispersion, dilution, and spatial dispersion contribute significantly to the large system attenuation factors of SD. Dilution and temporal dispersion make the attenuation factor largest for MID. Dilution results in more of the world population receiving the low dose rates, which makes attenuation slightly lower for SGD. The combination of dilution and temporal dispersion (longer dose duration) make CPD attenuation the lowest of the three. This would tend to give SD the highest margin of safety using MID standards and the lowest using CPD standards.

Presently there are about $1.9 \times 10^{22} \mathrm{~Bq}$ of radiation diluted in the oceans. With the attenuation of the canister, waste form, and sediments, a $10^{5}$ MTHM subseabed repository would add about $7.6 \times 10^{14}$ $\mathrm{Bq}$ of radiation to the oceans in $10^{5}$ years. This is a fractional increase of only $4 \times 10^{-8}$. If risks are found to be nonlinear with activity for any ocean pathway, this low fractional increase could impact the kinds of standards that would be appropriate for SD.

\subsection{Similarities and Differences in Terrestrial and Subseabed Disposal Characteristics}

This section compares characteristics of terrestrial and subseabed disposal processes, siting, pathways to humans, types of doses, and recipients of the doses.

Land transportation would be approximately the same for both options. Sea transportation would be a necessary part of SD but would only be a part of a terrestrial system if overseas transportation to a reprocessing plant or repository site or if coastal or river barge shipment were used. Assembly plants, port facilities, and aboveground terrestrial facilities would also be similar. A terrestrial repository would have separate excavation, emplacement, open, and closure phases lasting up to 100 years. With the penetrator option of SD individual canisters enter the sediment and the sediment closes all in one operation. There is no period when a SD repository is "open." A single ship could emplace $10^{5} \mathrm{MTHM}$ of waste in about 20 years.

Because of the dispersive nature of mixing in the ocean waters, risks from SD depend on the total amount of waste from all sites. This is in contrast to terrestrial repositories where risks are more localized. Risks from both SD and terrestrial repositories would continue affecting future generations for millions of years.

Subseabed repositories would be located outside the country of origin, and all nations could incur the risks, making it appropriate to regulate SD nationally and internationally. Because not all nations produce nuclear waste, special efforts should be taken to ensure that the risks would be acceptable to all nations. Under normal conditions, only the very long lived nuclides from a terrestrial 
repository could eventually reach the oceans. However, as observed by G. de Marsily [17], any geologic nuclear waste disposal is an international problem, not just a national one. Nuclear waste standards for any repository concern the future of mankind, not just the welfare of the present inhabitants of a given region. There are at least two reasons for this.

1. The period of time during which the consequences of the disposal will be felt make the present borders of each nation meaningless (it would take approximately 150,000 years before peak risks occur). During that time, national borders could change, new nations could be formed, and others cease to exist. The extensive mixing of populations implies that each of us will have descendants living in other parts of the world.

2. Disposal may not be possible in some small countries, or consequences may be felt in another territory when disposal is near a border.

Under normal conditions, risks from both SD and terrestrial-emplaced waste would be negligible for about the first 10,000 years, would continue for about the same length of time, and would come mostly from the same nuclides. The differences are in the release modes, pathways, dose levels, and the populations incurring the risk. Individual doses from SD are determined primarily by diet, so doses to the maximally exposed individual would not be much higher than to the average individual who consumes aquatic food. This is in contrast to terrestrial disposal, where water usage from a contaminated aquifer near a repository, or human intrusion, could lead to maximum individual doses that would be orders of magnitude higher than those received by the average members of the world population. The relatively uniform concentration of radionuclides in the world oceans would result in exposure of a larger number of individuals by SD than by terrestrial disposal. The tendency is for SD to have a larger margin of safety for MID than for CPD. The converse is true for terrestrial disposal.

The major differences between terrestrial and subseabed disposal are related to abnormal natural events, human intervention, and pre-emplacement accidents. Detrimental low-probability events for a terrestrial repository would be: human intrusion (potentially the dominant cause of release), tectonic disturbances, undetected geologic features that would increase nuclide transport, changing hydrology, changing climatic conditions, glacial erosion, and repository-induced changes in the formation. None of the above apply to subseabed disposal. The low probability abnormal natural event that could reduce the effectiveness of a subseabed repository would be vertical pore water velocity through the disposal site caused by compaction, or natural convection cells set up by an increased thermal gradient. Although risks from the sea transportation segment of SD are predicted to be low, this segment does not even exist for terrestrial disposal.

The confidence in risk predictions could be higher for SD than for terrestrial disposal. SD repositories would have higher resilience and stability, the pathways would be in more stable environments, and fewer predictions of future states would be required to do performance assessments.

Some features of existing standards for terrestrial disposal could be adapted to SD. However, there are enough differences in the two types of disposal that some new methods of regulation would be needed. 


\section{GENERAL RADIOLOGICAL PROTECTION STANDARDS FOR HIGH-LEVEL WASTE}

There is some risk associated with all activities in life. These risks cannot be eliminated, but most are minimal, can be modified, or the activities are regulated to acceptable levels of risk. With a process such as the nuclear fuel cycle that could potentially create serious hazards for a large part of the world population and last for millions of years, control must be particularly thorough and reliable with the highest degree of confidence possible. Although the entire nuclear fuel cycle requires controls and radiological protection standards, only the disposal of spent fuel and HLW are discussed in this report. The contents of this chapter include a qualitative discussion on health effects versus dose, categories of standards, the use of multiple standards, related existing standards, one form of a combined standard, duration of regulation, assurance measures, regulation of low-probability events, and uncertainties in predictions. Methods of regulation are covered but quantitative levels are not suggested.

\subsection{Relationships Between Doses and Biological Response}

Everyone is continuously receiving radiation doses from natural and anthropogenic sources. Natural background exposure from cosmic, terrestrial, and internal radiation varies from $7 \times 10^{-4}$ to $2 \times 10^{-3} \mathrm{~Sv} / \mathrm{yr}$ with the average being about $1 \times 10^{-3} \mathrm{~Sv} / \mathrm{yr}$. Time-averaged cosmic radiation varies from $3 \times 10^{-4} \mathrm{~Sv} / \mathrm{yr}$ at sea level to $6 \times 10^{-4}$ at one mile above sea level. Terrestrial radiation comes from radioactivity in soils and rock and varies from $2 \times 10^{-4} \mathrm{~Sv} / \mathrm{yr}$ along the Atlantic coast to $9 \times 10^{-4} \mathrm{~Sv} / \mathrm{yr}$ in the Colorado Plateau. The remainder of natural radiation comes from radioactive material in our bodies, principally from C-14 and $\mathrm{K}-40$. Internal radiation from food and water averages $1.2 \times 10^{-3} \mathrm{~Sv} / \mathrm{yr}$ with doses several times higher in regions with more radioactive water supplies. Inhalation doses average $2 \times 10^{-3} \mathrm{~Sv} / \mathrm{yr}$. In addition, the average US citizen receives about $1 \times 10^{-3} \mathrm{~Sv} / \mathrm{yr}$ from medical diagnosis and treatment. The general public is currently receiving an average of $5.2 \times 10^{-3} \mathrm{~Sv} / \mathrm{yr}$. About $1 \times 10^{-4}$ $\mathrm{Sv} / \mathrm{yr}$ of the above-mentioned doses result from industry, mining, and global fallout.

Everyone is already receiving variable radiation doses significantly larger than the predicted doses from any proposed HLW repository. Doses from HLW repositories must then be treated as small incremental additions to background radiation, rather than be treated separately. Because of the dilution by the oceans and the retardation and temporal dispersion by the sediments, most of the dose increments to individuals from a subseabed repository are extremely small. Under these conditions, the relationship between low-dose rates and health effects can be important.

In the mid-dose range the relationship between doses and health effects is nearly linear, but direct measurement of the effects in the low-dose range is very difficult, and extrapolating the higher dose rate linear relationship to low-dose rates is questionable. There are many examples where biological response is highly nonlinear with dosage. Using fertility, growth rate, longevity, and genetic effects as bases, the following types of nonlinear responses have been found [18].

1. Substances that are toxic at high doses but are nontoxic, beneficial, or even essential at very low doses. Some nutrients are in this category. 
2. Substances that have an optimum dose rate. Low doses of many vitamins result in depression of growth; at optimum levels, growth is stimulated and at higher doses toxic symptoms occur, and growth is again depressed.

3. Substances that exhibit a reversal in response with changing doses. Caffeine decreases the heart rate at low doses, but increases it at high doses.

In addition to nonlinearity of response at low doses, there are other response characteristics that would influence safety standards [19]. When some nontoxic or stimulating effects occur at low doses, this does not exclude the coexistence of other toxic effects at the same doses. In some cases it may not be possible to separate the beneficial from the harmful response, so the net response must be used. If the positive and negative responses are of different types, longevity and genetic effects for example, the evaluation of net benefit or detriment is more difficult. Examples of agents that simultaneously are hazardous and beneficial are $\mathrm{Ni}$ and $\mathrm{Cr}$. Both are necessary to nutrition, but both are known carcinogens. A second response characteristic that complicates the development of standards is that not all individuals respond similarly to a given dose. Some vary in the magnitude of the response and others in the type of response, or a reversal of the same response. This variation requires the use of an average response or statistical bracketing of the response. Finally, some responses depend on dose rates while others depend on the total dose received over a period of time. The above examples and our own experiences indicate that many things have both good and bad qualities. Since biota, including humans, have survived with background radiation, radiation exposure may not be an exception to this generalization.

In general, biological responses are too complex to be described by a single function. Often the optimum level for health and survival is at or near naturally occurring levels. Some preliminary studies $[19,20]$ suggest the mechanisms that account for the proportionally lower detriment at low doses are: (1) the organisms have time to recuperate so the doses are not additive, and (2) organisms can adapt to exposures that are only slightly higher than background levels. Some research has indicated that low levels of radiation can be beneficial under certain circumstances. Hormesis, a process whereby low doses of an otherwise harmful agent could result in stimulatory or beneficial effects, has been found in nature in biological response to harmful chemical and physical agents [21]. Hormesis could be the result of regulatory overcorrections by biosynthetic control mechanisms to small increases in radiation. Hormesis could also result when there are small increases in radiation in locations where background radiation is lower than optimum. The latter may be the explanation for the findings of $\mathrm{K}$. Nambi and S. Soman [22]. They found that in some parts of India where external background levels range from 0.3 to $0.8 \mathrm{mSv} / \mathrm{yr}$, the incidence of cancer decreased with increasing background radiation. In this range, a small increase in radiation dose might be beneficial. However, in industrialized countries when the combined natural and man-made background radiation can be over $1.5 \mathrm{mSv} / \mathrm{yr}$, a small increase is more likely to be detrimental. In summary, some research has indicated that the detrimental effects per unit dose may be less with low doses than with high doses. There may be a threshold radiation dose level for harmful effects, and some beneficial effects might result from very low dose exposures.

Figure 12 is a hypothetical biological response curve for radiation doses based on the above discussion for low doses and information from References 4 and 5 for the high-dose range. There is some experimental evidence for all the regimes shown, but the low-dose range is still poorly defined. Even this generalized response curve does not include synergistic or antagonistic effects between 
radiation and chemical doses. It also represents the net response, which in some cases requires subjective judgments. Although only a single line is shown representing the mean response, the response varies with individuals so there is actually a response band. Radiation standards could be based on the mean, or be statistical bound. There is a considerable amount of research that indicates response is nearly linear with dose in the mid-dose range. At the low end of the high-dose range, non-stochastic effects begin to occur, and there is a larger change in response with an incremental increase in dose. As the dose increases, the fatal level is reached where death is caused directly by the radiation rather than an increased incidence of cancer.

The value of the projected background dose $10^{4}$ years after disposal, when the incremental dose from the repository begins, is important for setting radiological standards for nuclear waste disposal. If the background dose is at " $\mathrm{A}$ " in Figure 12, the small incremental dose from the repository would be beneficial; if it is at " $\mathrm{B}$ " there would be small detrimental effects, and if it is at " $\mathrm{C}$ " there would be larger detrimental effects. Background doses have increased as nations become more industrialized. However, this trend could reverse with increased environmental restrictions, and if medical substitutes for radiation are found. Any reversal would be slow because of the time required for existing radionuclides to decay. Another variable that would be difficult to quantify is the possible adaptation of biota to increased background radiation.

Use of the radiation paradigm that all radiation is harmful at all dose levels, and all low-level effects can be predicted from high-dose level tests [19], could over-predict the detrimental biological effects of radiation exposure. This could be true when background doses are in the low-dose range, and when the incremental doses are low. The potential for error is greatest when computing the risk from CPD or for setting CPD standards because of the very small incremental doses received by most individuals. More research is needed to accurately predict low-level responses, at least down to the background dose level. Background is the base to which the incremental doses from waste repositories, and all other man-made radiation sources, must be added.

\subsection{Categories of Radiological Protection Standards}

There can be multiple levels of criteria that regulate the performance of waste repositories. Fundamental and dose criteria regulate the entire disposal system, whereas lower level criteria regulate components or groups of components. Lower levels of criteria cannot be computed or defined until all the levels above them are fixed. There is usually a branching of criteria at the lower levels with multiple sets of design criteria that are traceable to a single fundamental criterion [12].

The top level, which is the fundamental criterion, specifies the detriment or level of risk that is acceptable for a specific material or process. This is the only level that explicitly defines the safety requirements of the repository. To have any radiological risk significance, all other levels must be 


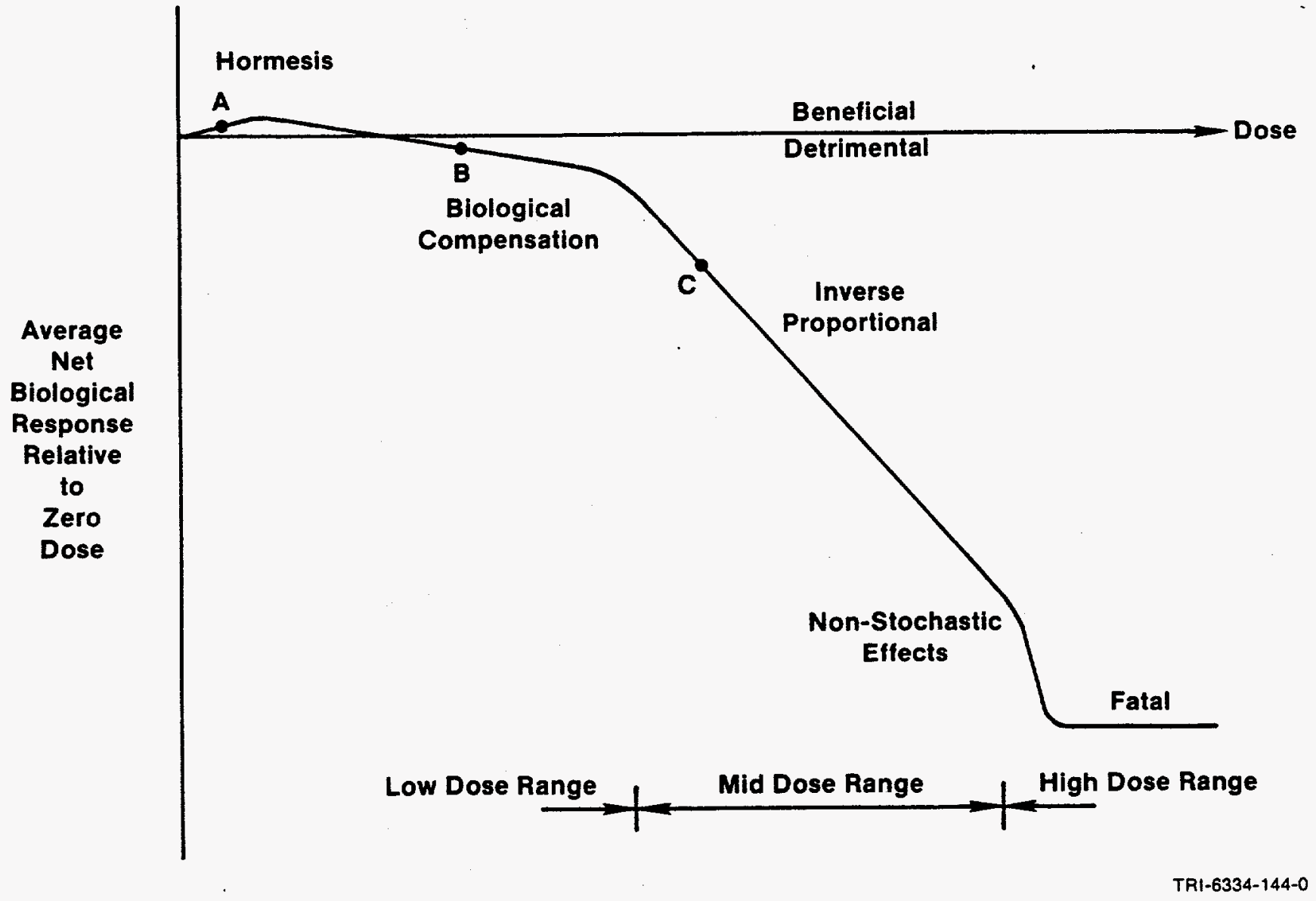

Figure 12. Generic biological response to radiation. 
traceable to level 1. Fundamental criteria can limit risk rates to maximally exposed individuals or single generations during a specified time interval or at the time of peak risks. They can also limit collective population risks over a specified time, or any combination of the above. One of the basic philosophies for the acceptable level of protection is that waste disposal should not impose any greater risk on future generations than is accepted today. On the other hand, the standards cannot be so stringent that repositories cannot be built at reasonable costs. Guidance for setting fundamental criteria is given by advisory bodies such as the International Commission on Radiological Protection (ICRP) [4,5] and the Nuclear Energy Agency (NEA) [23]. The second level (dose criteria) defines the dose limits that correspond to the level 1 risk limits. Derived criteria (level 3) are computed from dose criteria using nuclide-transport and biological pathway models. Prescriptive criteria (level 4) are requirements placed on a repository that are intended to reduce risk, but are not derived mathematically from the fundamental criterion. They are usually based on the requirements in the three higher levels, but are neither necessary nor sufficient to ensure compliance [12].

Most of the radiological protection options that have been considered for HLW repositories are discussed in Reference 10, and are summarized in Section 1.3.1 of this report. This section of Chapter 3 covers the attributes, capabilities, and deficiencies of the categories of standards that could be adapted to subseabed HLW disposal. Standards that are based on allowable detriment or dose are discussed in Section 3.2.1; a combination of all dose standards is discussed in Section 3.2.2; and derived and prescriptive standards are discussed in Section 3.2.3.

\subsubsection{Fundamental and Dose Standards}

The three major categories of standards that have been used to regulate risks from radiological and carcinogenic chemical wastes are based on: (1) annual or lifetime individual risks to members of the maximally-exposed group at the time of peak exposure or during a specified time period, (2) risks to a single generation at the time of peak exposure or during a specified time period, and (3) collective risk to a specific or the world population for a specified period of time. These categories can apply to biota as well as humans.

Waste standards have been implemented using a risk/benefit approach, where the allowable risk is proportional to the benefits derived from the process that generates the waste, and the absolute approach, which limits the incremental risk from a given process regardless of the benefit or quantity produced. Obviously risk/benefit standards must have an upper limit, but it may be higher than that used with absolute standards because people are more willing to accept a higher risk when it is associated with a benefit. The weighting of risks and benefits is subjective, and varies with products, populations, and regulators. Risk/benefit standards also create the ethical problem of equity when risks are incurred over long periods of time as they are with nuclear and chemical waste repositories. Highest risks from HLW repositories would be incurred by future generations that receive none of the benefits (Figure 6). Coordinated control over all man-made sources is required with absolute standards to allocate and enforce quotas, and to ensure the total allowable detriment is not exceeded. Levels set for the allowable dose increments are usually those that would be acceptable today under the same circumstances, which 
may or may not be applicable $10^{5}$ years from now when dose rates from a HLW repository would be the highest.

Various time scales have been applied to the three major categories. Maximum individual and single-generation standards can be limited to a specific time interval, or they can specify peak rates with no time limits. The argument for a specified time limit is that confidence in predictions decreases as time increases. The duration of analyses is only one factor that affects the confidence in predictions. Other factors include:

- Robustness of the repository system

- Stability of pathway environments

- Dependence of the analyses on predictions of future states

- Quantity and quality of input data

- Consistency of low probability events

From the standpoint of confidence, an acceptable duration of regulation would not be the same for all repositories. However, if the time interval for evaluation does not include at least the peak dose rates, the computed risks could be gross under predictions of actual risks. This can be seen by observing that doses are almost nonexistent for about the first 8,000 years in Figure 5, and that they peak at about $1.5 \times 10^{5}$ years. The same arguments hold for time-integrated collective dose standards. For SD, a $10^{-4}$ year interval of integration would almost miss the entire dose curve in Figure 6, and the total predicted collective dose would be a factor of $4 \times 10^{6}$ lower than for a $10^{5}$-year integral. A quantitative example of how collective dose integration time affects the apparent safety a repository is given in Section 4.1.4. References 24 and 25 show that doses start and peak for undisturbed terrestrial repositories at about the same times as for subseabed repositories. Another problem with using an early cutoff date is that the relative attenuation of the components in the waste disposal system will be distorted. A parametric study showed an early cutoff date exaggerates the relative importance of the waste package because other components in the system would have only begun to function at that time $[2,15]$.

Another cutoff applied to risk standards is the minimum risk level that must be controlled. Reference 26 showed that in the US, chemical carcinogens are not regulated when individual lifetime risks are below $10^{-4}$ and less than $10^{4}$ individuals are affected. This de minimis individual-risk level drops to $10^{-6}$ when the population affected is $2.3 \times 10^{8}$. There are also de manifestis risk levels that are so high that regulations have always enacted to reduce them. The de manifestis lifetime individual risk level is about $4 \times 10^{-3}$ when less than $10^{5}$ individuals are affected and decreases to about $3 \times 10^{-4}$ when the affected population is $2.3 \times 10^{8}$. Between the de minimis and de manifestis levels processes may or may not be regulated. The primary determinant for regulation of these processes is the cost-effectiveness of regulation. Only processes with risk reduction costs of less than about $\$ 2$ million per life saved were regulated. A determinant for regulation that is difficult to quantify. is how the public perceives risk [27, 28]. Factors that influence perceived risk as opposed to actual risk are: familiarity with the source of risk, association of the risk with more familiar processes, magnitude of the consequences, voluntariness, equity, natural or man-made, randomness of the risk, and if the risk is self-imposed, imposed by others, or natural. 


\subsubsection{PROTECTION OF MAXIMALLY-EXPOSED INDIVIDUALS}

Of the three major categories of radiological protection standards, the peak individual dose or risk to the maximally-exposed group (MID) has been the most widely used. This standard has been recommended by the ICRP [4], NEA [29], IAEA [30], NAS [31,32], and SDP Workshop on Radiological Protection Standards [11]. MID standards were the basis for defining radiological waste that are unsuitable to dump at sea $[6,8]$. They were used to evaluate the risks from low-level radioactive waste dumping [7] and have been used to find disposal options that were not unacceptable [2, 33, 34, 35, 36]. The ICRP [5] states that the MID should not exceed $10^{-3} \mathrm{~Sv} / \mathrm{yr}$ from all anthropogenic sources for continuous lifetime exposure. Usually MID standards are applied to the maximally-exposed group of individuals at the time of peak exposure. However, they can be applied to other groups or to the average individual during any specified time period. MID standards could be used to define acceptable disposal options or to eliminate unacceptable options as recommended by the ICRP. The SDP Workshop on Radiological Protection Standards recommended that no specified exposure limits should be established for individual biota [11].

The advantages of individual dose or risk standards are:

1. They prevent any individual from receiving higher than acceptable doses.

2. All individuals receive the same degree of protection regardless of the population density [37].

3. With very low limits, the risk may be acceptable to future generations that receive none of the benefits.

The deficiencies of individual standards are:

1. Acceptable levels could be achieved by dilution and/or temporal spreading of the dose to reduce peak dose levels with little reduction of activity in the more accessible environment. Dilution and temporal dispersion increase the number of individuals and the number of generations that would receive increased doses.

2. MID standards do not take into account the number of people that are affected, i.e., the total number of detrimental health effects from the disposal of the waste.

3. MID standards do not include the dose duration and hence do not cover cumulative genetic effects.

4. A large number of individuals receiving doses just below the allowable limit could result in a significant number of health effects, particularly where background radiation is high.

Although MID standards have distinct advantages, there are many aspects to radiological protection, and this approach alone does not cover all of them. 


\subsubsection{PROTECTION OF SINGLE GENERATIONS}

Single-generation dose (SGD) standards limit the dose or risk to a given population either annually or over an average lifetime. Given the long duration of risks from HLW disposal and the potential for dilution and dispersion, use of the entire world population would seem appropriate. Because of the slowly changing dose rates and the long duration of near peak dose rates from a HLW repository (Figure 6 and Table 9), many generations would receive approximately the same dose. Singlegeneration standards have had little official use in regulating risks from hazardous materials. However, lower lifetime individual risks from chemical carcinogens have been allowed when larger populations are affected [26, 38]. In the US, for populations less than 230 million, the allowable individual risk was found to be proportional to approximately the inverse square root of the size of the population at risk. There are several methods that could set limits for a single-generation dose-rate limit for HLW disposal. One would be to take some fraction of the annual background radiation to the world population. For the current world population of five billion people, annual background radiation is approximately $6 \times 10^{6}$ person-Sv/yr. It could also be based on some allowable average lifetime risk to the world population. Assuming a one-in-a-million $\left(10^{-6}\right)$ average lifetime risk, the SGD allowable would be about $1.4 \times 10^{3}$ person-Sv/yr or approximately a factor of 4,000 lower than the total annual background dose. Another approach would be to extend Milvy's equation [38], which would make the allowable SGD equal to some constant times the square root of the projected world population. If reasonably low SGD limits are applied at the time of peak dose, as the ICRP recommends for individual doses, the incremental dose levels should be acceptable to future generations.

The SDP Radiological Standards Workshop [11] concluded that no exposure limits should be established for individual biota; the primary concern is to protect populations. It will be necessary to prove that waste disposal will not cause any species to become extinct or disrupt any significant food chain. This could be accomplished with single-generation exposure standards. Insufficient information is available to set biota exposure limits at this time, but some fraction of natural background was recommended for interim assessments.

The advantages of single-generation dose or risk standards are:

1. Single-generation dose standards are the only standards preventing any generation from receiving unacceptably high doses.

2. They account for the size of the population being affected in each generation.

3. They prevent a future generation from receiving doses that would be unacceptable today.

The deficiencies of SGD standards are:

1. They do not prevent small groups of people from receiving very high doses.

2. They do not cover multi-generation genetic effects. 
3. They do not account for the total number of people that are affected over time and hence do not limit the total number of detrimental health effects.

As with MID standards, SGD standards cover some, but not all aspects of radiological protection.

\subsubsection{PROTECTION OF COLLECTIVE POPULATIONS}

Collective, time-integrated population-dose (CPD) standards limit the total dose that an entire population receives over a given period of time. Considering the long time scales associated with HLW disposal, it is not possible to track any particular group, so the total world population would be the only practical population size. As discussed earlier, selection of the integration time is a trade-off between confidence in the models and data for short times, and the inclusion of the most significant doses for long times. Collective population dose is effectively an averaging standard. It treats high dose rates over a short period of time the same as low dose rates over a long period of time, and high-dose rates to each member of a small population the same as low individual doses to a large population. All doses in the population/time space are included in the evaluation unless individual doses below a specified level can be excluded from the integration.

The CPD method is recommended by the ICRP to optimize the repository selection after unacceptable options have been eliminated using the MID method [4]. However, the ICRP does not recommend using CPD standards as an acceptance criteria. The US EPA [3] and NRC [39] are using derived criteria based on CPD standards to regulate terrestrial geologic HLW and SF disposal. The EPA risk limit for waste disposal was based on estimated achievable risks of generic terrestrial repositories, rather than on acceptable risk, but it is approximately equal the total risk from a comparable amount of unmined uranium ore, the first $10^{4}$ years after disposal. This CPD standard states that there will be no more than 1,000 excess cancer deaths over the next 10,000 years from disposal of wastes from $10^{5}$ MTHM or an average dose rate to the world population of $10^{-4} \mathrm{~Sv} / \mathrm{yr}-\mathrm{MTHM}$. The allowable dose is proportional to the amount of fuel used, i.e., this is a risk/benefit standard.

The advantages of collective population dose and risk standards are:

1. Collective population dose standards account for the total number of people that are affected by the waste disposal and hence the total number of detrimental health effects that are caused.

2. They can account for genetic effects that could accumulate over multiple generations.

3. They discourage reliance on dilution, dispersion, and pulse spreading as the primary methods of reducing dose rates.

The deficiencies of CPD standards are:

1. Collective population dose standards do not prevent relatively small groups of individuals or generations from receiving extremely high doses. 
2. If the integration time is too short, most of the integrated dose could be missed. Possible solutions to the problem would require including peak dose rates in the integration similar to requirements for peak individual doses or selecting a time period, starting later than the time of emplacement, that would maximize the CPD [40].

3. The population and time integrations can involve a large number of very small dose increments. A linear relationship between dose and health effects must be assumed, and unless background radiation is in the mid-dose range, predicted risks could be much higher than actual risks.

Cumulative population dose standards cover aspects of radiological protection not covered by MID and SGD standards, but they, too, are not adequate by themselves.

\subsubsection{PROTECTION OF THE ENTIRE POPULACE}

Standards that protect populations do not necessarily protect individuals; the converse is also true. Unacceptable options can be eliminated with only one category of standards, and another category can be used to optimize the acceptable options, as the ICRP recommends [4]. However, one category of standards does not protect all groups under the conditions expected for HLW disposal. All three standards have deficiencies when used separately, but they complement each other, and when used together they should adequately protect the entire populace. To accomplish this, numerical standards specifying allowable doses to the maximally exposed individual at the time of peak exposure, a single generation at the time of peak exposure, and time-integrated world population dose through the time of peak exposure would be needed. The inherent dose averaging used in single generation and collective dose criteria could not jeopardize smaller population groups when combined with individual dose criteria.

Some performance assessment models can compute individual, population, and collective doses simultaneously, so there would be little additional effort to compute all three. The capability to accurately predict each of the three categories of risk depends on the type of repository and its location. Computations of population doses may require predictions of future populations for one type of repository while knowledge of maximum food-harvest rates would suffice for another. Depending on the repository, individual doses may be primarily governed by the maximum consumption rate of a particular food group, by local drinking water contamination, or by the probability of human intrusion. Also, the relative ease of meeting each of the three standards varies with repository type, location, and disposal medium.

One approach for optimizing selection of the acceptable repositories would be to use a weighted combination of the margins of safety (MS) from risk assessments based on each of the three standards as follows:

$$
M S=\frac{a \cdot M S_{M I D}+b \cdot M S_{S G D}+c \cdot M S_{C P D}}{a+b+c}
$$

where $a, b$, and $c$ are the weighting factors for MID, SGD, and CPD, respectively. Weighting factors could be functions of relative importance for each standard and the confidence level of each assessment. 
All three standards could be used to identify acceptable repositories, select the best option, optimize the repository design, and evaluate the selected repository.

\subsubsection{COMBINED STANDARDS}

Another potential approach to universal protection is a combined individual/population/duration standard. The purpose of this section is to help understand how MID, SGD, and CPD standards protect the entire populace, rather than to propose the use of a single combined standard at this time. Currently there is not enough reliable information on low level dose increments and future states to develop a combined standard, and the associated performance assessments would be difficult with current computer models.

Traditionally, individual risks have been restricted to lower levels as the number of people affected by an activity or process increases [26,38]. P. Milvy suggested that for a widely and randomly distributed carcinogen whose beneficial characteristics have been established, an acceptable lifetime (70 years) risk would be

$$
R_{L}=\frac{0.015}{\sqrt{P}}
$$

when affected populations (P) range from 100 to $2.4 \times 10^{8}$ individuals [38]. This equation is based on the assumption that an individual lifetime risk of $10^{-6}$ would be acceptable if the entire US population was affected, and that a lifetime risk of $1.5 \times 10^{-3}$, which is the occupational risk of "white collar" workers, would be acceptable if only 100 individuals were affected.

If the relationship of acceptable individual risk to the size of the population at risk in equation 2 can be extended over multi-generations, it can be used to generate a control surface that combines MID, SGD, and CPD standards. Figure 13 shows a bounding plane of the control surface that represents acceptable dose levels to a single generation. The SGD limit is represented by an area equal to the population at risk multiplied by the individual dose limit of that population. The next step extends the control surface over the duration of risk as shown in Figure 14. The surface YOZ represents the dose limit if the risk only affects a single generation, the same as Figure 13. The surface XOY represents the reduction in allowable individual doses as more generations are affected. The equation for the limit in the XY plane is not necessarily the same as in the YZ plane. The limit in the XY plane would be a function of life expectancy, altered by multi-generation genetic effects, and weighted as a function of time. Less weight could be given to later times because of greater uncertainties, or more weight could be given because no benefits would be received by future generations. The shaded rectangular prism in Figure 14 is defined by a population at risk $\mathrm{A}$, a duration of risk $\mathrm{C}$, and the individual risk limit $\mathrm{D}$ that is located by the control surface. The collective dose limit is the volume of the rectangular prism. The single generation dose limit is the shaded surface OABE. The individual dose limits in equation 2 and in Figures 13 and 14 only apply when all individuals at risk receive approximately the same dose, or when average doses are used. 


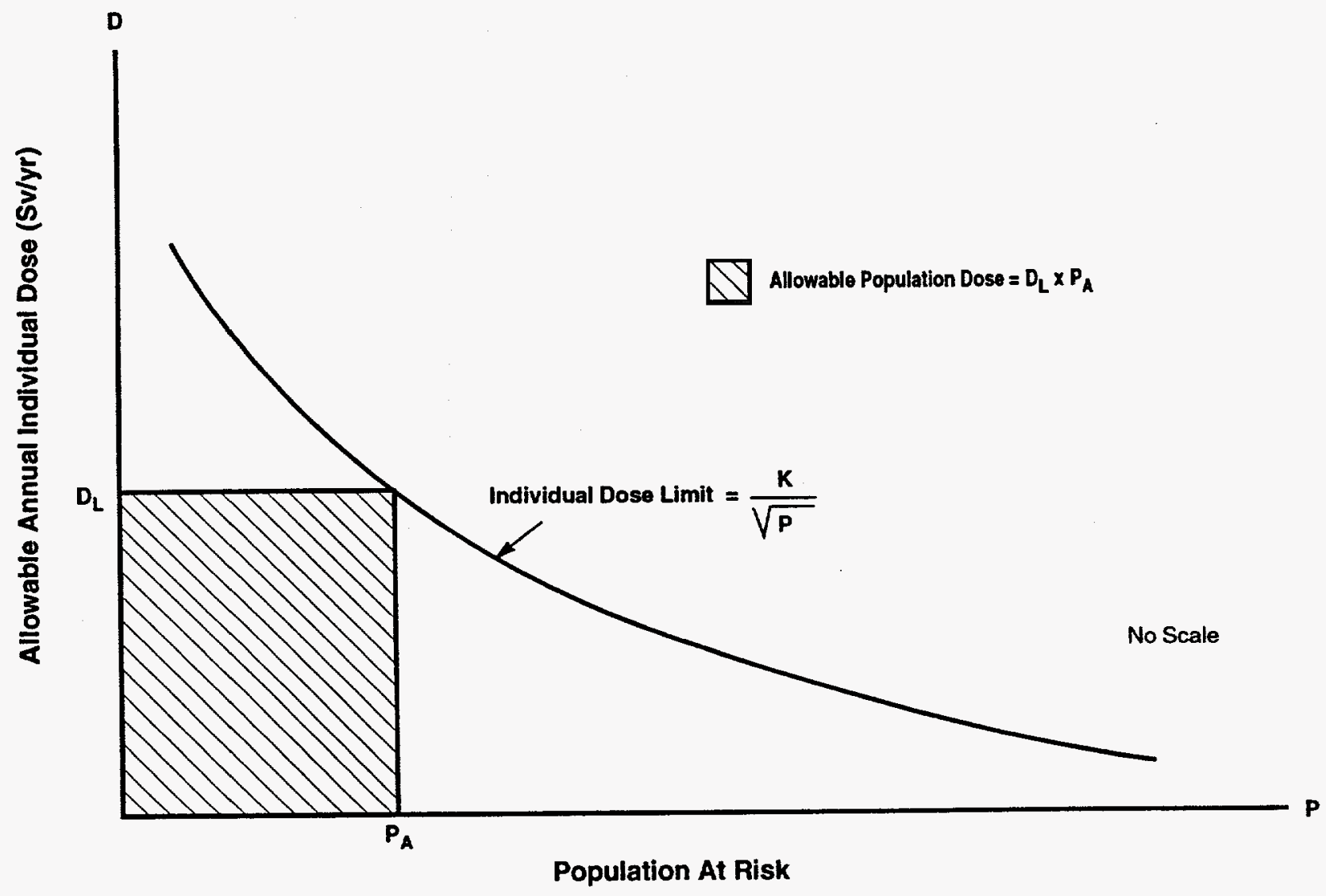

TRI-6341-24-1

Figure 13. Average allowable individual dose rate and allowable population dose rate as a function of population at risk. 


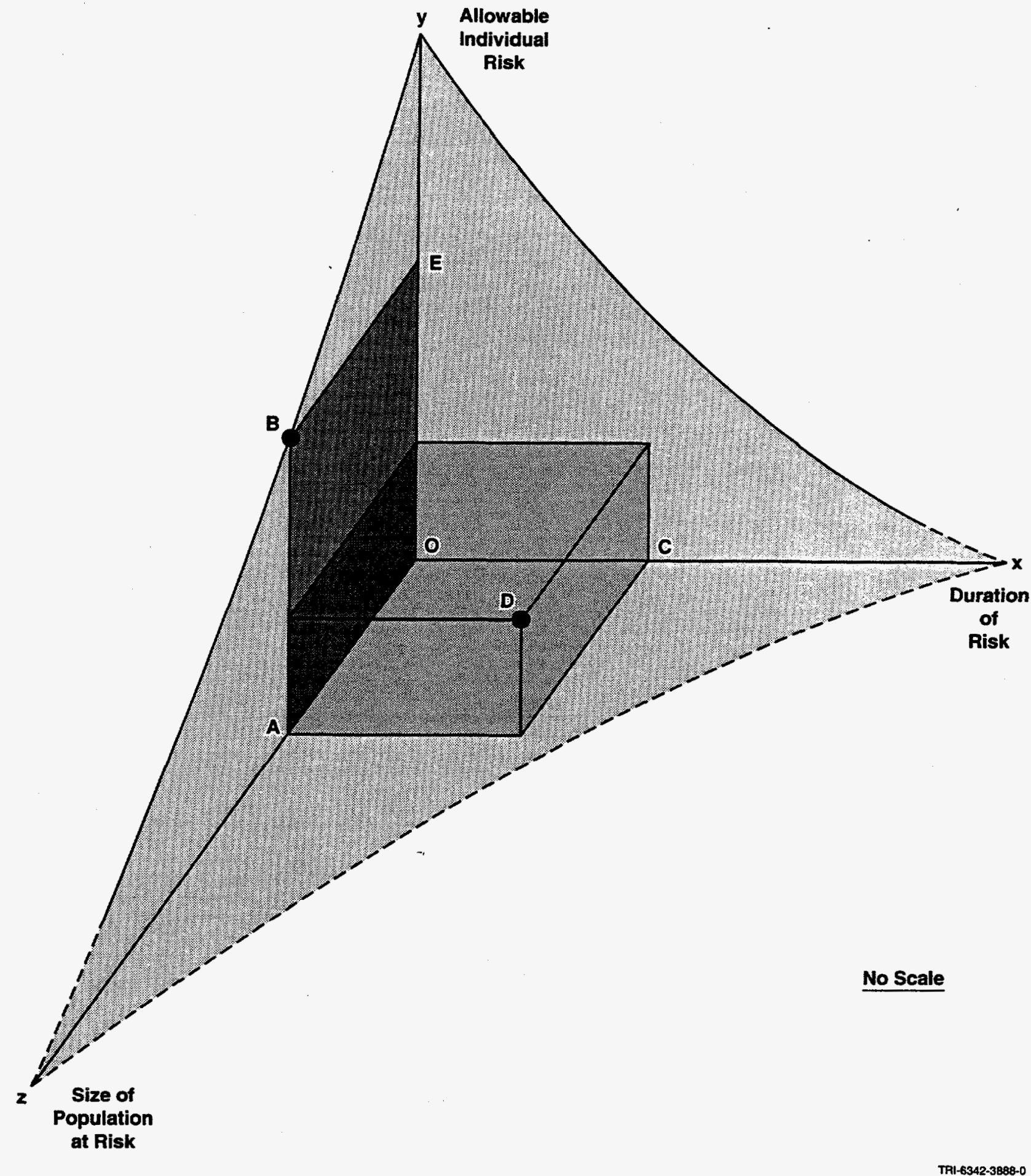

Figure 14. Control surface for combined standards. 
In actual practice, the control surface in Figure 14 would be modified by natural constraints and existing regulations, and to expedite performance assessments. Four of the most likely modifications are shown in Figure 15. Regulators may limit doses to small groups of individuals to levels below that defined by the control surface. This surface, which could be the ICRP individual dose limit, is labeled as the MID limit. Very low individual doses could be excluded from the development of population dose limits, as well as from performance assessments. This modification is labeled de minimis in Figure 15. De minimis, as applied to radiological standards, can pertain to either a material with a specific activity so low that is not regarded as radioactive, or to doses or risks that are so low compared to those from natural sources that they are of no regulatory concern. Although the activities of HLW and SF are definitely high enough to require regulation, some of the doses they would produce could be below the de minimis level if they are placed in a well designed repository. Individual risk levels less than $10^{7}$ per year are usually considered to be in the de minimis range. Regulation of materials that are hazardous for extremely long times, such as radioactive waste, may be terminated before they reach innocuous levels. This type of modification is illustrated as the time limit of regulation in Figure 15. There are always limits to the size of the population at risk. It could be the entire world population, or the number of people that could be affected by the dominant pathway from the repository to humans. Examples of the latter are people that use a contaminated aquifer, or those that consume contaminated aquatic food that has a limited rate of production. The modified control surface in Figure 15 contains all three types of standards and all their constraints.

\subsubsection{Derived and Prescriptive Standards}

The terms derived and prescriptive standards are often used interchangeably. In this report, derived refers to standards that can be traced through models to the fundamental criterion. Prescriptive refers to standards that are intended to reduce risk, but are not traceable to the fundamental or dose standards, and are not sufficient in themselves to assure adequate protection. Derived and prescriptive standards are covered in the same section because they have many of the same uses, characteristics, and limitations.

Derived standards are requirements placed on the performance of components or processes in the disposal system, or on the flux or concentration of radionuclides at locations along pathways from the waste site to humans. The purpose of derived standards is to facilitate regulation, control, and monitoring. They must be computed from, and traceable to, the fundamental criteria that define the acceptable detriment. They never replace the fundamental or dose criteria, and are a measure of risk only as they relate to the fundamental criteria [4]. Therefore, a single derived standard that is traceable to a single fundamental criterion will be site and application specific. Derived standards must only be used for the circumstances for which they were derived [4]. Therefore, generic derived standards that are applied to all sites, all pathways, or all release modes are inherently inaccurate. Optional or multiple generic derived standards are more accurate than single generic derived standards, because they allow the regulator to select the most appropriate standards and apply them at the most appropriate locations [12]. Because of their inaccuracies, there is a tendency to make generic derived standards extremely conservative. The level of conservatism is unknown and nonuniform, which makes the allowable risk different for each repository and the actual risk margin of safety unknown. 


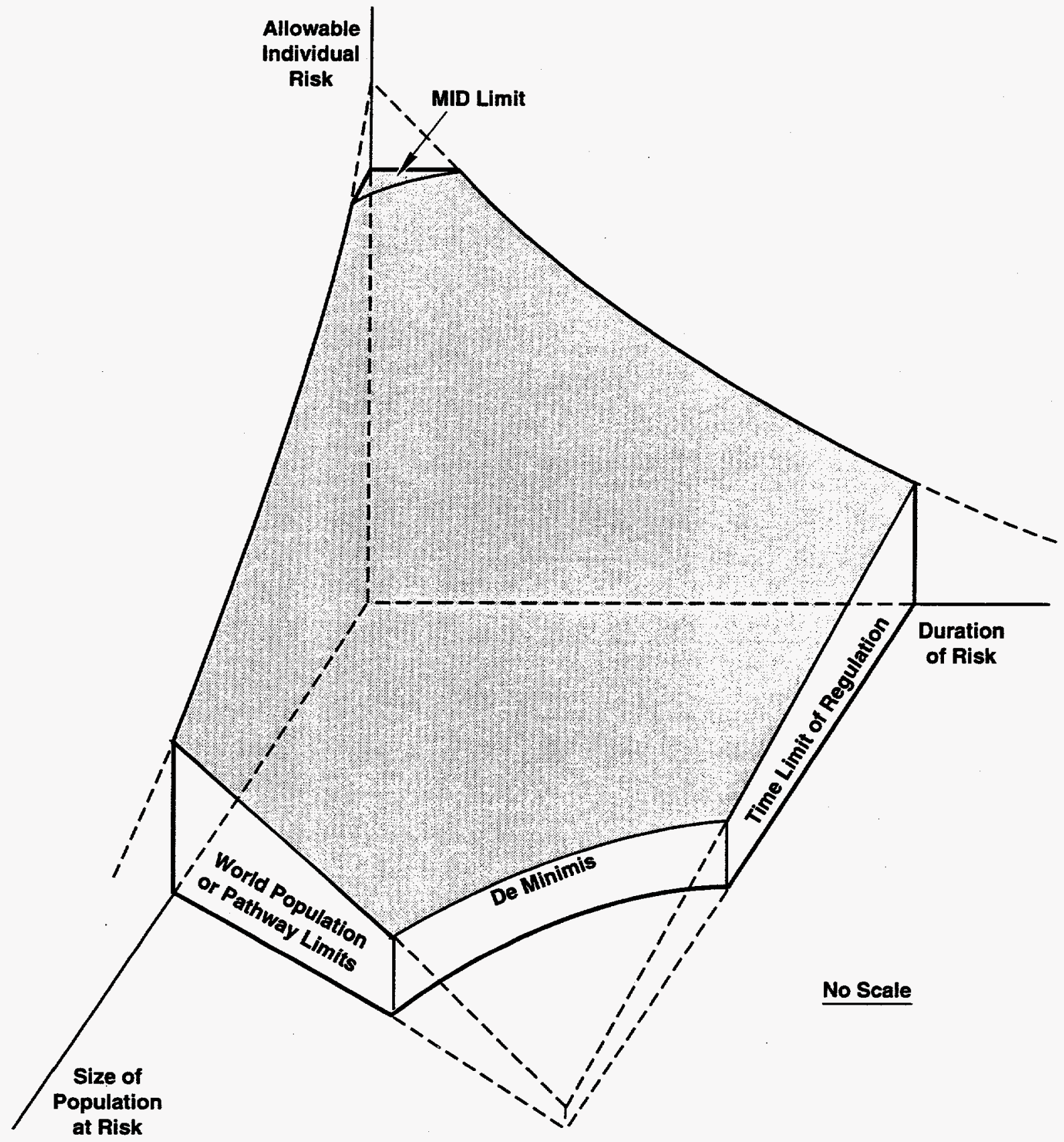

TA1-6342-3835-0

Figure 15. Combined standards modified by natural constraints and specific regulations and to expedite evaluation. 
Derived standards can be set at any location in the disposal system, preferably at a component boundary to expedite analyses. They are computed by modeling the disposal system from the location of the derived standard to the locations of the populace at risk. The accuracy of this link depends on the realism of these models [41]. The PA models only cover the radionuclide transport from the initial waste location to the location of the derived standard. The derived standards, along with the performance assessments, constitute the risk assessment for the repository. This relationship is illustrated in Figure 16. Two approaches to risk assessment are shown. One procedure uses only the fundamental or dose criteria and computes the nuclide transport sequentially from the source to humans; the other uses derived release limits computed from the fundamental criteria, followed by performance assessments that compute nuclide transport from the source to the location of the release limits. The accuracy of the risk assessment depends on the accuracy and realism of all models, regardless of the procedure used. Splitting the risk assessment into two segments does not reduce the accuracy requirements of either segment, nor does it reduce the uncertainty. Since the derived standard is an integral part of the risk assessment, it should be computed with the same level of functional quality assurance that the PA uses to evaluate the repositories. If the derived standards are to be defensible, formalized logic should be used, the steps in their development and all decisions should be traceable, and verified models, data, and assumptions should accurately represent pathways and effects. Even if derived standards are developed rigorously and are repository specific, they still create an inconsistency in probabilistic risk assessments. When derived standards are used, only the performance assessment segment is probabilistic; the analyses in the second segment to develop the derived standards are deterministic.

Derived generic collective release limits are a significant part of the 40 CFR 191 [3] regulatory strategy for terrestrial mined geologic repositories. The intention was to simplify risk assessments and still have the standards apply to all terrestrial repositories. They do simplify the assessments, but they omit some of the most important components in the disposal system and base the risk entirely on a pathway that is unlikely for any terrestrial repository, i.e., they do not represent the actual risk potentials of repositories.

Because of the uncertainties in predicting nuclide transport processes, natural events, and human behavior over the long duration of potential risk from radioactive wastes, numerical risk criteria may not provide the certainty necessary for environmental protection or promote public confidence in the disposal system. Qualitative assurance requirements in the form of prescriptive criteria can be used to supplement the numeric criteria and reduce the uncertainties. Examples of prescriptive criteria for repositories are: limitations on groundwater velocity in the vicinity of a repository, avoidance of natural resources, minimum containment times for engineered barriers, controlled site access and nonintrusive monitoring for a limited time, public records of the repository, long-lasting passive warning markers, and the requirement to design the repository so the waste could be retrieved at reasonable expense after emplacement.

Prescriptive criteria are requirements placed on site selections, repository designs, and institutional controls that tend to reduce risk in most disposal systems or assure compliance with statutory requirements. Prescriptive criteria usually reduce the probability of releases caused by natural processes or human intervention, rather than prevent the release. They can be based on the three higher 


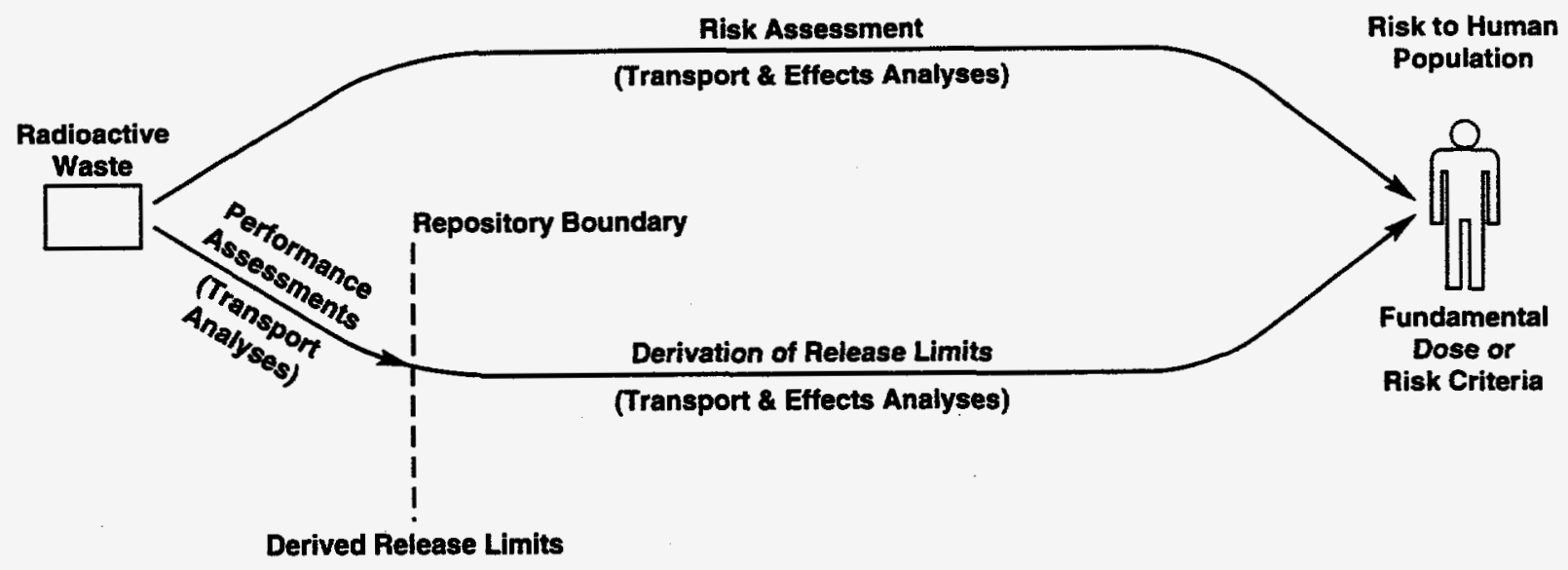

TRI-6341-140-1

Figure 16. Comparison of risk assessment procedures with dose or risk standards (top path) and with derived standards (bottom path). 
criteria levels but are not necessarily derived mathematically from them. They are neither necessary nor sufficient to ensure compliance with the fundamental risk criteria. When prescriptive standards are guidelines rather than requirements, they allow more flexibility in system optimization.

Component interactions in geologic repositories are complex, and should be carefully considered when defining the type and point of compliance of derived standards. This problem does not occur with dose standards, because the analyses are conducted sequentially from the waste source to humans. The complexity, uncertainty, and absence of proven guidelines for radioactive-waste disposal standards requires the development of criteria levels for all waste categories to be conducted in a systematic manner to assure consistency and appropriateness $[12,40]$.

Examples of some derived and prescriptive standards that have been placed on terrestrial mined HLW repositories, but may not be applicable for SD, are limits on integrated nuclide flux to the more accessible environment, limits on groundwater velocity, minimum canister life, maximum waste-leach rate, and retrievability $[3,41]$. The uses and limitations of each of these standards will be discussed in turn.

\subsubsection{NUCLIDE FLUX ACROSS A BOUNDARY}

SDP risk assessments $[1,2]$ showed that dose rates are proportional to release rates only when the radionuclides have a short residence time in the environment between the release point and the recipient of the dose, such as in rivers or on ocean shelves. In ocean waters beyond the shelves and in the atmosphere, dose rates are proportional to the accumulated inventory (the time-integrated release rate minus decay, scavenging, and removal) or concentration. Doses from the deep ocean are very sensitive to the time and rate of radionuclides entering the ocean.

When radionuclide concentrations are nearly uniform in all regions that are the source of doses to humans, as they would be for emplaced SD waste or from a deep ocean accident, dose rates received by the populace from all pathways are roughly proportional to the amount of each radionuclide in those regions. The CPD is then proportional to the time-integrated quantity of each accessible nuclide (integral of ocean burden for SD). Typically, dose rates increase as more nuclides are released from the repository to the more accessible environment, and then decrease as release rates decrease and decay of the nuclides becomes dominant. This is illustrated in Figure 6. The unsorbed nuclides such as C-14 cause doses to humans before nuclides that are retarded by the sediments (e.g., Cs-135, etc.). The doses from shorterlived nuclides such as C-14 begin to decrease before those from longer-lived nuclides (Tc-99 and I-29).

Figure 17 shows the normalized total release to the ocean and the ocean burden for a typical radionuclide leaving a subseabed repository. Since the total amount of waste released to the oceans is not proportional to the ocean burden (dose), total releases cannot be used to compute release limits for deep ocean release. The retardation and temporal dispersion of each repository is different, so release rates to the accessible environment are unique for each disposal system. Therefore, the assumed release rates used in the derivation of release limits must have exactly the same rate vs. time distribution during the interval of regulation as the actual repository. The effects of the initial release time and release 


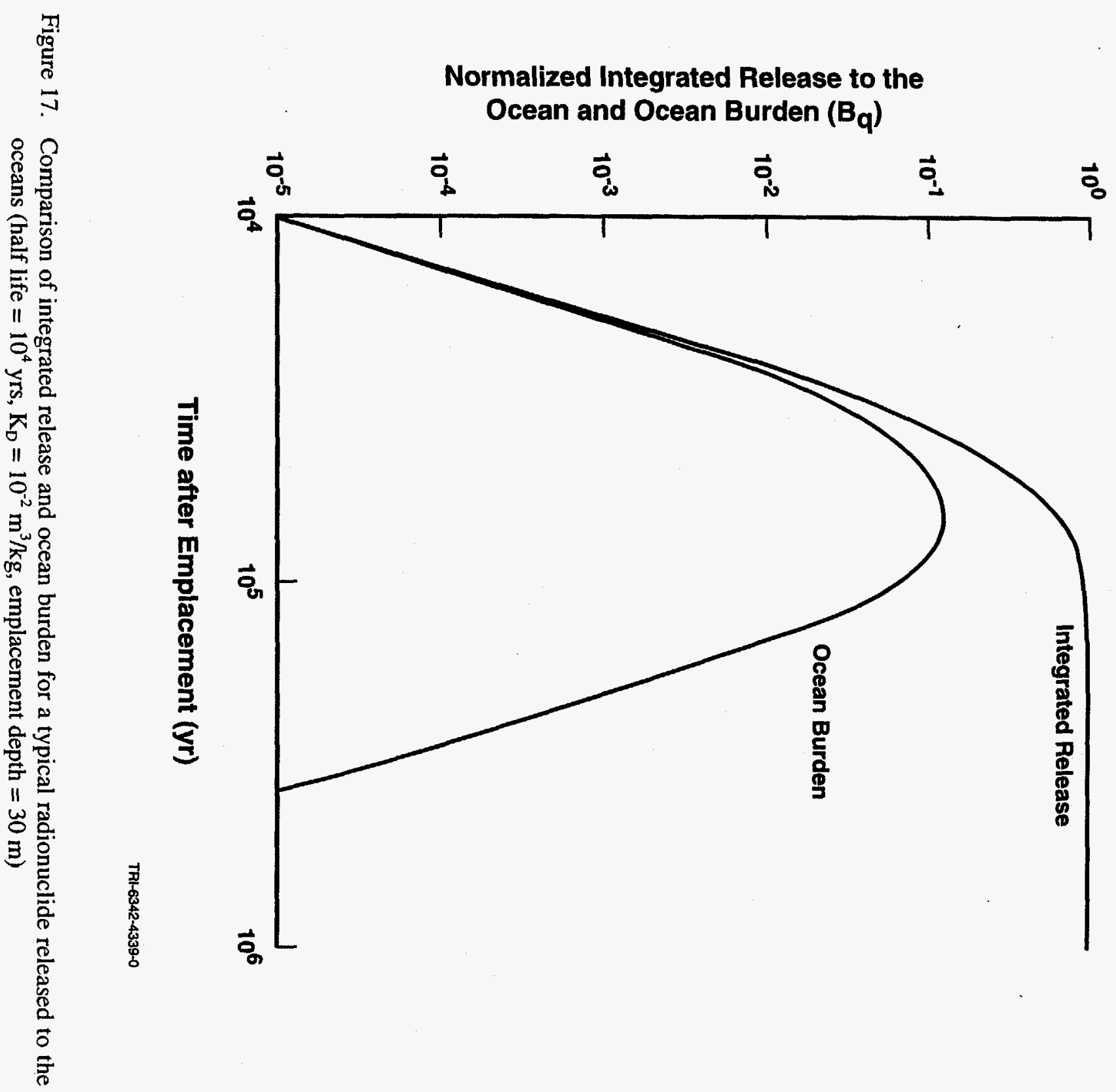


profile on collective dose is illustrated by the following example. Assume that a given amount of a very long-lived radionuclide $(R)$ is released to the accessible environment with three different time schedules between emplacement $\left(t_{0}\right)$ and the end of the regulatory interval $\left(t_{i}\right)$.

Case $1=$ Instantaneous release $R$ at time $t_{0}$.

Case $2=$ Uniform release from $t_{0}$ to time $t_{i}$ at a rate $R / t_{i}$.

Case 3 = Instantaneous release $R$ at time $t_{i}$.

All three cases would have the same time-integrated release between times $t_{0}$ and $t_{i}$. However, the time-dependent dose rates of each case would differ greatly, as shown in Figure 18. The reduction of activity with time, due to decay, is omitted for clarity. The quantity of waste in the region, and hence the dose rate, would be nearly constant for the entire time in Case 1; it would increase linearly in Case 2; and it would be zero, except at the last instant, in Case 3. The integration of these three curves from $t_{0}$ to $t_{i}$ would be proportional to the actual CPD. The CPD of Case 2 would be only half that of Case 1 , and the CPD of Case 3 would approach zero.

If the radionuclide residence time is very short in a region that produces relatively high doses, and if very low doses are received from all other regions containing radionuclides, dose rates are approximately proportional to the release rates in the high-dose region, and the CPD is nearly proportional to the time-integrated release to this region. In this limited case, the concentrations in the high-dose region are in near equilibrium, because activity is leaving at approximately the same rate as it is entering the region. An example would be release to a river that empties into an ocean, where collective doses from the river and ocean shelf are much greater than those from the deep ocean.

The only reliable derived metric to represent doses from all ocean waters was found to be the accumulated inventory, not the time-integrated release. The same would hold for releases to the atmosphere. The use of derived release limits should be restricted to disposal systems with short radionuclide residence times between the release point and where the dose is received. For some events, such as near shore accidents, consequences are source location dependent, so care should be taken to ensure that the derived standards are appropriate for the application. Release to the readily accessible from terrestrial repositories are also location dependent.

\subsubsection{GROUNDWATER VELOCITY OR TRAVEL TIME}

Prescriptive standards for groundwater travel time are used for site screening, rather than as a means of limiting dose. This criterion gives an indication of the amount of water available to leach the waste if matrix porosity is known and the time it would take non-sorbing nuclides to reach the boundary of the repository. Since this criterion does not consider the chemistry of the water or the geologic matrix, the effects of solubility limited release and retardation by the matrix are not included. This limits the usefulness of this criteria for comparing sites with different geologies, different repository designs, or both. Retardation and solubility vary with geology and groundwater chemistry, and different repository designs use different methods of attenuating the dose potential. Subseabed sediments do not have 


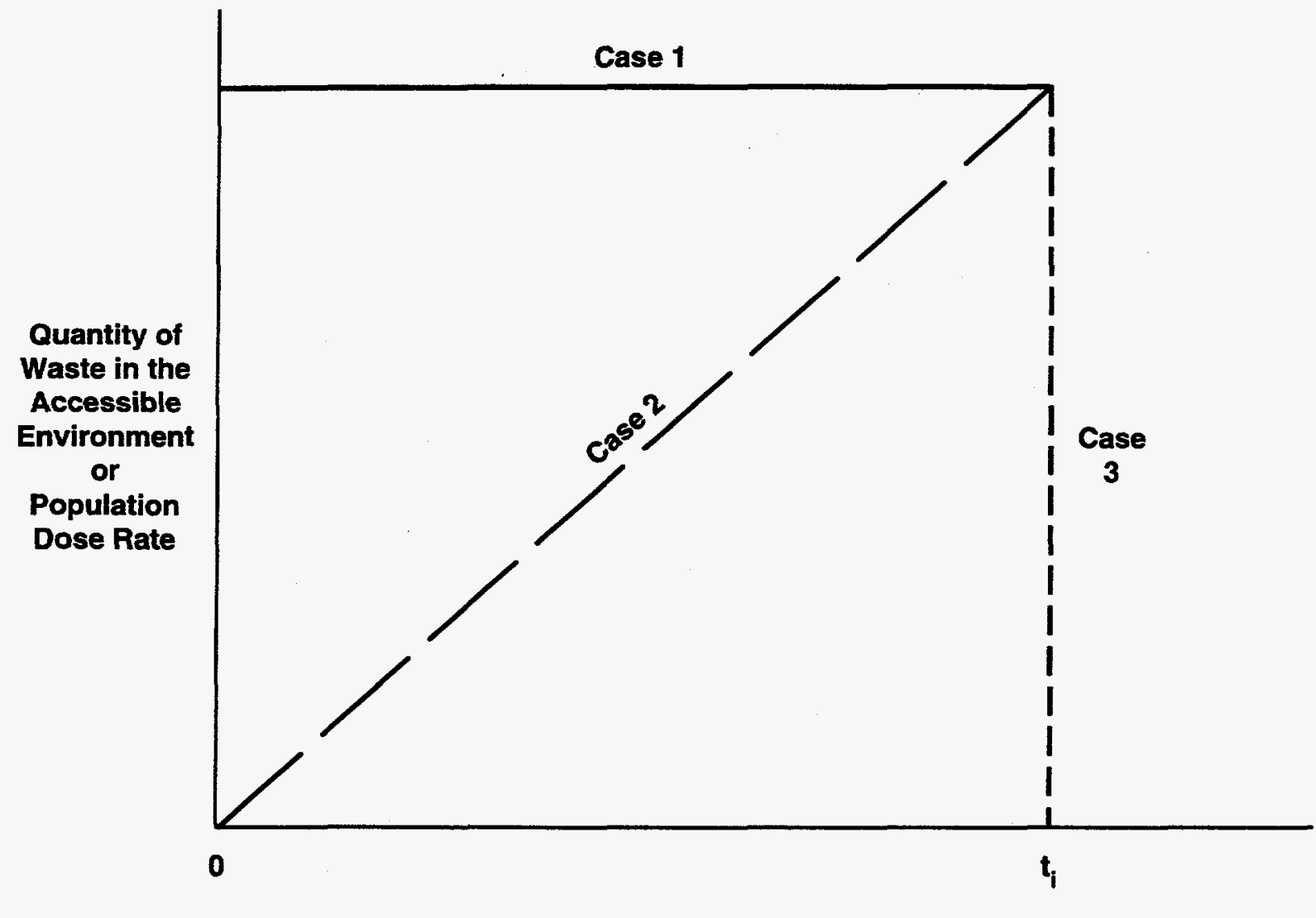

Time

TRI-6334-146-0

Figure 18. Dose rates from three release scenarios.

Case 1 - instantaneous release at $t_{0}$ Case 2 - uniform release from $t_{0}$ to $t_{i}$ Case 3 - instantaneous release at $t_{i}$ 
gravity-driven groundwater flow, but some sediments have low pore water velocities caused by natural thermal gradients or sediment compaction. Areas with significant vertical pore water velocity should not be used as SD sites.

\subsubsection{CANISTER LIFETIME}

Canisters serve many and varied functions, depending on the type of repository. The required duration of containment also varies with the type and location of the repository. Canisters provide high containment and facilitate handling for assembly, storage, transportation, emplacement, and possible recovery following an accident or retrieval of emplaced waste. Canisters isolate the waste during the time of high heat generation when there could be convection cells and thermally driven diffusion in some disposal media. Canisters also isolate the waste from the disposal media during the potentially detrimental radiation chemistry period. For these purposes a 100 to 300 year canister is adequate for subseabed disposal $[2,15]$. The delay of radionuclide mobilization by the canister has a surprisingly small effect on the amount of waste reaching the accessible environment, and on doses to humans. An AF analyses for subseabed disposal [9] showed that even canisters with a 5,000-year lifetime would reduce peak individual doses from emplaced waste by less than $1 \%$ compared to uncontained waste. The reduction of cumulative population doses integrated $10^{5}$ years would be less than $5 \%$. Realistic canisterlife standards cannot be set until the repository location and design concept have been selected.

\subsubsection{WASTE-FORM DISSOLUTION RATE}

Dissolution rates of individual waste nuclides in geologic repositories are controlled by the leach rate of the waste form, or by the solubility limit of the water surrounding the waste after canister failure. A slow dissolution rate delays nuclide mobility, allowing some decay to take place at the source location. For SD, the delaying effects of dissolution are even less than those of the canister. However, slow dissolution can be a dominant attenuation mechanism for some other geologic repositories. Slow dissolution reduces diffusion rates by decreasing concentration gradients and increasing concentrationdependent distribution coefficients. This effect is also extremely small for SD. The dissolution rate is important for the dispersal of waste in the ocean if a canister is lost on the sea floor and not recovered. A $10^{3}$ - to $10^{4}$-year dissolution time would be adequate for this purpose $[2,16]$. Dissolution-rate standards are at least as site and design dependent as are canister life standards.

\subsubsection{RETRIEVABILITY}

There can be a requirement that emplaced waste must be retrievable for the first 25 to 50 years after emplacement or until a mined geologic repository is closed. Reasons given for this short-term retrievability are:

1. To preserve the options of waste retrieval until the completion of a performance confirmation program and its review by the US Nuclear Regulatory Commission [41]. 
2. To remove the waste if the engineered barriers or the disposal media do not behave as predicted.

3. To retrieve waste that has been emplaced in a repository if geologic conditions are encountered as mining continues that would render the repository unsuitable [42-44].

4. To provide future generations with the option to correct any mistakes that this generation makes [3].

The need for 1 and 2 above are questionable. It is extremely unlikely that a canister designed to last 300 to 1,000 years with the QA used in the design and construction of a HLW repository would have a failure rate of any statistical significance the first 25 to 50 years. Other performance measures of a repository would not normally occur until up to $10^{5}$ years after emplacement. Performance confirmation relies primarily on pre-emplacement tests and analyses using validated models.

Reference 43 suggests an alternative to retrieval by using a thorough site-exploration program prior to any emplacement of waste that would negate reason 3. Although it may not be possible to do the extensive coring necessary to completely categorize a non-homogenous terrestrial repository because of the reluctance to penetrate the repository horizon, exploration could be conducted by constructing all drifts prior to emplacing any waste. This problem does not exist for SD because of the uniformity of the sediment. Furthermore, holes in the ductile sediment are self-closing, which permits adequate sampling and in situ testing prior to emplacing waste. The fourth reason has merit, but depends on the margin of safety and robustness of the repository and the technology level of future generations.

In any media, retrieving waste would be difficult, costly, and potentially dangerous. Designing a repository so that the waste can be retrieved could compromise the isolation capabilities of the repository. A repository that is open longer than required to emplace the waste has a higher overall risk potential than that of a well-sealed repository. High temperatures, radioactivity, and canisters that may become damaged or wedged in the boreholes are major concerns for retrieval. Any plan for retrieval must include canister removal, repository clean-up, storage, possible redesign of the entire disposal system, repackaging, repository construction, and re-emplacement of the waste. The risks and cost of all these operations must be weighed against the risk of leaving the waste in the original repository even if it is not operating exactly as planned. Attenuation factor analyses have shown that some repositories can operate satisfactorily even when some components fail or some environments change [9].

There is probably no need to require retrievability for SD, but if it applied, the wording of the requirements would have to be changed. There would be no period when a subseabed repository is "open." The ductile clay seals the entry hole behind each penetrator as they travel through the sediment. All repository operations are carried out each time a canister is emplaced.

In summary, derived standards must be traceable to the fundamental requirement of no unreasonable risk to the health and safety of the public, and should be implemented only if they contribute to regulation, evaluation, or safety. Many derived standards apply to specific repository types, sites, or both, so realistic derived standards can not be set until significant design and site information is available. The members of the Subseabed Disposal Workshop on Radiological Protection Standards concluded that official, derived, or prescriptive standards should not be applied early in the program to 
permit design flexibility, and definitely should not be applied during the feasibility phase of the program. Potential types of derived standards for subseabed disposal are discussed in Section 5.2 of this report.

\subsection{Duration of Regulation}

The selection of the duration of regulation for HLW disposal has to be a compromise between short durations that increase the confidence in some aspects of risk assessments, and long durations that provide better evaluation of collective risks and enable the evaluation of peak individual risks. Except for human intrusion and abnormal natural events, there would usually be no releases to the accessible environment for the first $10^{4}$ years after emplacement, and peak individual and population doses would occur more than $10^{5}$ years after emplacement. Therefore, short duration standards usually evaluate only the repository's vulnerability to abnormal disturbances. On the other hand, regulations that extend beyond the time of peak dose add nothing to the evaluation of individual risks, and if they extend long enough, the uncertainty in calculating collective risks masks any differences in alternative disposal systems.

The factors that affect the confidence in predictions of future risks caused by HLW repositories are:

1. Natural stability of processes and parameters along all pathways.

2. Likelihood of human intervention.

3. Understanding of transport and biological processes.

4. Quality of data.

5. Quantity of data including frequency and duration.

6. Consistency of abnormal events and whether they are cyclical or random.

7. Stability of the components to changes in parameters.

8. Resilience of the disposal system to changes in efficiency of the components.

9. Likelihood and dependence on sequential abnormal events.

10. Dependence on future human behavior.

11. Time span of the prediction.

For a given confidence level in risk predictions, the optimal duration of regulation depends on the sensitivity of the disposal system to the first ten factors. The truncation time again depends on sitespecific factors and on the disposal options being considered. The duration of risk analyses should emerge from assessments rather than being imposed "a priori" [45]. 
If the regulatory period ends before the time of any significant consequences, except those from abnormal events, the standards are not only a poor judge of absolute risk, but also cannot evaluate the relative efficiencies of different repositories. A quantitative example of how integration time affects predicted collective doses is illustrated in Figure 19. In this example, the allowable CPD was $2 \times 10^{-5}$ person:Sv/yr-MTHM, which is similar to the EPA fundamental criterion for terrestrial HLW repositories. The apparent margin of safety is a factor of $4 \times 10^{6}$ higher when a $10^{4}$ year interval of integration is used than when a $10^{5}$ interval is used. Another problem with using an early cutoff date is that the relative attenuation of the components in the waste disposal system is distorted. A parametric study showed an early cutoff date exaggerates the relative importance of the waste package, because other components in the system would have only begun to function at that time [2].

The duration of regulation is another example of the limitations of generic standards for HLW repositories. For a given confidence level, the duration of regulation for subseabed disposal could be longer than for terrestrial repositories, because of the greater robustness and less dependency on future state predictions. Subseabed repositories also require a longer duration of regulation to assure peak risks are covered because the lower probability of human intrusion and abnormal natural events makes risk from normal operation dominant.

\subsection{Assurance Requirements}

An important part of any standard is a requirement on the level of confidence that is needed to demonstrate the intent of the standard has been achieved. This is particularly important when performance assessments use predictions over geologic time periods and when knowledge of nuclide transport and biological processes is not complete. There are four non-mutually exclusive approaches to ensure that a standard is met:

1. Require that the standard be met with a quantitative level of confidence; for example, require that at least two standard deviations from the mean dose fall below the limit.

2. Require that the accumulated scientific evidence provide a reasonable degree of confidence that the standard has been met.

3. Supplement the numeric criteria with prescriptive requirements on the disposal system that would reduce the probability of releases to the more accessible environment.

4. Require a robust disposal system that is resilient, insensitive to changes, and located in a stable environment.

For the development of a given disposal option, the first approach provides a quantitative method of directing the program activities to minimize uncertainties in risk predictions. However, there are difficulties in implementing such an approach in a formal regulatory setting because repository performance cannot be proven with tests carried out over a meaningful time period. Performance predictions for high-level waste repositories must be made using mathematical models to assess future 


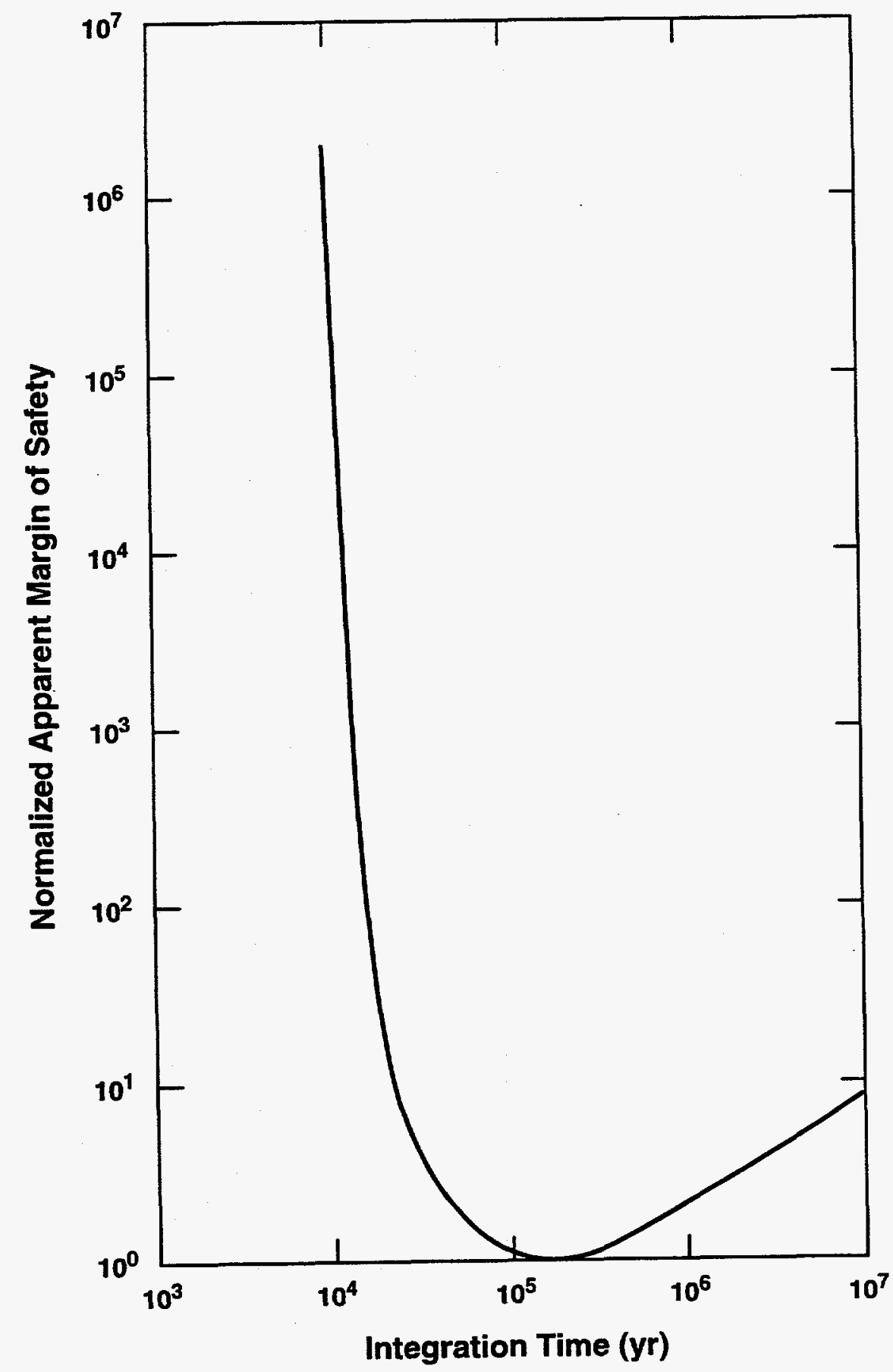

TR1-6341-26-1

Figure 19. Normalized apparent margins of safety for duration of regulation for the reference subseabed repository using collective population dose criteria. 
behavior. Not all the uncertainties in these models can be quantified. Confidence in these models depends on a variety of quantitative and qualitative evidence that is weighted by expert scientific judgment. While quantitative confidence limits should be considered for the development of the subseabed disposal option, by themselves they may not be an appropriate basis for future regulations. For regulatory purposes, a prudent approach would require both quantitative and qualitative assurance measures.

The second approach specifies the types and thoroughness of site and regional characterization needed to support a comprehensive performance assessment. It also specifies the QA requirements on the data acquisition and PA.

Rationale for the third approach and its limitations are given in Section 3.2.2. The assurance requirements could include all the prescriptive standards discussed in Section 3.2.2 plus requirements for active and passive institutional controls, monitoring, engineered barriers, and avoidance of natural resources in site selection. Active institutional controls include controlling access to the disposal site, and maintenance for a relatively short time after repository closure. Passive institutional controls include semi-permanent site markers that convey the potential danger of intrusion in as many ways as possible, and repository records and archives. Monitoring of the site must not compromise the integrity of the repository in any way, and would only be practical for a short time. Therefore, it would only detect extreme deviations from expected performance. Engineered barriers include the canister, waste form, and sorptive backfill. They provide redundant attenuation to compensate for unexpected performance of the natural part of the disposal system. Some engineered barriers have multiple functions, such as the container that is needed to handle the waste and provide temporary containment if there is a transportation accident. Avoidance of sites that have natural resources reduces the probability of human intrusion and precludes access to valuable resources. Too many generic prescriptive standards could rule out good sites and good designs, and inhibit system optimization. Subseabed disposal has less need for prescriptive standards than terrestrial disposal, and fewer can be applied effectively.

The fourth approach only requires that the disposal system be robust, and lets the project scientists and engineers find the best way to accomplish this for each repository. A robust disposal system would consist of the following:

- A resilient system designed to function satisfactorily when some components are operating at less than full efficiency.

- Components with high stability that function satisfactorily when there are environmental changes, or when input parameters are not precisely defined.

- Stable environments between the waste and the biosphere that have negligible changes or fluctuations of important characteristics during the time of interest.

Section 2.1.4 discusses the features of subseabed disposal that enhance its robustness, reliability, and confidence in risk predictions. 


\subsection{Probabilistic Acceptance Measures}

Predictive radiological risk assessments will inevitably be subject to considerable uncertainty. The sources of this uncertainty fall into the following categories.

- Incomplete or erroneous definitions of current processes in the disposal system, or of properties that affect the processes.

- Unknown variability of processes or properties with location and time.

- Future changes in pathways, uptake, and response by biota.

- Probability, timing, and sequence of natural or man-made disruptive events.

- Computational uncertainty caused by the limited number of samples in probabilistic analyses.

Because of the uncertainties and variabilities in long term geological waste disposal systems, probabilistic risk assessments (PRAs) are the most common method of analysis used to evaluate repository safety. Safety criteria are also written to accommodate or to require PRAs. The sections in 3.5 discuss the elements of PRAs addressed in developing probabilistic acceptance measures.

The radiological impact of nuclear waste disposal depends on the transport processes between the repository and the dose recipients, and on events that define or alter these processes. Some events and processes, such as those associated with properly emplaced waste, are almost certain to occur. Others have time-dependent probabilities of occurrence. Low-probability events could include transportation accidents, improper emplacement, human intrusion into the repository, climatic changes, changes in groundwater levels or movement, and tectonic events. There is also uncertainty about when events will occur, or if they will occur at all. Disruptive events that take place near the time of normal peak risk could affect the MID more than if they occurred earlier or later. The probabilistic sequence of events can affect the risks to individuals, generations, and collective populations. Even if an event that could lead to doses to humans or biota is certain, the specific individuals that receive the dose, and the effects on those exposed individuals, are probabilistic.

\subsubsection{Requirements for Risk Computations}

Many strategies have been proposed to regulate probabilistic risks from radioactive wastes. These range from deterministic assessments using mean parameter values and probabilities of occurrence, to deterministic assessments with upper and lower bounds, to complete stochastic analyses with no lower limit on included probabilities. One of the most widely accepted is the approach recommended by the ICRP [4] and the NEA $[23,46]$. They suggest using a limit on individual risks as the primary criterion, but the approach they define is not limited to individual risks. A primary risk or dose criterion would be used to screen repository systems to identify those that are not unacceptable. One or more secondary criteria would then be used to select the most acceptable disposal system.

The ICRP has defined a criteria curve that corresponds to an annual individual risk of $10^{-5}$ (Figure 20). The only nonlinearity in this curve is caused by the relationship between dose and health effects in the high-dose region. The ICRP recommends using this curve to eliminate disposal concepts, 


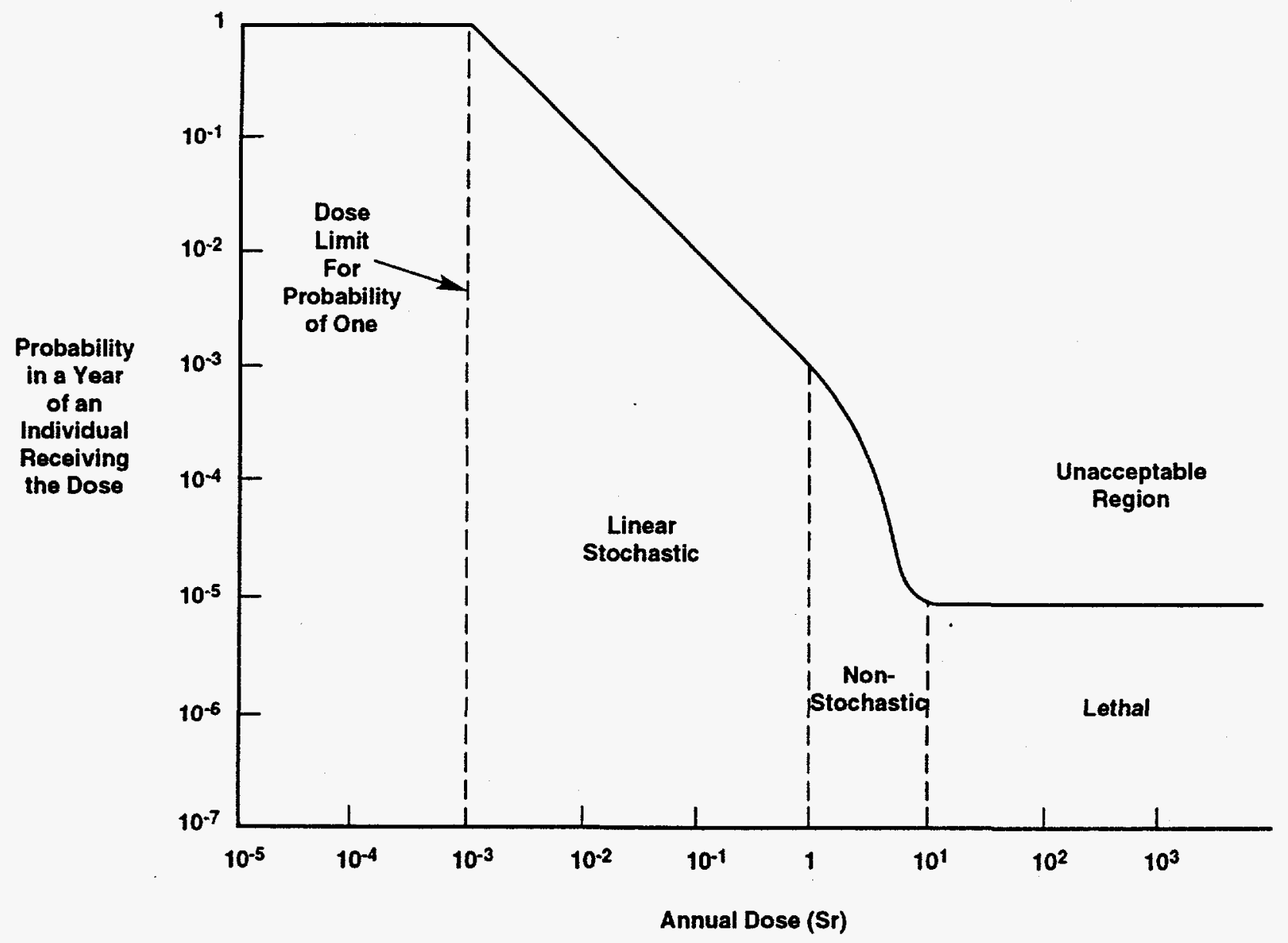

TA1-6334-145-0

Figure 20. Probability curve for an annual risk of less than $10^{-5}$ from all sources except natural and medical (Reference 4). 
designs, and site locations that are unacceptable. If the dose from any single event falls into the unacceptable region of the ICRP probability/dose plot, the disposal system is unacceptable. This curve cannot be used to show that a repository is acceptable.

When a probabilistic distribution of doses exists that reflects variability and uncertainty in modeling parameters and the variety of probabilistic events and processes, the risk is defined as the integral of this distribution [23]. Stated another way, risk is the consequence of an event or parameter variation, times the probability that the event or variation will occur, summed over all events or variations. This is the area under the consequence complementary cumulative distribution function (CCDF), as illustrated in Figure 21, where the risk of a single event or variation is represented by the shaded region. The advantage of using a risk limit is that the contribution of unlikely events which may or may not occur in the future can be taken into account in a straightforward and consistent manner.

Similar risk-type analyses could be used with SGD and CPD standards. These analyses would have fewer stochastic components than MID risk analyses. The critical group receiving the high total risk need not be found when computing risks to populations. When risks are integrated over long periods of time, as they are with CPD standards, the precise time the event occurs is less important, because the peak risk value is not computed. A modification of the risk approach can be used with multi-pathway derived standards. This procedure is defined in Sections 4.2.2.9 and 6.1 of Reference 12, and in Reference 47.

Low-probability events in a risk analysis could take place at any time. Because of the long exposure duration associated with most events, they could possibly be additive, and would almost certainly be added to the exposure from the normally emplaced waste. A probabilistic analysis would be required to define the distribution function of probabilistic peak individual risk. Comparing this probabilistic risk to regulating standards by assigning a threshold value to the probability of a preestablished dose level has been proposed. The Time of Event statistical problem could be greatly simplified for a subseabed risk analysis. Except for transportation accidents which would occur at a known time, there are few abnormal events that could affect risk. The effects of most of these events are so small that their peak risks could be added to peak risk from emplaced waste with only a very small overprediction of risk [2]. Only possible pore-water convection would have to be added stochastically.

\subsubsection{Secondary and Multi-attribute Evaluation}

A secondary criterion for optimization has been proposed by the ICRP [4] to address high consequence events that have probabilities low enough to meet risk criteria. The reason for using this secondary criterion is that events of very low probability have a large intrinsic uncertainty around the expected value of radiation impact, because any actual outcome will be substantially different than the expected value. For low probability events, the variation coefficient will be inversely proportional to the square root of the probability value [48]. This uncertainty will detract from the usefulness of the expected value in decision making. One secondary criterion suggested for low probability events is to limit the allowable probabilities of occurrence for specific high consequence levels. This is similar to the 


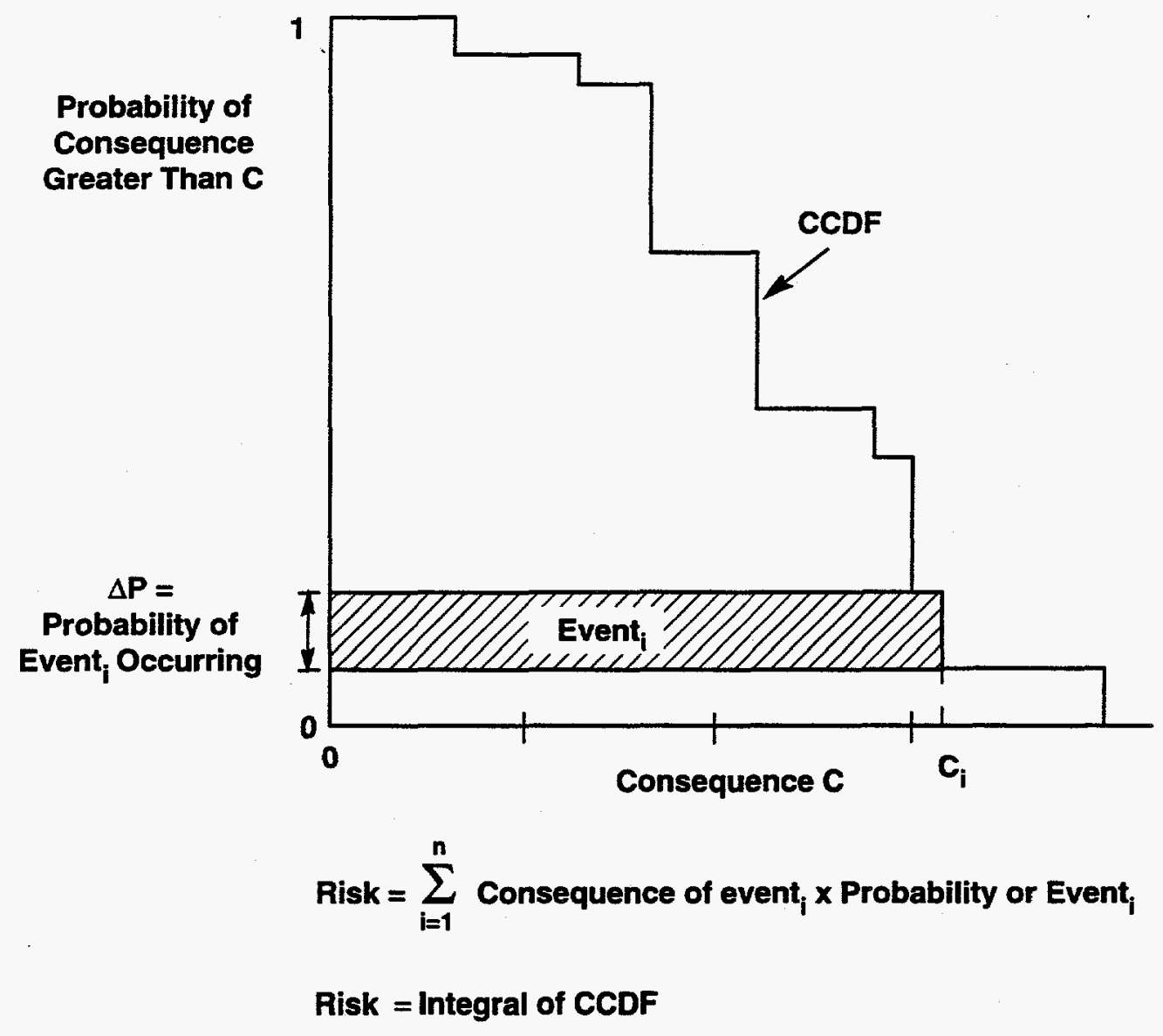

Figure 21. Graphical representation of risk. 
approach the US EPA uses to limit the collective risk CCDF for all probability and consequence levels for terrestrial HLW and TRU waste repositories.

High consequence, low probability events do not create the same relative risks to individuals, single generation populations, and collective populations. The use of all three types of standards as described in Section 3.2.1.4 increases the usefulness of PRAs in the decision making process. However, some real or perceived consequences may be unacceptable regardless of the probability. An example for subseabeddisposal would be the sinking of a very large disposal ship if there was no means of recovery available. Knowledge of this consequence could lead to prescriptive standards that would limit the quantity of waste on each ship and require recovery hardware and procedures before disposal begins. The magnitude of specific consequences as well as risk may be needed to evaluate the safety of a repository.

The SDP conducted risk analyses that predicted the detrimental health effects to individuals, single-generation world populations, and cumulative populations from all HLW disposal events. In addition to total risk, the consequences of all significant events and their estimated probabilities have also been presented. This approach is particularly suitable for the SDP because fundamental criteria have not been set. This also permits the analyses to be used with related standards for comparison with terrestrial disposal systems. Multi-attribute analyses would be beneficial during the feasibility phase of most waste disposal projects.

\subsubsection{Event Trees}

Processes in waste disposal that lead to risks can be separated into normal mechanisms with predictive exposure patterns in space and time, and random disruptive events, for which probabilities of occurrence, times of occurrence, and an exposure pattern can be postulated [48]. The normal releases are expected to occur slowly and after there has been significant decay of the radionuclides, while disruptive events can cause releases at any time and at any rate, with the consequences of some combinations of events are sequence dependent. The difficulties in direct application of event tree analyses to this type of risk assessment are caused by the very long time periods involved, and the randomness of the disruptive events.

In practice, the number of disruptive events, their timing, and the sequence combinations in event trees must be limited. The degree of simplification in the assumptions depends on the analysis time, realism behind the results, and the amount of uncertainty that can be tolerated for each disposal system.

\section{3:5.4 Exemptions and Cutoffs}

The use of exemptions and cutoffs in safety standards and risk assessments arises from the need to assign priorities so that limited resources are not wasted on trivial problems at the expense of major problems. Some materials with very low activities or procedures that produce very low risks are excluded from regulation. Even very efficient radioactive waste disposal systems would not fall into this category because of the high initial total activity and the perceived risk of anything radioactive. 
Regulations have been set that exclude events with very low probabilities or consequences from risk assessments. Events or sequences of events with mean probabilities of occurrence less than $10^{-7}$ per year are usually not considered. In 40 CFR 191 [3], the US EPA excludes collective individual events with a total probability of less than $10^{-3}$ in $10^{4}$ years $\left(10^{-7} / \mathrm{yr}\right)$ from the containment requirements. These exemptions apply to all repositories covered by the regulations. However, when unlikely exposure scenarios could contribute significantly to the potential detriment (catastrophic events), information should be presented separately on probabilities, individual doses, and collective doses for consideration in multi-attribute analyses [45].

Excluding individual risks below a certain level from collective risk assessments is a more complex problem, and a single level cutoff criteria cannot realistically be applied to all disposal systems. The same can be said for terminating analyses at some prescribed distance from the repository. The justifications for individual dose and distance cutoffs are similar to those for the exemption of some scenarios. When no individual dose cutoffs are used and large quantities of radioactive material are released, the dose footprints can become very large. This can lead to loss of computational accuracy caused by exceeding model capabilities and increasing pathway uncertainties. Atmospheric transport pathway uncertainty is more sensitive to process and parameter variations caused by large dose footprints than geologic transport pathways, and far more sensitive than oceanographic transport. Low individual dose cutoffs can greatly increase computational time for all types of repositories, which is an important consideration for PRAs.

The National Council on Radiation Protection and Measurements (NCRP) introduced the concept of a Negligible Individual Risk Level (NIRL) to determine when risk mitigation was warranted. It then extended this concept to collective risk assessments [49]. The NCRP recommended that assessments of increments of collective annual dose from any particular individual source or practice should exclude those individuals whose annual effective dose equivalent from such a source was 0.01 $\mathrm{mSv}$ or less. In Reference 50, the NCRP withdrew this statement as a formal recommendation, but pointed out that making an assessment of collective dose when individual doses are less than $0.01 \mathrm{mSv}$ may not be cost-effective. In this context, the value 0.01 is somewhat arbitrary. The Negligible Individual Dose (NID) should be evaluated for each application, and be based on modeling constraints, the cost of analysis as a function of cutoff, and the sensitivity of population dose to the individual dose cutoff.

As part of the Defense Programs Transportation Risk Assessment (DPTRA), a sensitivity study was conducted to define the effects of individual dose cutoffs on predicted collective latent cancer fatalities (LCF) for atmospheric releases of tritium and plutonium [51]. The variables included individual dose cutoffs from $10^{-8}$ to $10^{-3} \mathrm{~Sv}$ in decade increments, six atmospheric stability categories, fire driven and non-buoyant release modes for tritium, and fire driven and detonation release modes for plutonium. The quantity of release was $100 \mathrm{gr}$. for all cases.

Table 10 lists the underprediction factors relative to total collective risk for each cutoff level, radionuclide, and release mode, averaged over all stability categories. There is almost no difference in predicted risks in the lower cutoff range, and the difference relative to a $10^{-8} \mathrm{~Sv}$ cutoff is less than a $7 \%$ for plutonium and less than $57 \%$ for tritium with a $10^{-6} \mathrm{~Sv}$ cutoff. Figure 22 shows that the cutoff effect is exponential, and that collective risk predictions can be over a factor of 220 lower when an individual 


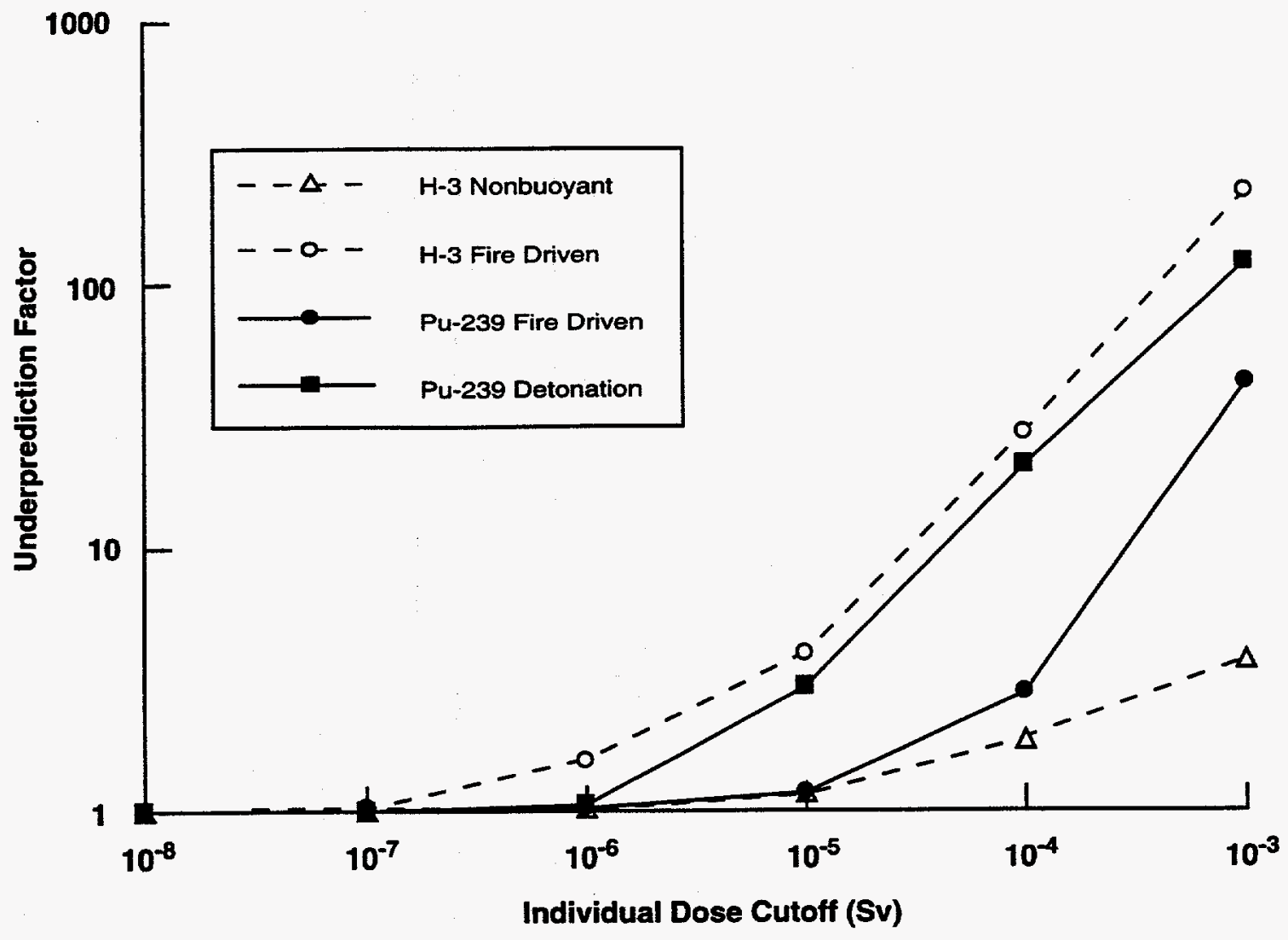

TRI-6342-4391-0

Figure 22. Effects of individual dose cutoff on predicted population doses for two radionuclides and three atmospheric release modes. 
Table 10. Underprediction Factors of Collective Doses vs. Individual Dose Cutoff

\begin{tabular}{|c|c|c|c|c|}
\hline \multirow{2}{*}{$\begin{array}{c}\text { Individual Dose } \\
\text { Cutoff (Sv) } \\
\end{array}$} & \multicolumn{4}{|c|}{ Radionuclide and Release Mode } \\
\hline & H-3 Nonbuoyant & H-3 Fire Driven & Pu-239 Fire Driven & Pu-239 Detonation \\
\hline $1.00 \mathrm{E}-08$ & 1.00 & 1.00 & 1.00 & 1.00 \\
\hline $1.00 \mathrm{E}-07$ & 1.01 & 1.04 & 1.00 & 1.00 \\
\hline $1.00 \mathrm{E}-06$ & 1.05 & 1.57 & 1.04 & 1.07 \\
\hline $1.00 \mathrm{E}-05$ & 1.18 & 3.95 & 1.19 & 3.00 \\
\hline $1.00 \mathrm{E}-04$ & 1.86 & 27.42 & 2.79 & 20.57 \\
\hline $1.00 \mathrm{E}-03$ & 3.78 & 226.59 & 42.17 & 121.95 \\
\hline
\end{tabular}

dose cutoff of $10^{-3} \mathrm{~Sv}$ is used. In this limited study, the underprediction factors for a $10^{-3} \mathrm{~Sv}$ cutoff varied by a factor of 25 with atmospheric stability, 60 with release mode, and 5 with radionuclide. Similar effects could be expected for radioactive waste disposal risk assessments, with different cutoff effects for each repository, radionuclide, pathway, and release mode.

Since the effects of individual dose cutoffs are nonconservative, and so nonuniform, it is unlikely that regulators or advisory groups should or will define an acceptable individual dose cutoff to be used in all collective dose risk assessments. If either distance or dose cutoffs are used in collective risk assessments, the level should be selected with sensitivity studies similar to the one described above to verify that the cutoff will produce acceptable results. If the use of low cutoffs makes the cost of analyses prohibitive or exceeds computational capabilities, correction factors could be applied to high cutoff assessments to obtain acceptable results. A single correction factor could not be used for all assessments; separate correction factors would have to be generated for each major parameter group.

\subsubsection{Implementation and Limitations of Probabilistic Risk Assessments}

Although probabilistic risk assessments are an essential part of any disposal system evaluation, it is important to keep in mind the limitations of PRAs, and that other types of analyses are more efficient for some parts of the evaluation. These limitations and alternatives can be reflected in regulatory requirements and in the latitude given to the analysts.

There are a number of decisions that have to be made during the planning stage of all risk assessments, which include:

- What results are needed and how will they be used?

- Will the results be used as design input, to direct research, or only to evaluate the system?

- Are comparative or absolute results needed, and what are the accuracy requirements?

- Will a deterministic analysis using best estimate and mean data be sufficient, or will bracketing or probabilistic analyses be needed?

- Will conventional or adjoint sensitivity studies be needed to quantify uncertainties and the consequences of approximations in the analyses? 
- Will an adjoint sensitivity analysis assure that the least and most favorable input parameters are used in bracketing analyses?

- Will a probabilistic assessment require simplifications, approximations, or incomplete analyses, and is the loss of accuracy acceptable?

- Which computer model(s) is(are) best suited for the assessment?

- How will a lack of component failure criteria, an incomplete set of models, or limited verification tests be handled?

- How will the absence of data or insufficient data to define statistical distributions be handled?

Failure to address all these questions can result in erroneous risk predictions and not providing the repository design team, regulators, and the public with the information they need. This part of risk assessment planning is analogous to the functional requirements phase of systems engineering, and is the joint responsibility of the analyst and the customer.

Deterministic analyses using best estimate and bracketing input parameters can be a useful way to begin large complex probabilistic risk assessments. They provide reference values to check the results of the PRA and show the net effects of the assumptions, simplifications, and estimated statistical distributions used only in the PRA. It is also useful to know the sensitivity of the results to variations in the dominant input parameters, approximations in event trees, and simplifications in the computational procedures that are made to facilitate the PRA. The results of sensitivity analyses can be used to estimate confidence bands, compute adjustment factors to compensate for simplifications, and decide which approximations are justified.

Balance in a risk assessments can be obtained by matching the quality of data to the thoroughness of the model and the consistency of methods and assumptions, and by doing the most thorough analyses on the parts of the assessment that have the largest effect on risk. Highly sophisticated models and intricate event trees add little to the assessment if the additional data and statistical distributions are not available and have to be estimated. Parts of a PRA that have little effect on the results or have poorly defined statistical input can be done deterministically, so more effort can be spent where the benefit is greatest. Where only macro output is needed, there is no need to do micro calculations. High level decisions that are not dictated by regulations are usually based on the predicted severity of events and mean risks, with possibly some concern given to the upper and lower bounds of risk.

There are several ways that variability and uncertainty are handled when presenting the total risk prediction from a PRA. Parameter variations have been used to compute separate CCDFs for each scenario [52,53]. This procedure results in a family of CCDFs that contain all the probabilistic risk information, but can be difficult to interpret. These CCDFs can be combined into a single risk CCDF or CDF [12] that summarizes the probabilistic risk of the disposal system.

There is a tendency to place an inordinate amount of faith in the final results of probabilistic analyses. Estimated input distributions can distort the actual risk distribution, and the simplifications needed to conduct the large number of computer runs in a PRA can bias the risk distribution. The distribution of the predicted risk is controlled by the distributions of the input parameters, which in most cases are estimates by the analysts based on past history or the opinions of specialists. Confidence bands 
on predicted risk distributions usually do not tell the whole story about the uncertainties in the assessment. They can only be calculated for computational uncertainty, which are often the only ones included in the results of PRAs. The confidence in human behavior, natural processes, and timing predictions are estimates based on historical evidence and expert opinion, and cannot be quantified analytically.

\subsection{Definition of Future States}

The risk attenuation of many repositories depends on parameters that could change significantly during the duration of regulation. Some of the more important future states used in the performance assessments could be standardized by specifying them in the standards. This would not reduce the uncertainties discussed in the previous section, but it would improve the consistency of risk assessments. Future state categories include changes in geology, hydrology, climate, biota varieties and populations, technology related to breaching and isolating the repository or pathways to humans, use of resources, human populations, demographic patterns, the human diet, sources of food and water, response to radiation, and medical technology. They include conditions and standard practices related to disturbed and undisturbed performance of the disposal system.

A reference biosphere, demography, and human characteristics should be defined in such a way that important individual site characteristics are not obscured, and compatibility with the standards and their derivations is assured. Except for world population, present processes and parameter values were assumed in the derivation and justification of the standards for terrestrial mined geologic repositories [44]. Therefore, it would be appropriate to continue assuming that the reference future states are essentially as they are today in other US radioactive waste disposal standards. The present demographic pattern could be retained by multiplying local populations by the ratio of the $10^{10}$ world population used in the EPA release-limit derivation to the present world population. Human characteristics such as physiology, nutrition, water use, technical and intellectual ability, medical resources, social structure, and values could be defined as they are today. Although the five basic release modes analyzed in the EPA derivation probably would still exist for mined geologic repositories, they would not all apply uniformly to all repository sites, and would not apply at all to subseabed repositories. Geologic and hydraulic risk attenuation are site specific, and it would not be appropriate to include them as part of the standards.

Predictions of most future events and scenarios require the identification of issues to be included in regulations followed by the systematic integration of the opinions of specialists in related fields. However, the process of "expert judgment" elicitation violates most principles of scientific analyses, and should be incorporated into safety standards and PA processes cautiously and with strict safeguards [54]. Even then, definitions of future states can only be treated as educated estimates.

The effects of changes in present day processes and parameters can be assessed with sensitivity studies and stochastic analyses covering ranges of climatic, geologic, and hydraulic conditions. Insensitivity to processes and the values of estimated data increases the confidence in risk assessments. Sensitivity studies can also quantify the effects that estimated events and scenarios have on the results of 
PAs. Risk assessments that require fewer or less significant future state predictions also have higher confidence levels.

Subseabed repository risk assessments are not as sensitive to future state predictions as terrestrial repository assessments. They do not depend on population sizes or distributions, because population doses are controlled by the harvest of aquatic food, which has a limited production rate, and individual doses are controlled by the maximum individual aquatic food consumption. Changes in climate or glaciation would have almost no effect on SD risks, so that is not a critical future state. The repositories would be in some of the most tectonically-stable locations on earth, and the ductile sediments are selfhealing, so geologic stability predictions are not critical. Human activities that would lead to repository intrusion would be almost nonexistent. Most other future states predictions that are important to terrestrial repositories are also important to subseabed repositories.

\subsection{Summary of General Radiological Protection Standards}

The different levels of criteria used to assure the safety of radioactive waste disposal systems are summarized in Table 11. Since there are no official regulations for SD and it is too early in the program to finalize lower level criteria, a segment of the Yucca Mountain project is used in this example. Only level one defines the acceptable risk, and only the top two levels apply to all repositories. The lower the level of the criteria, the more site and design specific they are. To have any radiological significance, all lower level criteria must be quantitatively or qualitatively traceable to the fundamental criterion. Levels 1 through 4 are set by regulators, and levels 5 through 7 are part of the formal systems engineering process. Criteria levels are discussed more thoroughly in Reference 12.

It is the purpose of the fundamental criteria to protect the populace, and therefore they should be based on acceptable risk rather than the projected capabilities of any class of repositories. The use of peak individual, peak single generation, and collective risk limits assures that all segments of the populace are protected. It is particularly important to carry all three types of fundamental criteria at least through the feasibility phase of disposal programs, because

- No single fundamental criterion assures protection of all groups, and the three criteria complement each other.

- The nuclide transport and risk models and most computations apply to all three criteria, so there is little added expense.

- It provides more information for design and research decisions.

- It allows comparison to other repositories, regardless of the criteria they use.

- It provides more information and more flexibility for evaluation of the disposal concept.

- It provides a more complete background for regulators when they develop the official standards.

- The assessments that are made during the feasibility phase will not have to be repeated after the official standards are promulgated. 
Table 11. Criteria Tractability Using the Yucca Mountain Project Thermal Design Requirements Branch as an Example

\begin{tabular}{|c|c|c|}
\hline $\begin{array}{c}\text { Criteria } \\
\text { Level }\end{array}$ & Criteria Category & Criteria Example \\
\hline 1 & Fundamental & $\begin{array}{l}\text { Level of allowable risk to the populace, US EPA } 40 \text { CFR } 191 \\
\text { [3] }\end{array}$ \\
\hline 2 & Dose & $\begin{array}{l}\text { Level of allowable dose, ICRP } 60 \text { [5] and US EPA } 40 \text { CFR } 191 \\
\text { [3] }\end{array}$ \\
\hline 3 & Derived & $\begin{array}{l}\text { Time-integrated radionuclide flux across repository boundaries, } \\
\text { US EPA } 40 \text { CFR } 191 \text { [3] }\end{array}$ \\
\hline 4 & Prescriptive & $\begin{array}{l}\text { Retrieval, containment, and groundwater travel time, US NRC } \\
10 \text { CFR } 60 \text { [54] }\end{array}$ \\
\hline 5 & $\begin{array}{l}\text { Functional } \\
\text { Requirements }\end{array}$ & $\begin{array}{l}\text { Dry canister, no spalling, no phase change, limit on fuel rod } \\
\text { failure, limit on surface condition change, limit on rock thermal } \\
\text { fracturing, and maintain human access to drifts }\end{array}$ \\
\hline 6 & $\begin{array}{l}\text { Design } \\
\text { Requirements }\end{array}$ & $\begin{array}{l}\text { Temperature limits on canisters, boreholes, drifts, and the } \\
\text { formation }\end{array}$ \\
\hline 7 & $\begin{array}{l}\text { Secondary Design } \\
\text { Requirements }\end{array}$ & $\begin{array}{l}\text { Areal power density, repository layout, inventory, ventilation } \\
\text { cooling, and ventilation drying }\end{array}$ \\
\hline
\end{tabular}

Official criteria below level 2 are not needed during the feasibility phase of a waste disposal program. It is also risky to set the lower level criteria before the site is selected, the design concept is completed, and all the data are available.

Derived standards are requirements placed on the performance of components or processes in the disposal system, or on the flux or concentration of radionuclides at locations along pathways from the waste site to humans. The purpose of derived standards is to facilitate regulation, control, and monitoring. Derived standards are only applicable to the specific sites and repository design that they were derived for. They must be quantitatively traceable to the fundamental criteria so they do not distort the intent of the safety requirements. To accomplish this, they must cover all possible source locations, during and after emplacement, and include all pathways for the specific repository system.

Quantitative design criteria (levels 5 through 7) can be set more efficiently by repository systems engineers than by regulators, and only after all the input information is available. Design criteria that are set by organizations that are not involved in the design, or that are set too early in the program, can create detrimental design constraints and prevent system optimization. In addition, the system could be bound by requirements that are impossible to meet, even though overall risk and dose limits can be achieved [32]. 


\section{STANDARDS USED IN THE 1983 AND 1987 FEASIBILITY ASSESSMENTS}

The radiological standards used during the 1983 and 1987 SDP feasibility assessments [1,2] were selected by members of the SWG to aid in evaluating the concept, and had no regulatory or legal status. The development of interim standards for the feasibility phase of the SDP did not begin until after the 1983 assessment was completed, and only the background phases of the project $[10,11]$ were completed prior to the 1987 assessment. Without sufficient guidance from the standards development study to set new interim standards specifically for the SDP, existing recommendations and criteria for other types of disposal were adapted for use in the SDP assessments. ICRP recommendations [4] were the bases for MID limits, and the US EPA criteria for terrestrial repositories [3] were the bases for CPD limits. No related SGD or aquatic biota criteria existed, so single generation and biota doses were computed, but not compared, to any interim standards. Since there were no official criteria for SD, the interim standards were treated as goals in the design requirements for the repository, penetrator, emplacement ship, and port facility. Except for limits on radionuclide fluxes across component boundaries and on the ocean burden that were used to facilitate a few sensitivity and attenuation factor analyses, derived standards have not been used by the SWG or the SDP. The derived limits used were traceable to the fundamental and dose criteria. They had limited application, were never used to evaluate feasibility, and are not presented in this report. Prescriptive standards are not appropriate for the feasibility phase of a program. The assessments made during this phase of the program provided information that can be used to develop prescriptive criteria for the design, fabrication, and operational phases of the SDP.

The first two performance assessments were required to cover all possible inventories and source locations from the port to emplaced waste in the repository. All potential pathways to humans were included in the initial assessments. These were

- Aquatic food pathways, including the food chain and direct exposure of aquatic food from the ocean. The aquatic food included surface and mid-depth fish, crustaceans, mollusks, and seaweed.

- Ingestion of desalinated water.

- Ingestion of sea salt.

- Inhalation of shore sediments and sea spray.

- External exposure to water and sediment through swimming, boating, and walking.

- Evaporation of gaseous radionuclides from the ocean and precipitation on the continents, followed by external exposure, inhalation, and ingestion.

Even though most of the risk assessments during the early part of the feasibility phase were done deterministically, the risks predicted for pre- and post-emplacement abnormal man-made and natural events were added stochastically to those from an undisturbed repository to predict total risk. The results of PRAs were evaluated by two methods. One approach integrated dose and LCF CCDFs, and the resulting risks were compared directly to dose and risk criteria. The other approach was to record any fraction of the CCDFs that exceeded allowable levels. Prior to 1990, the ICRP recommended a linear relationship between dose and latent cancer fatalities (LCF) with $1 \mathrm{~Sv}=10^{-2} \mathrm{LCF}$. This relationship was used in both interim feasibility assessments.

Because of the low probability of abnormal events that could have adverse effects on a subseabed repository, and the low sensitivity to those that could happen, the risk assessment could be 
continued through the time of peak dose rate from an undisturbed repository with little reduction in the confidence of the predictions. The time of peak dose would be about $1.5 \times 10^{5}$ years after disposal. There would be almost no risk before $10^{4}$ years, so any assessment of subseabed disposal that terminated at that time would be meaningless. Therefore, the duration of regulation used in the EPA fundamental criterion for terrestrial repositories had to be extended for the subseabed standards.

\subsection{Standards for Peak Dose Rates to Maximally Exposed Individuals}

ICRP Publication 46 [4] contains the recommendations of the ICRP during the time of the 1983 and 1987 SDP feasibility assessments. The ICRP recommended that individual risk limits should be applied to the group that would receive the greatest exposure. The habits, characteristics, and location of the group should be based upon present knowledge using cautious, but reasonable assumptions. Since aquatic food ingestion was found to be the dominant cause of risk from subseabed disposal of HLW, Japanese fishermen with their diet high in aquatic food were selected by the SWG to be the critical group for individual risk.

The ICRP concluded that average annual risks to any individual from all events associated with radioactive waste disposal greater than $10^{-5}$ per year would be unacceptable. The corresponding average annual dose over a lifetime would be $10^{-3} \mathrm{~Sv} / \mathrm{yr}$. The ICRP MID limit is an absolute value that applies to all repositories, so a lower level must be set for each repository. The SWG selected one tenth of the ICRP dose limit $\left(10^{-4} \mathrm{~Sv} / \mathrm{yr}\right)$ as the dose limit for a single $10^{5} \mathrm{MTHM}$ subseabed repository. The Commission defined risk as the consequence of an event multiplied by the probability of the event occurring, summed over all events. This definition was used by the SWG. The MID limit was applied at the time of peak individual dose, which was about $1.5 \times 10^{5}$ years after emplacement.

\subsection{Standards for Collective Doses to the World Population}

The US EPA fundamental collective risk criterion does not follow the protection philosophy adopted by the ICRP, and applies only to terrestrial repositories, but it was the only collective criterion in use at the time of the SDP interim feasibility assessments. The SWG did not agree with the philosophy of the EPA criterion, but used a modified form of the EPA criterion to facilitate comparison of subseabed disposal to US terrestrial disposal systems. The EPA criterion is not a measure of absolute risk, because it is a risk/benefit standard, e.g., it allows risk to be proportional to the amount of waste placed in repositories. It is also not based on acceptable risk, but the estimated level of risk attenuation that could be provided by several hypothetical terrestrial mined geologic repositories.

The fundamental collective EPA criterion for spent fuel and HLW repositories allows no more than $10^{3}$ premature deaths during the first $10^{4}$ years from the disposal of waste from $10^{5}$ MTHM [3]. As will be shown in the next chapter this is an extremely conservative limit. Since there is no limit on single generation population risks during the duration of regulation, the criterion effectively limits collective dose to an average of no more than $10^{-4}$ Person-Sv/yr-MTHM. The EPA criterion only requires collective risk analyses to include the first $10^{4}$ years after emplacement, and does not require the analyses 
to include the duration of peak risk rates. However, a feasibility assessment that does not include peak risk from an undisturbed repository would not be a true evaluation of the risk attenuation of the repository. this is particularly true for a subseabed repository that has low probabilities of abnormal events and high confidence in long duration risk analyses. The SWG version of the EPA collective risk criteria used the EPAs average CPD rate multiplied by the duration of analyses. SDP assessments of CPD were carried out to $10^{7}$ years after emplacement, but it was found that the most stringent collective criteria occurred at approximately the time of peak population risk rate, which was about $10^{5}$ years after emplacement (Figure 19). The $10^{5}$ year CPD limit used by the SWG was 10 Person-Sv/MTHM.

Subseabed collective PAs have almost no dependence on future state predictions. Since the dominant pathway is aquatic food consumption, conservative analyses can be based on the maximum harvesting of aquatic food that does not deplete the species.

\subsection{Comparison of 1987 Preliminary SDP Risk Assessment with the 1987 Interim Standards}

The status of the SDP performance assessment after the second of the three planned iterations in the feasibility phase can be summarized as follows:

- Basic transport models from emplaced waste to humans are complete. Accurate predictions can be made with analytic and relatively simple numeric models.

- Sensitivities of all known input variables are defined.

- AF analyses indicated subseabed disposal is resilient to component malfunctions, and has low sensitivity to changes in most parameters.

- Interim risk assessment predict large margins of safety with conservative standards.

- Risk- and sensitivity-based functional analyses have led to penetrator and emplacement ship conceptual designs that meet cost and safety requirements.

- Sites with greater than $0.1 \mathrm{~mm} / \mathrm{yr}$ vertical pore water movement would be unacceptable, and sites with dislocations may be unacceptable.

- Sites have been found in the Atlantic and Pacific that passes initial screening tests.

- Transport properties of all sediments tested indicate that ocean sediment is an effective barrier.

- A waste package can be built that will survive long enough for recovery following an accident and during the thermally active period following disposal.

However, the technical feasibility study is not complete, and there are still some uncertainties in the SDP performance assessment. These uncertainties emanate from the following:

- The database is not complete.

- All transport-related processes may not be known.

- Theories for all observed transport and biological processes are not completely developed.

- Biological and ocean models may have to be refined.

- Probabilities of abnormal events are not known.

- Probabilistic risk analyses are based on estimated distributions because of data limitations.

- A method of retrieving emplaced canisters has not been completely developed. 
- Site requirements are not finalized.

- Disposal sites are not completely characterized.

- Models are verified, but not validated with field tests.

- Standards to evaluate risks to biota have not been developed.

The feasibility phase of the program is far enough along that comparison to interim standards are meaningful. Figure 23 compared the results of individual dose predictions conducted with three levels of input parameters to the $1987 \mathrm{MID}$ limits. Even assuming the least favorable parameter values, the margin of safety for one 105 MTHM repository would be about four orders of magnitude. Figure 24 compares collective population dose predictions with the 1987 CPD limits. When there are no inflections in the dose curves, the most conservative time of evaluation is when the slope of the dose curve is one. Table 12 shows that all margins of safety are positive for all three data levels and both interim standards. The risk/benefit CPD margins of safety do not depend on the repository size, but the MID margins of safety do depend on the repository size. All margins of safety are larger when MID limits are used, but the difference decreases as the quantity of waste increases. All analyses to date indicate that subseabed disposal would be a safe and economical method of HLW disposal, and that predictions could be made with a high degree of confidence.

Major physical and biological pathways to humans have been identified.

Table 12. Margins of Safety for a $10^{5}$ MTHM Repository using 1987 Limits

\begin{tabular}{|c|c|c|}
\hline Data Level & $\begin{array}{c}\text { Peak Individual } \\
\text { Dose }\end{array}$ & $\begin{array}{c}\text { Collective } \\
\text { Population Dose }\end{array}$ \\
\hline Most Favorable & $1.0 \times 10^{9}$ & $1.2 \times 10^{8}$ \\
\hline Best Estimate & $1.9 \times 10^{5}$ & $4.6 \times 10^{2}$ \\
\hline Least Favorable & $1.4 \times 10^{3}$ & 1.9 \\
\hline
\end{tabular}




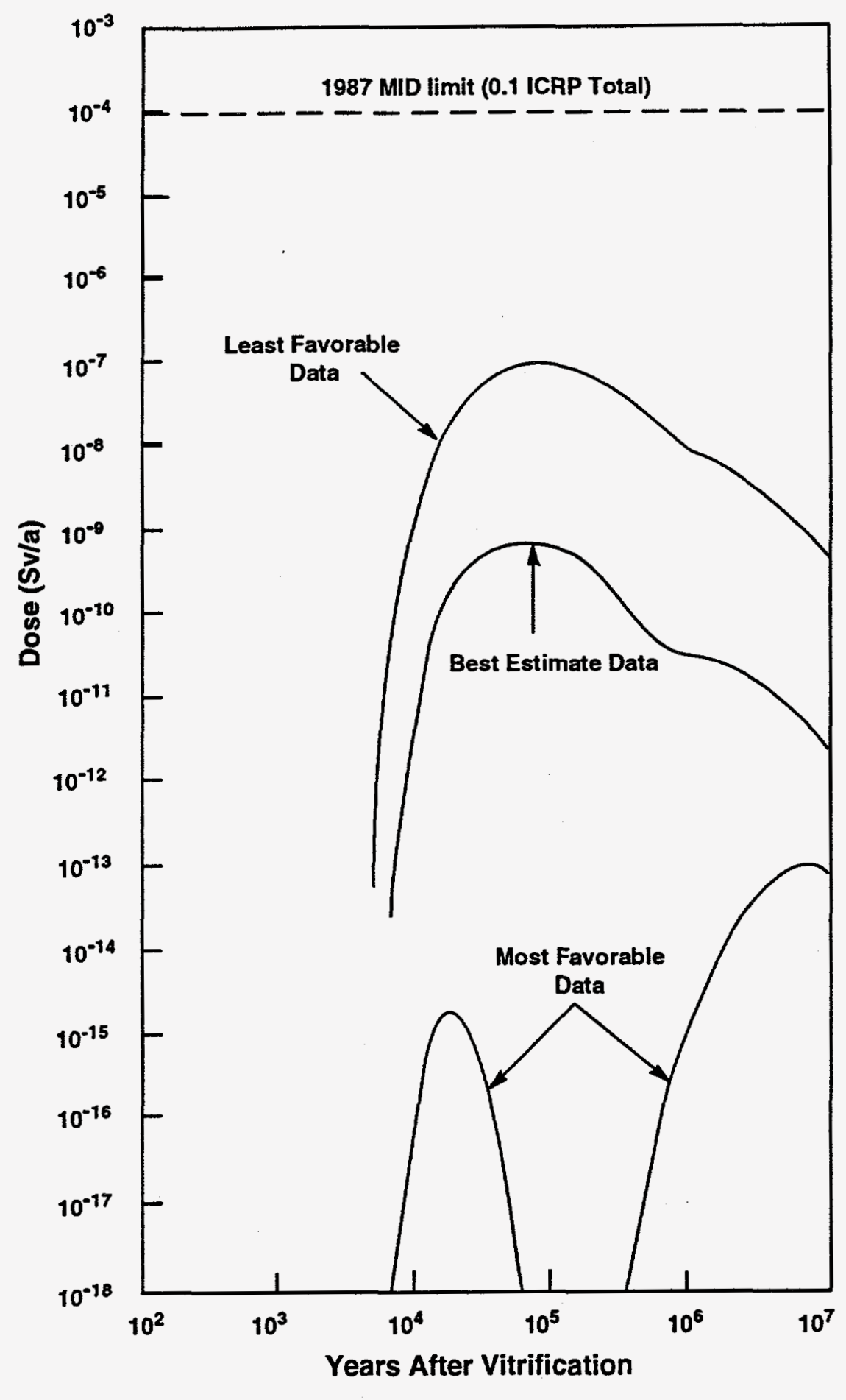

Figure 23. Doses to the Maximally Exposed Individual from a $10^{5} \mathrm{MTHM}$ Subseabed Repository. 


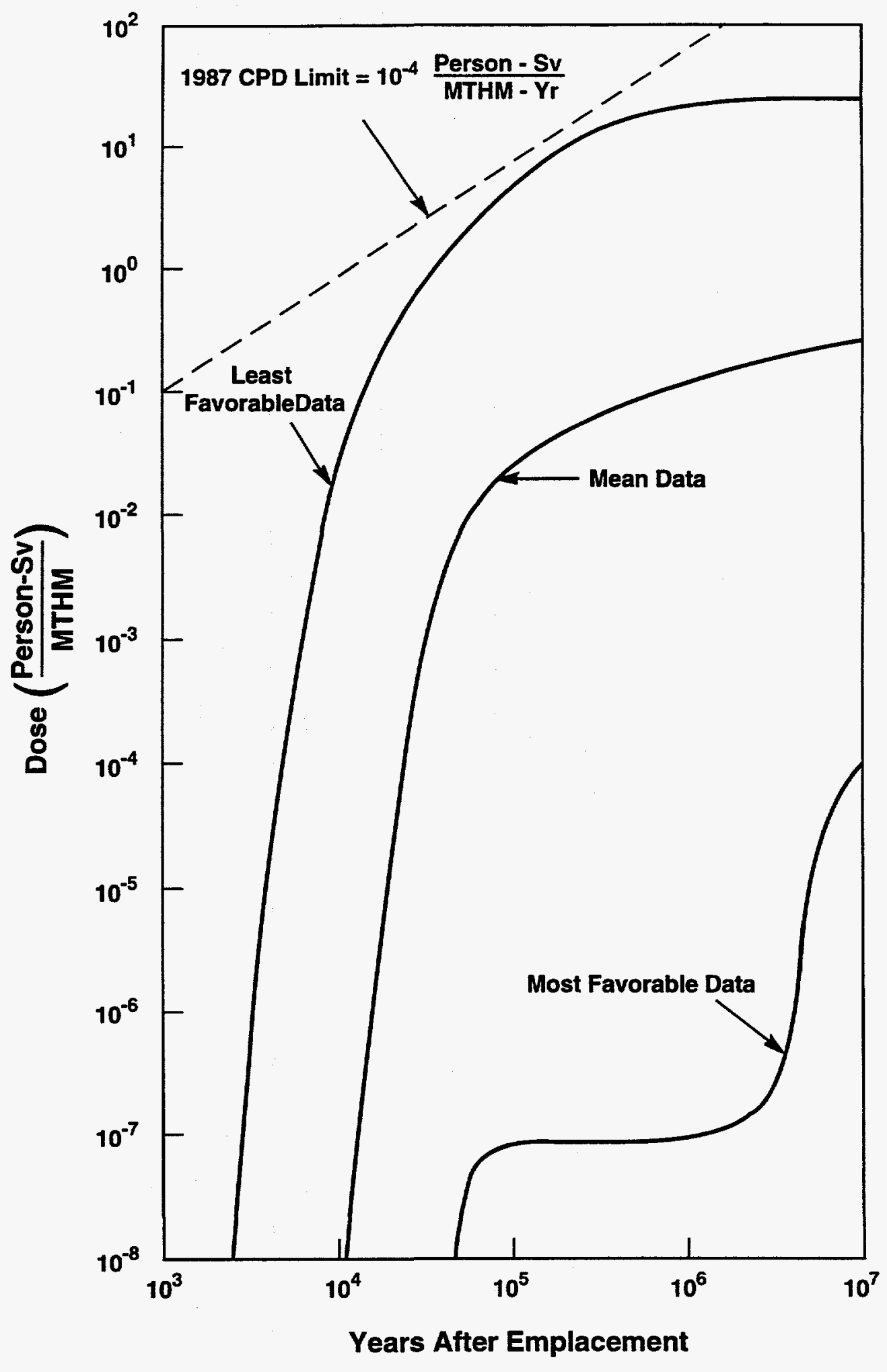

TRI-6342-3839-0

Figure 24. Collective Population Doses per MTHM from a Subseabed Repository. 


\section{RECOMMENDED STANDARDS FOR THE REMAINDER OF THE FEASIBILITY PHASE OF THE SUBSEABED DISPOSAL PROJECT}

This chapter is the culmination of a three-part program to select interim radiological standards for the SDP feasibility assessment. As with all standards used during the feasibility phase of the SDP, these standards have no regulatory or legal status. Furthermore, since Radiological Assessment Task Group (RATG) activities have been suspended, these standards have not been sanctioned by the SWG and are only the recommendations of the author. The purpose of these standards is to help evaluate the radiological, technical, and economic feasibility of the seabed disposal concept, rather than to certify the acceptability of a specific repository. They would be used as goals in sensitivity studies, to establish functional requirements for the design of repositories, in system tradeoff studies, guidance for research, and finally to select the best SD option and compare it to other disposal concepts. These standards are based on reasonable safety requirements and are not influenced by the capabilities of any disposal system. Some regulatory philosophies and dose levels are referenced that have been recommended or are being used in regulations. Several new regulatory options are presented along with rationale that can be used to select an option. Approaches are suggested for setting risk levels, and levels are recommended for the remainder of the SDP feasibility phase.

\subsection{Dose Standards for Subseabed Disposal of High-Level Waste}

There are several compelling reasons to use all three of the dose standards defined in Section 3.2.1 to evaluate risks to humans for the feasibility phase of any radioactive waste disposal system. For the SDP, the reasons are:

1. It is the only way to assume that all individuals and population groups are protected.

2. It is the best way to find any flaws in the disposal concept, reference site, or reference repository design.

3. They encompass all existing recommendations and regulations so it is easier to compare SD with other disposal concepts.

4. They provide the maximum input to research and design during all phases of the program, and to regulatory agencies during the design, production, and operation phases.

5. Since the SDP models can compute individual, single generation, and collective population doses simultaneously, and since all three should be computed through the time of peak dose, there is little added expense.

6. It is more economical to do all the calculations at once than to determine acceptability with one dose standard, and then optimize with a different dose standard at a later time. 
A uniform set of assumptions and constraints were used to develop all three dose standards. Although some may differ from those used to develop related standards, the uniformity was necessary for consistent evaluation of SD feasibility. The assumptions are:

- The nominal fatality probability coefficient of $1 \mathrm{~Sv}=5 \times 10^{-2}$ LCF taken from ICRP 60 [5].

- There is a liner dose/HE relationship even at very low dose rates, which may be conservative.

- A constant world population of $10^{10}$ is used [44].

- The average life span is 70 years.

- Dose scales linearly with the quantity of waste.

- The MID limit is applied at the time of peak individual doses.

- The SGD limit is applied at $t$ he time of peak world population doses.

- The duration of the CPD limit is from the time of emplacement to the time when the time averaged world population dose rate peaks.

- Doses to the maximally exposed individual is based on the aquatic food intake of Japanese fishermen.

- Maximum world population doses is based on maximum harvest rates without species depletion.

The limits are absolute and do not depend on the quantity of waste. A fraction of the total limits is apportioned to each repository. One tenth is the fraction allocated for a $10^{5}$ MTHM repository. A second risk/benefit CPD limit is presented to facilitate comparison to terrestrial repository PAs that use US EPA criteria.

There is insufficient information to set dose limits for aquatic biota at this time. An international panel concluded it was only necessary to show that SD will not cause any species to become extinct or disrupt any significant food chain [11]. This is the requirement assumed in the feasibility assessment.

Each of the proposed dose standards are compared to dose predictions from the 1987 interim feasibility assessment. The dose predictions were made with best estimate data and bracketed with predictions using least favorable and most favorable data.

\subsubsection{Maximum Individual Dose Standards}

The latest ICRP recommendation [2] is that the MID should not exceed 10-3 Sv/yr from practices such as waste disposal for continuous lifetime exposure. For the currently recommended nominal fatality probability coefficient of $\mathbf{0 . 0 5}$ latent cancer fatalities per Sievert, the allowable annual individual risk would be $5 \times 10^{-5}$ and the lifetime risk would be $3.5 \times 10^{-3}$. Most other advisory groups and regulating agencies have been accepting the ICRP's recommendations on MID limits. It is recommended that the SDP continue to use ICRP MID limits and apply them to the maximally exposed group at the time of peak dose, which is approximately $10^{5}$ years after emplacement. 


\subsubsection{Maximum Single Generation Dose Standards}

The values used in the following options may not be exact for all SD repository systems, but they are used consistently to show the relative levels of protection offered by the various options. A projected world population $\left(\mathrm{P}_{\mathrm{w}}\right)$ of $10^{10}$, a regulatory time $(\mathrm{R})$ of $10^{5}$ years, and an average life span $(\mathrm{L})$ of 70 years are used in all examples. Other parameters are defined as the options are developed. The resulting limits are within the ranges usually suggested for the regulation of carcinogens.

There are several methods that could be used to set limits for a single-generation dose-rate limit for HLW disposal. One would be to take some fraction of the annual background radiation to the world population, which is approximately $1.2 \times 10^{7}$ person Sv/yr. The SGD could also be based on some allowable average lifetime risk to the world population. Assuming a one-in-a-million $\left(10^{-6}\right)$ average lifetime risk is acceptable, the allowable SGD would be about $2.9 \times 10^{3}$ person Sv/yr or approximately a factor of 4,000 lower than the total annual background dose.

If the ICRP maximum individual dose limit of $0.001 \mathrm{~Sv} / \mathrm{yr}$ is valid for population sizes less than some value (V), and individual risk to larger populations is inversely proportional to the square root of the population at risk as suggested by Milvy [11], the MID equation for large populations would be of the form

$$
M I D_{L}=\frac{K}{\sqrt{P}}(S v / y r)
$$

where the constant

$$
K=0.001 \sqrt{V}
$$

The lifetime individual risks corresponding to equation 2 with a $V$ of 10,000 ( $K$ of 0.01 ) is plotted in Figure 25 for large populations along with the ICRP limit for small populations. This limit falls between the traditional de minimis (below regulatory concern) and de manifestis (obvious regulatory concern) regions defined by Travis and Richter [11]. Assuming the dose defined by equation 2 would be acceptable for the entire population at risk, and multiplying by the world population, the SGD would be

$$
S G D=K \sqrt{P_{W}}(\text { person } \cdot \mathrm{Sv} / \mathrm{yr})
$$

or $10^{-4}$ person.Sv/yr (a factor of 1,000 lower than background). If either of the SGD limit options would be applied at the time of peak dose, as the ICRP recommends for individual doses, the incremental dose levels should be acceptable to future generation. It is recommended that a SGD limit of $10^{4}$ person Sv/yr be used for the remainder of the SD feasibility phase.

\subsubsection{Collective World Population Dose Standards}

It is not very likely that acceptable individual risks would be inversely proportional to the square root of the entire world population over the next $10^{5}$ years and this ratio may not be as valid for future generations as it is today. However, it will be used to illustrate a possible approach for an absolute SPD 


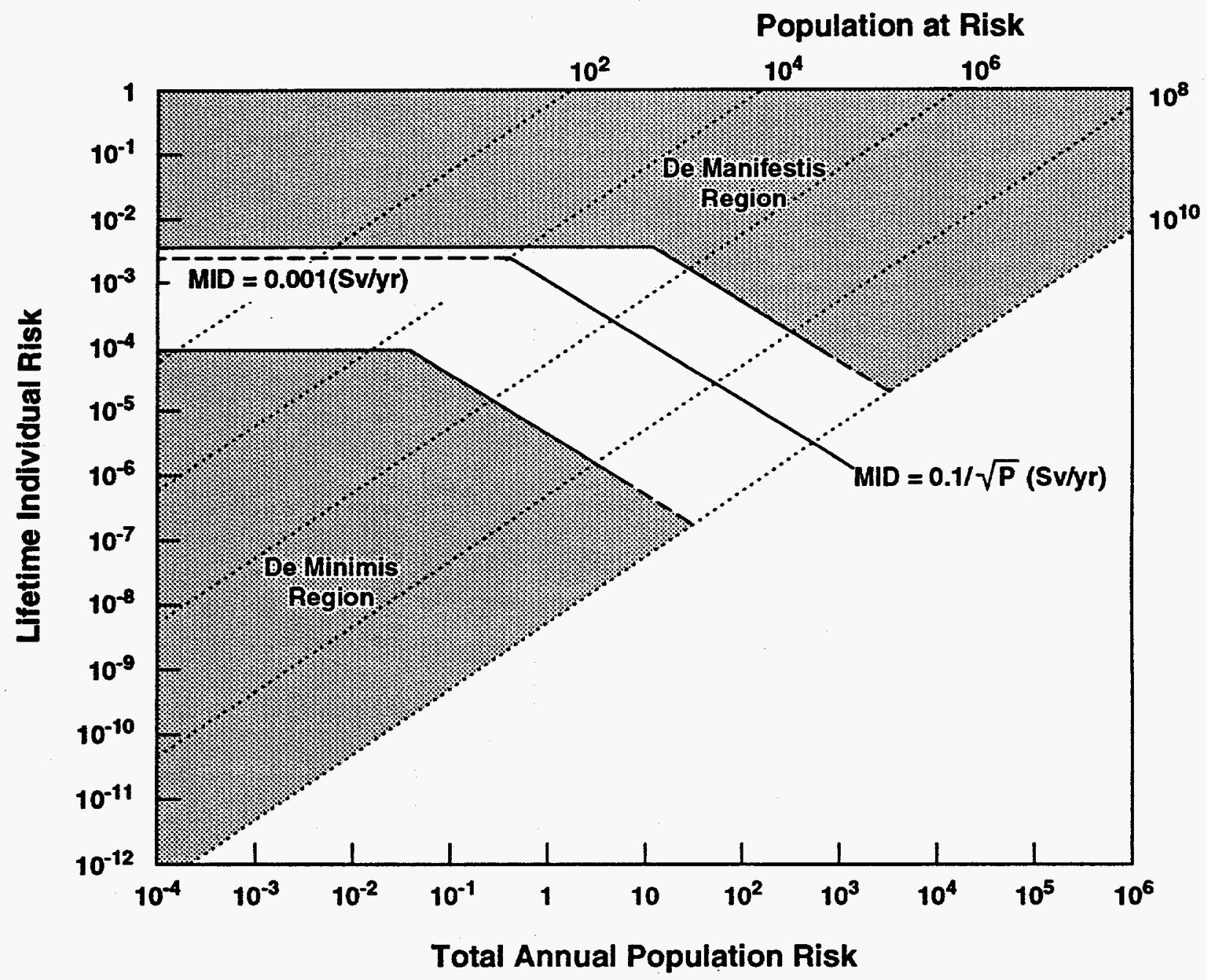

TRI-6341-135-2

Figure 25. Comparison of a proposed MID limit when large populations are exposed, with regulating agencies traditional de minimis and de manifestis risk levels for chemical and radiological carcinogens. 
limit. The potential number of people at risk for CPD criteria would be PW (1010) multiplied by R (105) divided by $\mathrm{L}(70)$. By using this population in equation 2 and multiplying the result by the world population and the duration of regulations, the CPD limit would be

$$
C P D=K \sqrt{L \times P_{W} \times R}(\text { person } \cdot \mathrm{Sv})
$$

or $2.7 \times 10^{7}$ person. $\mathrm{Sv}$ for the reference parameters. This is an average annual individual risk of about $10^{-9}$, which is very conservative.

To be consistent with the risk philosophy used for the MID and SGD recommended limits, the time duration of the CPD limit should be set to produce the maximum average population dose rate. The maximum can be found by integrating the population dose rate to incremental times after emplacement and dividing by the time. Figure 26 shows the average population dose rates for the entire range of input levels. The peak rate with the best estimate parameters is slightly over $10^{5}$ years after emplacement. There is less than a factor of two difference in the peak individual, world population, and average population dose rates. This is because of the relatively fast mixing time in the oceans and the long time that dose rates are near peak levels.

The fundamental risk/benefit CPD criterion used by the EPA to develop the release limit sin 40 CFR 191 [4] requires that there will be no more than 1,000 excess cancer deaths over the next 10,000 years from disposal of wastes from $10^{5}$ metric tons of heavy metal (MTHM). This is an average dose rate to the world population of $2 \times 10^{-5}$ person-Sv/yr-MTHM. This risk level was based on estimated achievable risk attenuations of generic terrestrial repositories rather than on acceptable risk. If the regulation time for this fundamental criteria is extended to $10^{5}$ years to include the times of peak dose rates, this CPD limit would be 2 person.Sv/MTHM with the same average allowable risk at 40 CFR 191 . It would take $1.3 \times 10^{7} \mathrm{MTHM}$ (approximately 130 repositories) using the risk/benefit criterion to equal the risk allowed by this absolute criterion from equation 5 , demonstrating that the EPA fundamental criterion is extremely conservative.

It is recommended that the interim CPD limit be set at $2.7 \times 10^{7}$ person.Sv with a duration of $10^{5}$ years. If future analyses show that the reference parameters used to develop this limit are not valid, the limit could be changed using equation 5 . A secondary CPD limit of 2 person-Sv/MTHM with a duration of $10^{5}$ years could be used for comparison to US terrestrial repositories. However, if a risk/benefit CPD standard is ever developed as official SD criteria, they should be based on a realistic acceptable risk, rather than the estimated performance of a group of disposal systems.

\subsubsection{De Minimis Options for SGD and CPD Limits}

The approaches discussed above may result in unnecessarily low allowable individual risks when large populations are involved. A uniform de minimis individual risk could be applied to all criteria categories to make them more reasonable. Table 13 compared the SGD and CPD limits from equations 4 


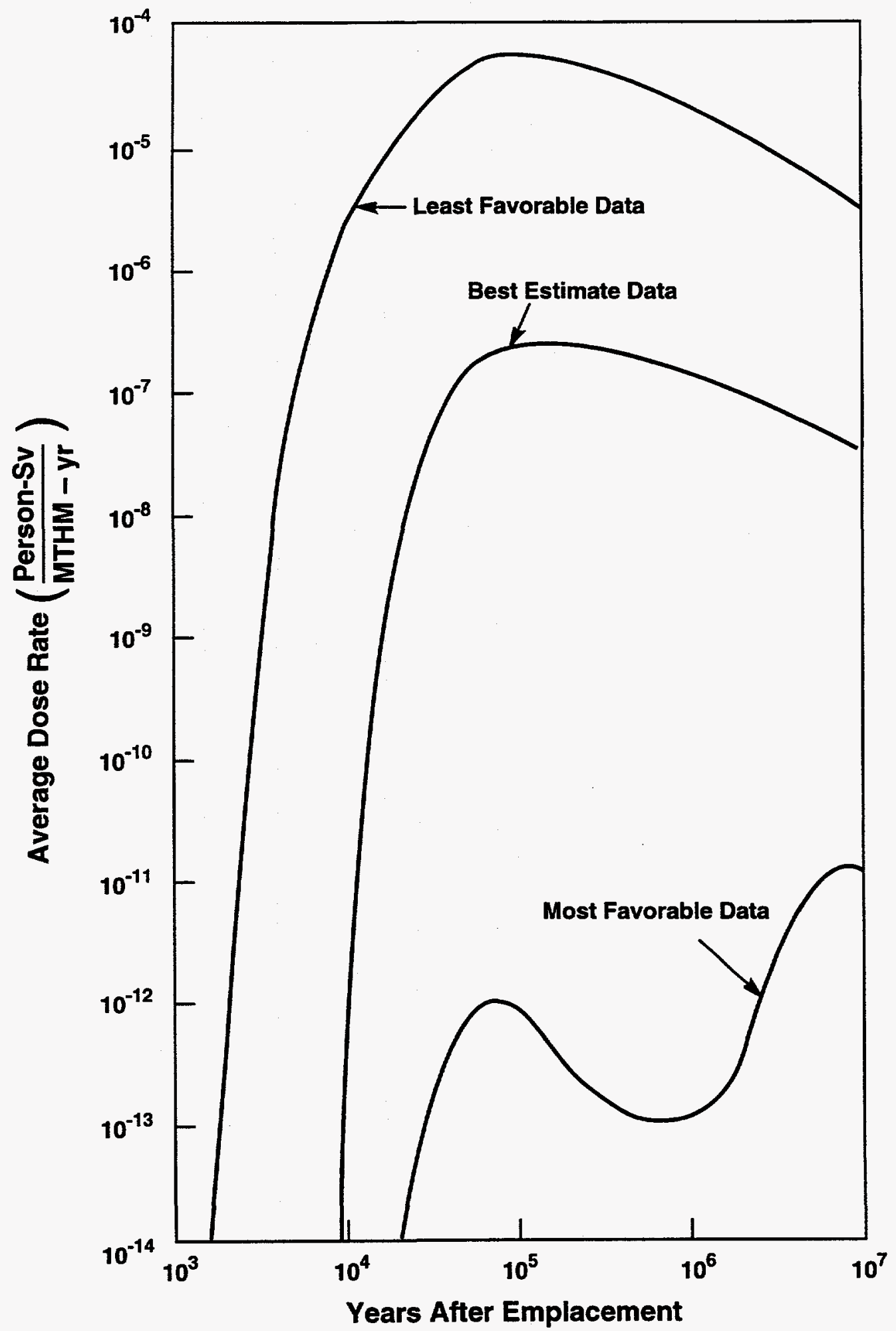

TRI-6342-3840-0

Figure 26. Time-averaged world population dose rate from the time of emplacement to the time on the abscissa. 
Table 13. Comparison of SGD and CPD Limits using the Reference Parameters

\begin{tabular}{lcccc}
\hline \multicolumn{1}{c}{ Criteria Category } & Equations 4 and 5 & & De minimis \\
\cline { 1 - 1 } Single Generation Dose (Person $\cdot S v / y r)$ & $10^{4}$ & & $2 \times 10^{4}$ \\
Collective Population Dose (Person $\cdot S v)$ & & $3 \times 10^{7}$ & & $2 \times 10^{9}$ \\
\hline
\end{tabular}

and 5 with those based on a de minimis individual risk of $10^{-7}$ per year. The difference could have a significant effect on the feasibility and cost of radioactive waste disposal. De minimis risk levels are thoroughly covered in Reference 11 .

\subsubsection{Biota Dose Standards}

The SD standards panel concluded it was only necessary to show that SD will not cause any species of biota to become extinct or disrupt any significant food chain [11]. This could be accomplished by limiting doses to populations, with no limits on individual biota doses. Since not enough is known at this time to set absolute levels on allowable doses, some small fraction of local background would be a conservative limit. Background radiation is known in most areas, and the incremental increase in radiation from SD is computed for each model compartment. The fractional dose from SD can then be computed. This is the biota dose evaluation procedure used in the feasibility assessment.

\subsubsection{Comparison of Preliminary SDP Risk Assessments with the Recommended Standards}

Two methods are used to compare the recommended standards with the predicted performance of the reference subseabed disposal system. The first is the most conventional, and compared each of the three standards with the corresponding predictions that were computed using best estimate, least favorable, and most favorable input data. For this comparison it is assumed that one tenth of the recommended limit is allocated to each $10^{5} \mathrm{MTHM}$ repository $\left(10^{-6}\right.$ of the limit for each MTHM). The margins of safety were positive with all standards and all data levels. The largest margins of safety were for individual doses and the smallest were for collective population doses. Figures 27, 28, and 29 show the MID, SGD, and CPD predictions as a function of time for the first $10^{7}$ years after emplacement. When the peak and integrated dose rates are evaluated using the recommended standards in Sections 5.1.1 through 5.1.3, the margins of safety range from $10^{9}$ for MID with most favorable data to 6 for CPD with least favorable data. If the CPD limit is based on the individual de minimis level as defined in Section 5.1.4, the smallest margin of safety for CPD with least favorable data would be 410 .

Since the recommended standards define absolute limits that cover doses from all repositories, it is possible to evaluate a disposal system by computing the total quantity of waste that the system can handle and then comparing that quantity with predicted total waste projection. Table 14 gives the information necessary to compute subseabed disposal capacity for best estimate data and all three recommended standards. Based on the MID standard, two million, $10^{5}$ MTHM repositories could be 


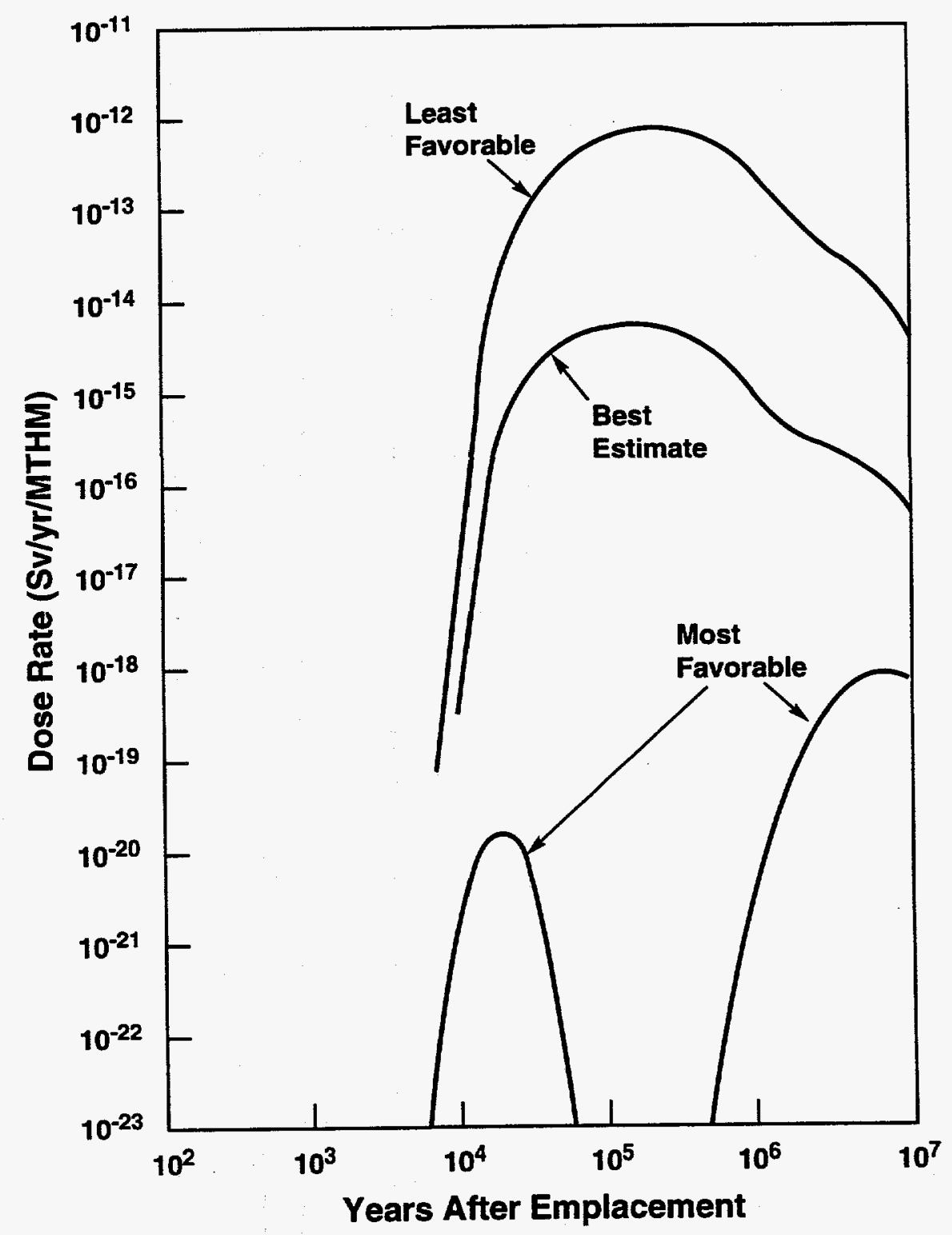

TRI-6342-3816-0

Figure 27. Dose rates to the maximally exposed individuals from HLW emplaced in deep ocean sediments. 


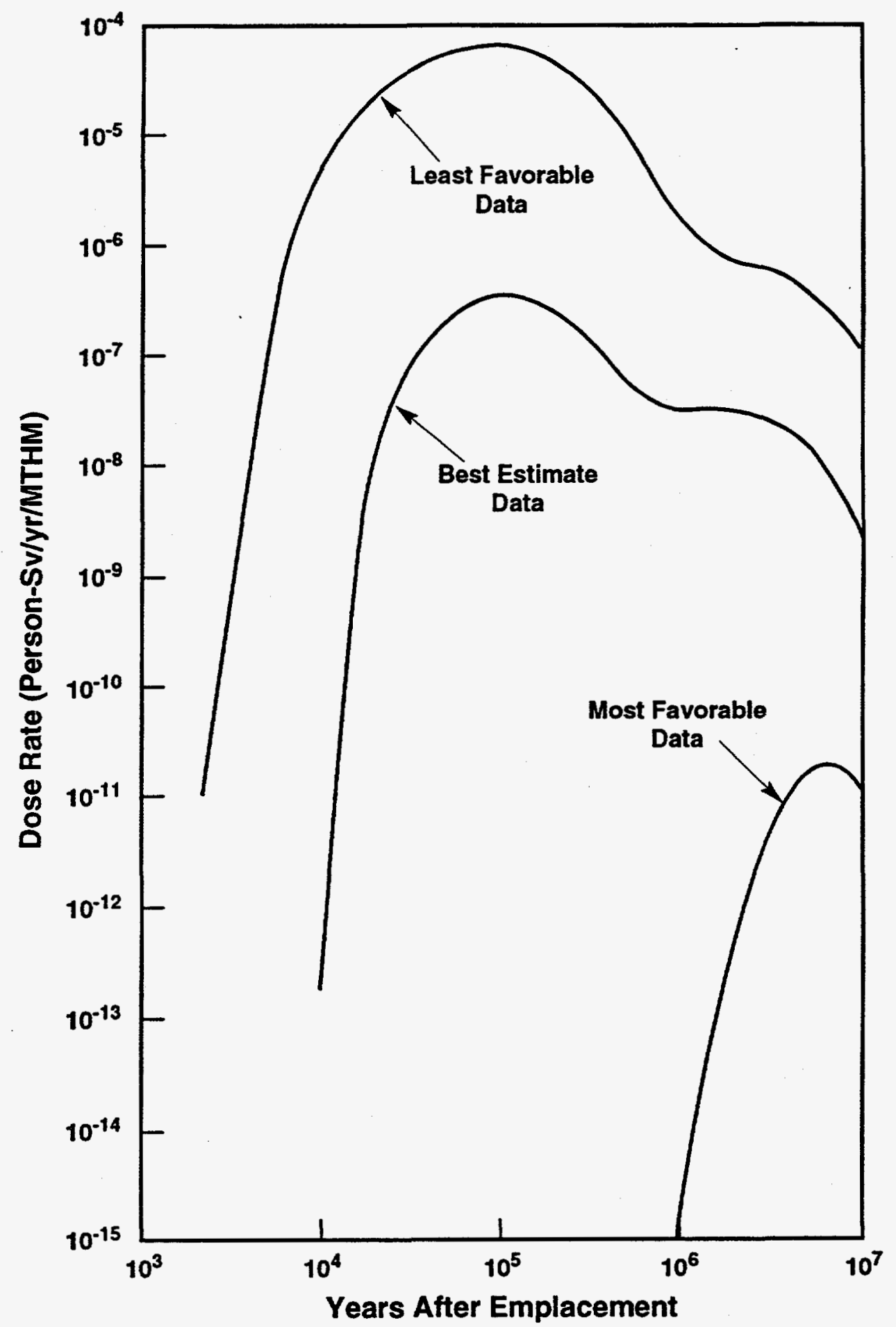

TRI-6342-3837-0

Figure 28. Dose ratio to the world population from HLW emplaced in deep ocean sediments. 


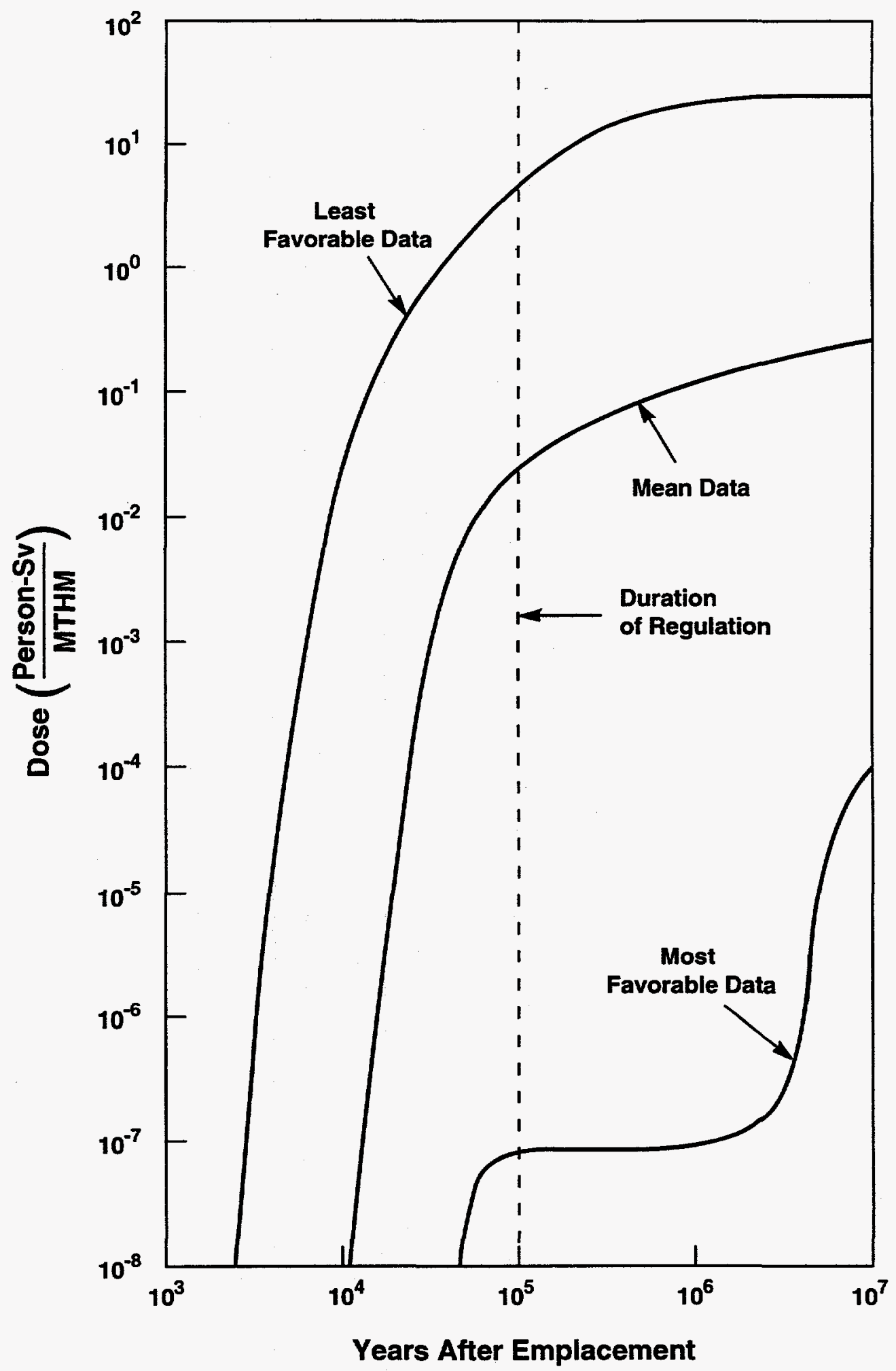

TRI-6342-3839-1

Figure 29. Collective dose to the world population from HLW emplaced in deep ocean sediments. 
Table 14. Comparison of Subseabed Disposal Dose Predictions with Recommended Multiple Radiological Standards

\begin{tabular}{|c|c|c|c|}
\hline Standard & $\begin{array}{l}\text { Dose Limit for HLW } \\
\text { Waste Disposal }\end{array}$ & $\begin{array}{l}\text { Predicted Doses using } \\
\text { Best Estimate Data }\end{array}$ & $\begin{array}{c}\text { Waste Quantity } \\
\text { Permitted (MTHM) }\end{array}$ \\
\hline MID & $10^{-3} \mathrm{~Sv} / \mathrm{yr}$ & $5 \times 10^{-15} \mathrm{~Sv} / \mathrm{yr}$ MTHM & $2 \times 10^{11}$ \\
\hline SGD & $10^{4}$ person $S v / y r$ & $4 \times 10^{-7}$ person Sv/yr MTHM & $3 \times 10^{10}$ \\
\hline CPD & $3 \times 10^{7}$ person $S v$ & $2 \times 10^{-2}$ person Sv/MTHM & $10^{9}$ \\
\hline
\end{tabular}

placed in deep ocean sediments. Ten thousand repositories could be built using CPD standards. Table 15 shows the a minimum of 60,000 repositories could be built if de minimis limits are applied to population dose limits as suggested in Section 5.1.4 This evaluation method gives more useful information than the one in the previous paragraph for planning the uses of nuclear energy. Both methods show that subseabed disposal will offer more than adequate risk attenuation even with conservative standards.

Table 15. Comparison of Subseabed Disposal Dose Predictions with Multiple Radiological Standards with SGD and CPD constrained by a $10^{-7}$ Per Year Individual De Minimis Risk

\begin{tabular}{|c|c|c|c|}
\hline Standard & $\begin{array}{c}\text { Dose Limit for HLW } \\
\text { Waste Disposal }\end{array}$ & $\begin{array}{l}\text { Predicted Doses using } \\
\text { Best Estimate Data }\end{array}$ & $\begin{array}{c}\text { Waste Quantity } \\
\text { Permitted (MTHM) } \\
\end{array}$ \\
\hline MID & $10^{-3} \mathrm{~Sv} / \mathrm{yr}$ & $5 \times 10^{-15} \mathrm{~Sv} / \mathrm{yr}$ MTHM & $2 \times 10^{11}$ \\
\hline SGD & $2 \times 10^{4}$ person Sv/yr & $4 \times 10^{-7}$ person Sv/yr MTHM & $6 \times 10^{10}$ \\
\hline CPD & $2 \times 10^{9}$ person $S v$ & $2 \times 10^{-2}$ person Sv/MTHM & $9 \times 10^{10}$ \\
\hline
\end{tabular}

Doses of biota were computed using peak concentrations in each of the model compartments using best estimate and bracketing data. Except for the local disposal area, peak doses with the least favorable data were three to six orders of magnitude below natural background. No species would become extinct, and no major food chains would be disrupted.

\subsection{Derived and Prescriptive Standards for Subseabed Disposal}

The purposes and limitations of derived and prescriptive standards are given in Sections 3.2.2 and 3.4. These standards are not needed, and can actually be detrimental during the feasibility phase of a program by limiting design tradeoffs and optimization. Derived fluxes across boundaries and concentrations in model compartments can be used to expedite repetitive computations, but the development and use of these values is better left to the analyst. Even for the final certification of a disposal system, derived standards do not provide any information on safety that is not provided by the fundamental or dose standards. Derived standards apply only to the site, repository, and pathways for which they were derived [4]. The use of derived standards can result in erroneous risk assessments if 
they are applied to other systems or are used generically. Some carefully selected prescriptive standards that supplement numeric criteria can increase the confidence in risk predictions.

Since derived and prescriptive standards are usually incorporated in the final certification criteria, it is the obligation of the scientists, engineers, and analysts conducting the feasibility phase of a disposal system to provide regulators with the information they will need to develop the best possible standards. The remainder of this section consists of the relevant information that has been observed to date. Potential prescriptive standards that might be applied to subseabed disposal include:

- Accident avoidance and accident survivability requirements could be placed on the emplacement ship.

- Limiting the maximum allowable consequence of an event, regardless of the probability of the event. An example would be limiting the quantity of waste per shipment on the emplacement ship, so that unrecovered waste from an accident would not cause an unacceptable risk.

- Development and testing of recovery equipment and procedures could be required before any waste could be shipped and emplaced.

- Retrieval of properly emplaced waste is very controversial. It would be safer to analyze each case separately, rather than have a blanket retrievability requirements. See Section 3.2.2.5 for more details on this requirement.

- AF analyses have shown the canister lifetime and waste form leach rate have little effect on the safety of an operational repository. Canister lifetime should be set by accident recovery requirements, and leach rate limits should be set by the dispersion requirements of unrecovered waste.

- A limit on vertical pore water velocity could be a site selection criterion.

There are few potential uses for SD derived standards. Sensitivity, AF, and risk analyses have shown some of commonly used types of derived standards do not apply to SD, and only a few can produce accurate risk predictions. Release rates are only proportional to dose rates and integrated releases are only proportional to collective doses for near shore accidents, where the residence time of the radionuclides in the highly productive regions is very short. Time integrated releases are not proportional to doses or dose rates in any deep ocean region. Concentrations of radionuclides are proportional to dose rates in all regions. The time integrated ocean burden is the only parameter that is proportional to collective doses from deep ocean accidents on emplaced waste. Section 3.2.2.1 covers the limitations of release limits. The potential for error from the mistakes of SD derived standards outweighs the small contribution they might make in simplifying the PAs. 


\section{CONCLUDING DISCUSSION}

Because of the quantity, complexity, detail, and interrelationships of the information in this report it is not practical to write an executive summary. This concluding discussion includes the philosophy used to develop recommended interim standards for the remainder of the feasibility phase of the SDP, how they were developed, the resulting standards, and suggestions for their use.

The development of radiological standards is very complex, with many options, and some of the decisions made during the development are subjective. These characteristics require a knowledge of general radiological protection standards, a good understanding of how the disposal system being regulated attenuates the risk potential, a thorough development plan, and documentation of all steps and decisions in the development. The procedures used in formal systems engineering meet these requirements, and were used in the development of the interim standards.

The first step was to review the sensitivity, AF, and early performance assessments to understand how each component and the entire disposal system functions (Chapter 2 of this report). This was followed by a review of related standards, and a workshop, made up of international experts, to evaluate the options (Chapter 1). All factors of radiological protection regulations that could apply to SD were then organized and evaluated (Chapter 3). These factors included biological response to doses, the groups or populations to be protected, categories of standards, duration of regulation, assurance requirements, probabilistic acceptance measures, and definitions of future states. It was decided to use the peak individual dose rate, peak single generation dose rate, and 100,000 year collective population dose standards defined in Section 3.2.1 to evaluate risks to humans for the feasibility phase of the SDP for the following reasons:

1. It is the only way to assure that all individual and population groups are protected.

2. It is the best way to find any flaws in the disposal concept, reference site, or reference repository design.

3. They encompass all existing recommendations and regulations so it is easier to compare SD with other disposal concepts.

4. They provide the maximum input to research and design groups during all phases of the program, and to regulatory agencies for the development of final risk criteria.

5. Since the SDP models can compute individual, single generation, and collective population doses simultaneously, and since all three should be computer through the time of peak dose, there is little added expense.

6. It is more economical to do all the calculations at once than to determine acceptability with one dose standard, and then optimize with a different dose standard at a later time.

There is insufficient information to set dose limits for aquatic biota at this time. An international panel concluded it was only necessary to show that SD will not cause any species to become extinct or 
disrupt any significant food chain. This could be accomplished by limiting the incremental doses to biota population to some small fraction of natural background, with no limits on individual biota doses.

During the 1983 and 1987 preliminary feasibility assessments, only peak individual dose rate and a modification of the US EPA collective dose limits for terrestrial repositories were used to evaluate the risk attenuation of a reference subseabed disposal system. These limits are discussed and the results are reviewed in Chapter 4.

The standards recommended for the remainder of the SDP feasibility phase are developed in Chapter 5. The recommended dose limits for all subseabed radioactive waste disposal are:

- Peak dose rate to individuals in the maximally exposed group of $10^{-3} \mathrm{~Sv} / \mathrm{yr}$.

- Peak dose rate to the world population $=10^{4}$ person Sv/yr.

- Collective population dose to the world population during the first $10^{5}$ years after disposal $=2.7 \times$ $10^{7}$ person Sv. A secondary collective dose standard of 2 person Sv/MTHM for $10^{5}$ years is recommended for comparison with US terrestrial repositories.

The approaches used to develop the SGD and CPD limits are very conservative, and could be modified at some later date based on a uniform de minimis individual risk of $10^{-7}$ per year. Comparison of the 1987 performance assessments using best estimate data with the recommendation limits showed that the CPD limits are the most stringent for SD, and the MID limits are at least stringent. Ten thousand, $10^{5} \mathrm{MTHM}$ subseabed repositories would be allowed using the collective population dose limit, and two million repositories would be allowed using peak individual dose rate limits. Optimization of a disposal system using all three dose standards is discussed in Section 3.2.1.4.

No derived or prescriptive standards are needed during the feasibility phase. Analyses conducted during the feasibility phase can provide information to regulators for future derived and prescriptive standards. Chapter 5 contain a discussion of prescriptive standards that could apply to SD and some limitations on SD derived standards.

It is recommended that all three standards be used in risk, AF, sensitivity, and design tradeoff analyses. As a minimum, the analyses should be conducted using best estimate, least favorable, and most favorable input parameters. If sufficient information is available to establish reliable statistical distributions for the input data, probabilistic risk assessments are preferable.

The standards in this report have no regulatory or legal status, and are only the recommendations of the author. SWG activities have been suspended, so there can be no concurrence by that group. The procedures and background presented in this report should be useful in the development of final SD criteria, and the recommended dose levels can be used to demonstrate the feasibility of subseabed radioactive waste disposal. 


\section{REFERENCES}

1. Seabed Programs Division, The Subseabed Disposal program: 1983 Status Report, SAND83-1387, October 1983.

2. Feasibility of Disposal of High-Level Radioactive Waste into the Seabed: Volumes 1 through 8 , Nuclear Energy Agency, Organization for Economic Cooperation and Development, 2 rue AndrePascal, 75775 Paris CEDEX 16, 1988.

3. US Environmental Protection Agency, 40 CFR 191: Environmental Standards for the Management and Disposal of Spent Fuel, High-Level and Transuranic Wastes, Final Rule, Federal Register, Vol. 50, No, 182, September 19, 1985, pp. 38066-38089.

4. ICRP Publication 46 - Radiation Protection Principles for the Disposal of Solid Radioactive Waste, Annals of the International Commission on Radiological Protection, Volume 15, Number 4, 1985.

5. ICRP Publication 60 - 1990 Recommendations of the International Commission on Radiological Protection, Annals of the International Commission on Radiological Protection, Volume 21, Numbers 1-3, 1990.

6. The Radiological Basis of the IAEA Revised Definition and Recommendations Concerning HighLevel Radioactive Waste Unsuitable for Dumping at Sea, IAEA-211, International Atomic Energy Agency, Vienna, 1978.

7. Environmental Assessment Methodologies for Sea Dumping of Radioactive Wastes, IAEATECDOC-297, International Atomic Energy Agency, Vienna, 1983.

8. The Oceanographic and Radiological Basis for the Definition of High-Level Waste Unsuitable for Dumping at Sea, LAEA Safety Series Report 2, International Atomic Energy Agency, Vienna, 1984.

9. R. D. Klett, Waste Disposal Performance Assessment Using Attenuation Factors, SAND84-2624, March 1988.

10. M. F. Kaplan, R. D. Klett, C. M. Koplik, and D. A. Ensminger, Radiological Protection Options for Subseabed High-Level Waste Disposal, SAND84-0548, March 1985.

11. R. D. Klett, M. F. Kaplan, C. M. Koplik, and D. A. Ensminger, Subseabed Disposal Project Workshop on Radiological Protection Standards, SAND84-2625, February 1986.

12. R. D. Klett and M. M. Gruebel, Evaluation of Alternatives for High-Level and Transuranic Radioactive-Waste Disposal Standards, SAND92-0556, Sandia National Laboratories, Albuquerque, NM, December 1992.

13. B. L. Hutchison, D. H. Laible, D. H. Kristensen, and S. Jagannathan, "Conceptual Design and Probabilistic Safety Assessment for Nuclear Waste Transportation and Emplacement Ship," The Society of Naval Architects and Marine Engineers Transactions, Volume 95, pp 283-317.

14. B. L. Hutchison, Subseabed Nuclear Waste Disposal Ship Conceptual Design and Accident Analysis, 1986 Status Report, SAND87-7030, February 1988. 
15. R. D. Klett and E. S. Hertel, Preliminary Geologic and Waste Package Sensitivity Study for Subseabed High-Level Nuclear Waste Disposal, SAND86-1471, January 1988.

16. M. F. Kaplan and R. D. Klett, Biological and Physical Oceanographic Sensitivity Analyses of Subseabed Disposal of High-Level Waste, SAND83-7707, November 1984.

17. G. de Marsilly, "Nuclear Waste Disposal: Who Will Make the Final Decision?," Radioactive Waste Management, Volume 2, Number 1, August 1981.

18. A. Furst, "Hormetic Effects in Pharmacological Inversions as Prototypes for Hormesis," Health Physics - Special Issue on Radiation Hormesis, L. A. Sagan, Ed., Volume 52, Number 5, May 1987.

19. L. A. Sagan, "What is Hormesis and Why Haven't We Heard about it Before?," Health Physics Special Issue on Radiation Hormesis, L. A. Sagan, Ed., Volume 52, Number 5, May 1987.

20. C. C. Congdon, "Radiation Hormesis and Nuclear Safety," Nuclear Safety, Volume 29, Number 1, January-March, 1988.

21. J. J. Cohen, "Conference on Radiation Hormesis: An Overview," Health Physics - Special Issue on Radiation Hormesis, L. A. Sagan, Ed., Volume 52, Number 5, May 1987.

22. K. S. V. Nambi and S. D. Soman, "Environmental Radiation and Cancer in India," Health Physics Special Issue on Radiation Hormesis, L. A. Sagan, Ed., Volume 52, Number 5, May 1987.

23. Long Term Radiation Protection Objectives for Radioactive Waste Disposal, Nuclear Energy Agency, OEDC/NEA, Paris, 1984.

24. Environmental Assessment: Yucca Mountain Site, Nevada Research and Development Area, Nevada - Volume 2, DOE/RW-0073, May 1986.

25. Project Gewahr 1985 - Nuclear Waste Management in Switzerland: Feasibility Studies and Safety Analyses, National Cooperative for the Storage of Radioactive Waste, NGB 85-09, June 1985.

26. C. C. Travis, S. A. Richter, E. A. C. Crouch, R. Wilson, and E. D. Klema, "Cancer Risk Management," Environmental Science Technology, Volume 21, Number 5, May 1987.

27. D. Latai, D. D. Lanning, and N. C. Rasmussen, "The Public Perception of Risk," The Analysis of Actual Versus Perceived Risk, V. T. Covello et. al. Eds., Plenum Press, New York, 1983.

28. R. Gregory and R. Mendelsohn, "Perceived Risk, Dread, and Benefits," Risk Analysis, Volume 13, Number 3, 1993.

29. Radiation Protection and Safety Criteria, Proceedings of an NEA Workshop, Paris, 5-7 November 1990, Nuclear Energy Agency, Paris, 1991.

30. Safety Principles and Technical Criteria for the Underground Disposal of High-Level Radioactive Waste, International Atomic Energy Safety Series No. 99, Vienna, 1989.

31. Waste Isolation Systems Panel, Board on Radioactive Waste Management, A Study of the Isolation System for Geologic Disposal of Radioactive Wastes, National Academy Press, Washington, D.C., 1983. 
32. Board on Radioactive Waste Management, Rethinking High-Level Radioactive Waste Disposal, National Academy Press, Washington, D.C., 1990.

33. "PAGIS - European Assessment of the Radiological Impact from Repositories of High-Level Radioactive Waste," Radioactive Waste EC Focus, Commission of the European Communities, Number 9, August, 1988.

34. Review of the Continued Suitability for the Dumping Site for Radioactive Waste in the North East Atlantic, NEA/OEDC, Paris, 1980.

35. D. M. Wuschke, et. al., Environmental Safety Assessment Studies for Nuclear Fuel Waste Management, Volume 3: Post Closure Assessment, TR-127-3, Atomic Energy of Canada Ltd., 1981.

36. Final Storage of Spent Nuclear Fuel, Swedish Nuclear Fuel Supply Company, Division KBS, May 1983.

37. D. D. Doniger, Statement before the Subcommittee on Oversight and Investigations Committee on Energy and Commerce, November 7, 1983.

38. P. Milvy, "A General Guideline for Management of Risk from Carcinogens," Risk Analysis, Volume 6, Number 1, 1986.

39. C. Whipple, Ed., De Minimis Risk, Plenum Press, New York, 1987.

40. R. D. Klett, Proposed Extensions of United States Fundamental and Derived Standards for HighLevel and Radioactive Waste Disposal, SAND91-0211, Sandia National Laboratories, Albuquerque, NM, July, 1991.

41. US Nuclear Regulatory Commission, Disposal of High-Level Radioactive Wastes in Geologic Repositories, 10 CFR 60, January 1, 1988.

42. US Environmental Protection Agency, Draft Environmental Impact Statement for 40 CFR 191: Environmental Standards for Management and Disposal of Spent Nuclear Fuel, High-Level and Transuranic Radioactive Wastes, EPA 520/1 82 025, December 1982.

43. Review of 40 CFR 191: Assessment of Technical Issues and Evaluation of Alternatives, TR-3336-5, The Analytic Sciences Corporation, May 1983.

44. US Environmental Protection Agency, Background Information Document: Final Rule for HighLevel and Transuranic Radioactive Wastes, EPA 520/1-85-023, August 1985.

45. J. P. Olivier, O. Ilari, and P.D. Johnson, "Long-Term Radiation Protection Objectives in Radioactive Waste Disposal," Proceedings of the International Conference on Radioactive Waste Management, Seattle, May 16-23, 1983, IAEA, Vienna, 1984.

46. P. D. Johnston, "The Link Between General Performance Objectives and Performance Assessments of Disposal Facilities for Radioactive Waste," System Performance Assessments for Radioactive Waste Disposal, Nuclear Energy Agency, OEDC/NEA, Paris, October 1985. 
47. R. D. Klett, "Implementation of Multimode Release Criteria and Dose Standard Alternatives," Proceedings: EPRI Workshop 2 - Technical Basis for EPA HLW Disposal Criteria, EPRI TR101257, Electric Power Research Institute, March 1993.

48. D. Beninson and B. Lindell, "Application of ICRP Recommendations to Radioactive Waste Isolation," Proceedings of the International Conference on Radioactive Waste Management, Seattle, May 16-23, 1983, IAEA, Vienna, 1984.

49. National Council on Radiation Protection and Measurements, Recommendations on Limits for Exposure to lonizing Radiation, NCRP Report No. 91, 1987.

50. National Council on Radiation Protection and Measurements, Limitation of Exposure to lonizing Radiation, NCRP Report No. 116, March 31, 1993.

51. R. D. Klett, Critique of the Ross Tritium Transportation Analysis in DPTRA, memorandum to W. F. Hartman, July 11, 1994.

52. R.W. Cranwell, R.V. Guzowski, J.E. Campbell, and N.R. Ortiz, Risk Methodology for Geologic Disposal of Radioactive Waste: Scenario Selection Procedure, NUREG/CR-1667, SAND80-1429, Sandia National Laboratories, Albuquerque, NM, April 1990.

53. J.C. Helton, J.W. Garner, R.D. McCurley, and D.K. Rudeen, Sensitivity Analysis Techniques and Results for Performance Assessment at the Waste 1solation Pilot Plant, SAND90-7103, Sandia National Laboratories, Albuquerque, NM, March 1991.

54. E.J. Bonano, S.Hora, R.L. Keeney, and D. Von Winterfeldt, Elicitation and Use of Expert Judgment in Performance Assessment for High-Level Radioactive Waste Repositories, SAND89-1821, NUREG/CR-5411, May 1990.

55. R.D. Klett, Performance Assessment Overview for Subseabed Disposal of High-Level Radioactive Waste, SAND93-2723, February, 1996.

56. International Atomic Energy Agency, The Oceanographic and Radiological Basis for the Definition of High-Level Wastes Unsuitable for Dumping at Sea, IAEA Safety Series No. 66, 1984, Vienna. 
WIPP

Distribution List

SAND88-1700

\section{Federal Agencies}

U.S. Environmental Protection Agency (2)

Technology Assessment Division

Attn: R. Dyer

G. Sjoblom

Office of Radiation Programs

AW-458 Waterside Mall East

Washington, D.C. 20545

\section{Universities}

University of California (4)

Scripps Institution of Oceanography

Attn: R. R. Hessler

K. L. Smith

A. A. Yayanos, A-00

F. N. Speiss

LaJolla, CA 92093

Oregon State University

Attn: T. Bearsley

School of Oceanography

Corvallies, OR 97331

University of Rhode Island (6)

Graduate School of Oceanography

Attn: K. R. Hinga (5)

E. P. Laine

South Ferry Road

Narragansett, RI 02882

University of Washington

Attn: E. Miles

Institute of Marine Studies, HA-35

Seattle, WA 98195

University of Washington

College of Ocean and Fisheries Sciences

Attn: G. R. Heath

Seattle, WA 98195

\section{Laboratories/Corporations}

J. K. Research Associates, Inc.

3408 Bonnie Road

Attn: J. E. Kelly

Austin, TX 78703
The Analytic Sciences Corp. (3)

Attn: C. M. Koplik

1 Jacob Way

Reading, MA 01867

The Gloster Associates, Inc.

Attn: B. L. Hutchison

600 Mutual Life Building

605 First Avenue

Seattle, WA 98104 - 2224

Foreign Addresses

Societe Eurochemic

Attn: A. A. Bonne

Centre d'Etude de l'Energie Nucleaire

200 Boeretang

B-2400 Mol-Donk

BEGIUM

Atlantic Geoscience Centre

Bedford Institute of Oceanography

Attn: D. Buckley

P. O. Box 1006

Dartmouth, Nova Scotia B2Y 4A2

CANADA

Dalhousie University

Department of Oceanography

Attn: C. J. R. Garrett

Halifax, Nova Scotia B3H 4JI

CANADA

Bundeforschungsanstalt fur Fischerei Laboratorium fur Radiookologie der

Gerwasser

Attn: W. Feldt

Wustland 2

D-2000 Hamburg 55

GERMANY 
Deutsches Hydrographisches Institut (4)

Attn: G. Becker

D. Schulte

H. Nies

M.Kautsky

Postfach 220

D-2000 Hamburg 4

GERMANY

INFREMER (4)

Centre Bretagne

Attn: A. Cavanie

Y.Desaubies

M. Sibuet

F. Madelain

O. P. 337

29273 Brest

FRANCE

Radiation Protection and Waste Management

Division (2)

Nuclear Energy Agency

Attn: J. Oliver

B. Ruegger

38 Boulevard Suchet

75016 Paris

FRANCE

Ghislain de Marsily (GXG Chairman)

Universite Pierre et Marie Curie

Laboratoire de Geologie Applique

4, Place Jussieu

T.26 - 5 Etage, Cabe 123

75252 Paris Cedex 05

FRANCE

Division of Chemistry

Joint Research Centre

Attn: C. N. Murray

21020 ISPRA (Varese)

ITALY

National Institute of Radiological Sciences

Attn: R. Ichikawa

9-1 Amagawa-4-Chome

Chiba-Chi 260

JAPAN
Marine Technology Department

Japan Marine Science and Technology

$$
\text { Centre (JAMSTEC) }
$$

Attn: J. Hotta

2-15 Natsushima-Cho

Yokosuka 237

JAPAN

Ocean Research Institute (2)

University of Tokyo

Attn: Y. Horibe

Y. Nozaki

1-15-1 Minamidai

Nakano-ku

Tokyo 164

JAPAN

University of Kanazawa

Attn: T. Nakanishi

1-1 Marunouchi

Kanazawa-Shie

Ishikawa 920

JAPAN

Vening Meinesz Laboratorium

Attn: B. J. Collete

P.O. Box 80.021

3508 TA Utrecht

THE NETHERLANDS

Energy Research Foundation

ECN

Attn: B. Verkerk

P. O. Box 1

175526 Petten

THE NETHERLANDS

University of Bergen, N-5065

Institute of Marine Biology

Attn: J.B.L. Matthews

Blomsterdalen

NORWAY

Insituto Hidrografico

Attn: J.L. Cardoso

Rua das Trinas 49

Lisbon

PORTUGAL

Direccion de Proteccion y Medio Ambiente Junta de Energia Nuclear

Attn: J. G. Lopez

Ciudad Universitaria

SPAIN 
Department of Physics

University of Capetown

Attn: R. Cherry

RONDEBOSCH 7700, Cape

SOUTH AFRICA

Universite de Neuchatel

La. Geologique

Attn: F. Nyffeler

NI rue E. Argand

CH 2000 Neuchatel

SWITZERLAND

Swiss Federal Institute for Reactor Research

Health Physics Division

Attn: F. Alder, Head

CH-5303 Wurenlingen

SWITZERLAND

NAGRA

Attn: F. van Dorp

Parkstrasse 23

CH-5401 Baden

SWITZERLAND

MAFF (2)

Fisheries Radiobiological Laboratory

Attn: D. Woodhead

R. J. Penreath

Pakefield Road, Lowestroft

Suffolk NR33 OHT

UNITED KINGDOM

Department of the Environment

Attn: A. G. Duncan

Romney House

43 Marsham Street

London SWI 3PY

UNITED KINGDOM

National Radiological Protection Board

Attn:. S. Mobbs

Chilton, Didcot

Oxon OX11ORQ

UNITED KINGDOM

Institute of Oceanographic Sciences

Attn: A. S. Laughton

Brook Road

Wormley, Godalming

Surrey GU8 5UB

UNITED KINGDOM

\section{Other}

Robert D. Klett (10)

7201 Lantern Rd. NE

Albuquerque, NM 87109-2916

Internal

$\begin{array}{lll}\underline{\text { MS }} & \text { Org. } & \\ \mathbf{0 7 5 0} & \mathbf{6 1 1 8} & \text { J. L. Krumhansl } \\ 0560 & 5408 & \text { D. F. McVey } \\ 0701 & 6100 & \text { R. W. Lynch } \\ 1337 & 6000 & \text { W. D. Weart } \\ 1328 & 6849 & \text { D. R. Anderson } \\ 0863 & 2501 & \text { T. J. Garner } \\ 1342 & 6832 & \text { L. H. Brush } \\ 1335 & 6305 & \text { L. S. Gomez } \\ 0665 & 1142 & \text { S. L. Kupferman } \\ 1395 & 6821 & \text { M. G. Marietta } \\ 1395 & 6800 & \text { L. E. Shephard } \\ 1330 & 6811 & \text { K. Hart (2) } \\ 1330 & 4415 & \text { NWM Library 20 } \\ 9018 & 8940-2 & \text { Central Technical Files } \\ 0899 & 4916 & \text { Technical Library (5) } \\ 0619 & 12690 & \text { Review and Approval Desk (2) } \\ & & \text { for DOE/OSTI }\end{array}$

